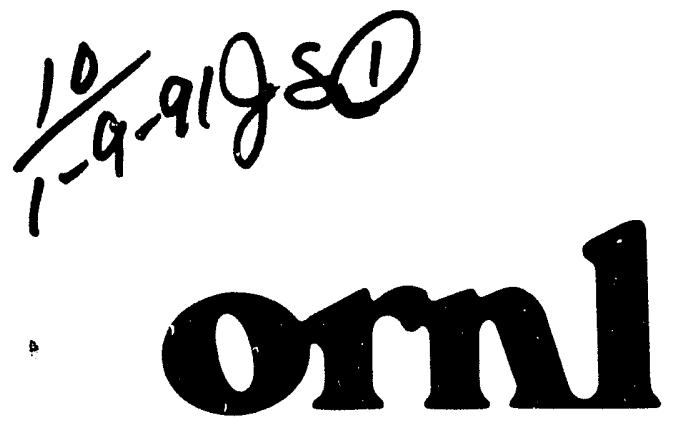

OAK RIDGE NATIONAL LABORATORY

MARTIN MARUETTA
ORNL/TM-11703

T. G. Kollie

D. L. McE!roy

H. A. Fine

K. W. Childs

R. S. Graves

F. J. Weaver 
This report has been reproduced directly from the best available copy.

Available to DOE and DOE contractors from the Otfice of Scientific and Technical Information, P.O. Box 62, Oak Ridge, TN 37831; prices available from (615) 576-8401, FTS 626-8401.

Available to the public from the National Technical Information Service, U.S. Department of Commerce, 5285 Port Royal Rd., Springfield, VA 22161.

This report was prepared as an account of work sponsored by an agency of the United States Government. Neither the United States Government nor any agency thereof, nor any of their employees, makes any warranty, express or implied, or assumes any legal liability or responsibility for the accuracy, completeness, or usefulness of any information, apparatus, product, or procisss disclosed, or represents that its use would not infringe privately owned rights. Reference herein to any specific commercial product, process, or service by trade name, trademark, manufacturer, or otherwise, does not necessarily constitute or imply its endorsement, recommendation, or favoring by the United States Government or any agency the "eof. The views and opinions of authors expressed herein do noi necessarily state of reflect those of the United States Government or any agency inereof. 


\section{A REVIEW OF VACUUM INSULATION RESEARCH AND DEVELOPMENT \\ IN THE BUILDING MATERIALS GROUP OF THE \\ OAK RIDGE NATIONAL LABORATORY}

T. G. Kollie, D. L. McElroy, H. A. Fine, K. W. Childs, R. S. Graves, and F. J. Weaver

Date Published:

September 1991

NOTICE: This document contains information of a preliminary nature. It is subject to revision or correction and therefore does not represent a final report.

Prepared for the DOE

Office of Buildings Energy Research

EC 0101000

Prepared by the

OAK RIDGE NATIONAL LABORATORY

Oak Ridge, Tennessee 37831-6092

managed by

MARTIN MARIETTA ENERGY SYSTEMS, INC.

for the

U.S. DEPARTMENT OF ENERGY

under Contract DE-AC05-84OR21400 
LIST OF FIGURES $\ldots \ldots \ldots \ldots \ldots \ldots \ldots \ldots \ldots \ldots \ldots \ldots \ldots \ldots$

LIST OF TABLES $\ldots \ldots \ldots \ldots \ldots \ldots \ldots \ldots \ldots \ldots \ldots \ldots \ldots \ldots \ldots \ldots \ldots$

ABBREVIATIONS, ACRONYMS, AND INITIALISMS $\ldots \ldots \ldots \ldots \ldots \ldots$ xi

ABSTRACT $\ldots \ldots \ldots \ldots \ldots \ldots \ldots \ldots \ldots \ldots \ldots \ldots \ldots \ldots \ldots \ldots \ldots \ldots \ldots$

1. INTRODUCTION $\ldots \ldots \ldots \ldots \ldots \ldots \ldots \ldots \ldots \ldots \ldots \ldots \ldots \ldots \ldots \ldots \ldots$

2. BACKGROUND $\ldots \ldots \ldots \ldots \ldots \ldots \ldots \ldots \ldots \ldots \ldots \ldots \ldots \ldots \ldots \ldots$

2.1 HISTORY $\ldots \ldots \ldots \ldots \ldots \ldots \ldots \ldots \ldots \ldots \ldots \ldots \ldots \ldots \ldots \ldots \ldots \ldots \ldots \ldots$

2.2 ORNL HISTORY $\ldots \ldots \ldots \ldots \ldots \ldots \ldots \ldots \ldots \ldots \ldots \ldots \ldots \ldots \ldots$

2.3 OBJECTIVES OF ORNL WORK $\ldots \ldots \ldots \ldots \ldots \ldots \ldots \ldots$

3. EQUIPMENT $\ldots \ldots \ldots \ldots \ldots \ldots \ldots \ldots \ldots \ldots \ldots \ldots \ldots \ldots \ldots \ldots \ldots \ldots$

3.1 ICE MELTING TEST $\ldots \ldots \ldots \ldots \ldots \ldots \ldots \ldots \ldots \ldots \ldots \ldots$

3.2 THE ORNL UNGUARDED THIN-HEATER APPARATUS ..... 11

3.3 THE ORNL HEAT-FLOW-METER APPARATUS ......... 13

3.4 THE ORNL UNGUARDED RADIAL-HEAT-FLOW APPARATUS . 15

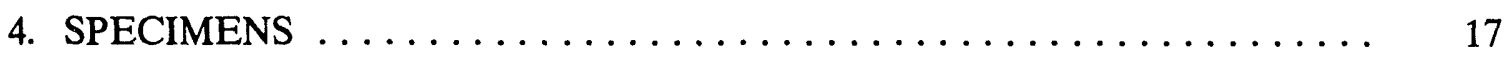

5. EXPERIMENTAL WORK AND DISCUSSIDN OF RESULTS ....... 18

5.1 ICE COOLER EXPERIMENTS $\ldots \ldots \ldots \ldots \ldots \ldots \ldots \ldots \ldots \ldots \ldots$

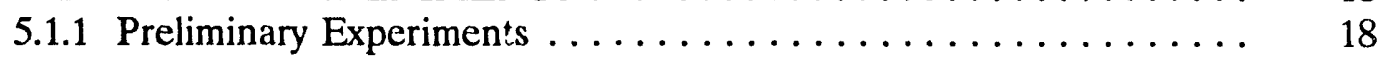

5.1.2 Tests on Coolers with Taped-In PEPs .............. 21

5.1.3 Tests on Coolers with Foamed-In PEPs ............... 21

5.1.4 Thermal Conductivity of PEPs and Foam ............ 23

5.1.5 Heat Transfer i Modeling of the Igloo 32 Coolers .......... 24

5.1.6 Effects of Edges and Corners ................... 34

5.1.7 Effect of the Area of Coverage of PEPs . . . . . . . . . . . . 34

5.1 .8 Effects of Position of the PEP $\ldots \ldots \ldots \ldots \ldots \ldots \ldots \ldots \ldots \ldots$

5.1 .9 Measurements on the Igloo 44 Coolers . . . . . . . . . 35

5.2 INTERNAL PRESSURE MEASUREMENT OF A PEP ........ 39 
5.3 BARRIER MATERIAL SELECTION $\ldots \ldots \ldots \ldots \ldots \ldots \ldots \ldots . \ldots \ldots$

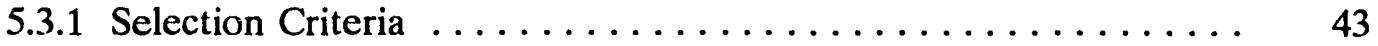

5.3.2 Literature Search Methodology ................ 46

5.3.3 Literature Search Results . . . . . . . . . . . . 46

5.4 MEASUREMENT OF PERMEANCE $(\Gamma)$ OF

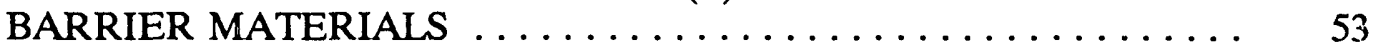

5.4.1 Early Attempts to Measure $\Gamma$ in this Program ........... 53

5.4 .2 Measurement Technology for $\Gamma \ldots \ldots \ldots \ldots \ldots \ldots \ldots \ldots \ldots \ldots \ldots$

5.4.3 Present Efforts to Measure $\Gamma$ of Barrier Material . . . . . . . . . 54

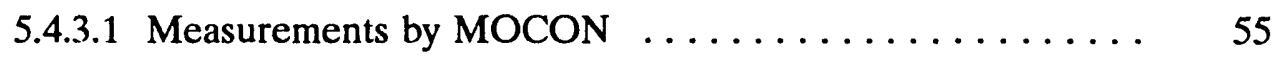

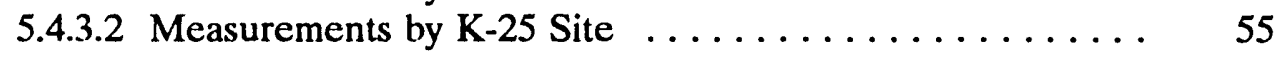

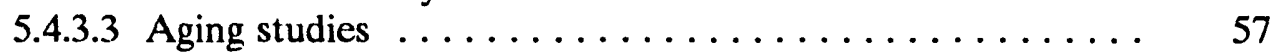

5.4.3.4 Comparison of $\Gamma$ measurements for He through laminate barrier $\ldots \ldots \ldots \ldots \ldots \ldots \ldots \ldots \ldots \ldots \ldots$

5.5 EXAMPLE OF USE OF $\mathrm{TS}$ MEASURED AT ORNL $\ldots \ldots \ldots \ldots \ldots$

5.6 MEASUREMENT OF R OF PEPs ................. 60

5.6.1 Comparison of Rs Measured in the UTHA and the HFMA .... 63

5.6.2 Resistivity Measurements of $\mathrm{SiO}_{2}$ Powder ........... 65

5.7 THERMAL ANALYSIS OF SERI CVI PANELS $\ldots \ldots \ldots \ldots \ldots \ldots$

5.7.1 Thermal Model of CVI . . . . . . . . . . . . . . . 68

5.7.2 Measurement and HEATING-7 Models of the R of the CVIs ... 73

5.7.3 Uncertainties of the Measurement of $\mathrm{R}$ of the CVIs . . . . . . . 74

5.7.4 The Effective $\mathrm{R}$ of Two, Identical, Stacked CVIs ......... . 77

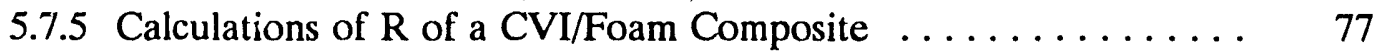

5.7.6 Effects of High-Conductance Claddings . . . . . . . . . 78

6. CONCLUSIONS $\ldots \ldots \ldots \ldots \ldots \ldots \ldots \ldots \ldots \ldots \ldots \ldots \ldots \ldots \ldots$

7. REFERENCES $\ldots \ldots \ldots \ldots \ldots \ldots \ldots \ldots \ldots \ldots \ldots \ldots \ldots \ldots \ldots \ldots \ldots$

8. ACKNOWLEDGMENTS ..................... 88 


\section{LIST OF FIGURES}

Figure

1 Flowchart for a standardized test procedure for ice coolers $\ldots \ldots \ldots \ldots \quad 10$

2 Schematic drawing of the ORNL Unguarded Thin-Heater Apparatus

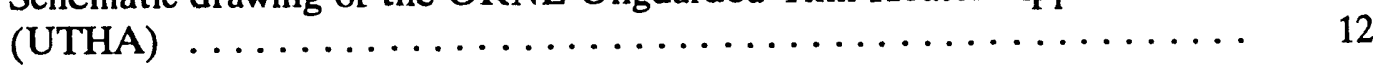

3 ORNL Heat-Flow-Meter Apparatus (HFMA) $\ldots \ldots \ldots \ldots \ldots \ldots$

4 Schematic drawing of the ORNL Unguarded Radial-Heat-Flow Apparatus

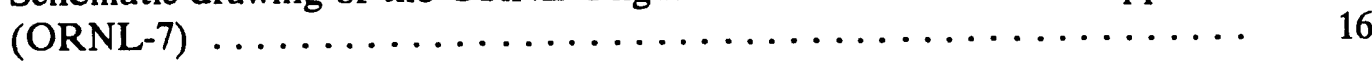

5 Schematic drawing showing the plane of symmetry of the coolers used for the 1D and 3D HEATING-7 models $\ldots \ldots \ldots \ldots \ldots \ldots \ldots \ldots \ldots$

6 Isothermal temperature contours at $7^{\circ} \mathrm{F}$ intervals for the cross section of the center of an Igloo 32 cooler without PEPs . . . . . . . .

7 Isothermal temperature contours at $1.3^{\circ} \mathrm{F}$ intervals of the back surface plus half of the side surface of the cooler without PEPs

8 Isothermal temperature contours at $7^{\circ} \mathrm{F}$ intervals for the cross section of the center of an Igloo 32 cooler with foamed-in PEPs ......

9 Isothermal temperature contours at $1.3^{\circ} \mathrm{F}$ intervals of the back surface plus half of the side surface of the cooler with foamed-in PEPs

10 Isothermal temperature contours at $7^{\circ} \mathrm{F}$ intervals for the cross section of the center of an Igloo 32 cooler with taped-in PEPs . . . . . .

11 Isothermal temperature contours at $1.3^{\circ} \mathrm{F}$ intervals for the back surface plus half of the side surface of the cooler with taped-in PEPs

12 The $\mathbf{R}$ of a composite wall of a 2 - $\mathrm{ft}$ cube versus the percent of the inside wall covered by the PEP as calculated by $3 D$ HEATING-7 and $1 D$ electrical-analog models (foam 7 R/in.; PEP $20 \mathrm{R} / \mathrm{in}$ )

13 Percent over estimate of the change in $\mathbf{R}$ as computed by the 1D electrical-analog model for the foam/PEP component wall versus the percent of the inside wall covered by the PEP $\ldots \ldots \ldots \ldots \ldots$ 
Figure

Page

14 Plot of the difference (error if ORNL data are assumed correct) between the ORNL and GE and the ORNL and Global measurements of the internal pressure in ORNL PEPs $\ldots \ldots \ldots \ldots \ldots \ldots$

15 Oxygen transmission rate versus relative humidity ${ }^{44} \ldots \ldots \ldots \ldots \ldots$

16 Oxygen transmission rate versus temperature ${ }^{44} \ldots \ldots \ldots \ldots \ldots \ldots$

17 Area-averaged heat fluxes for the HFMA with a $24 \times 24 \times 4$ in. batt with a $12 \times 12 \times 1 / 2$ in. PEP at the center of the mid-plane of the PEP plotted as a function of the distance from the center of the heat-flow sensor and shown parametrically for various $R / i n$.

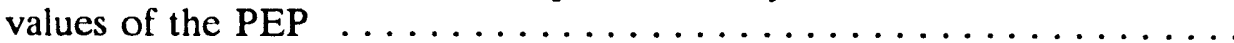

18 The $\mathrm{R} / \mathrm{in}$. of the batt/PEP composite as measured by the HFMA versus the $\mathrm{R} / \mathrm{in}$. of the PEP as computed by the 3D HEATING-7 model and the $1 \mathrm{D}$ electrical-analog model $\ldots \ldots \ldots \ldots \ldots$

19 The $\mathbf{k}$ of the batt/PEP composite as measured by the HFMA versus the $\mathrm{R} / \mathrm{in}$. of the PEP as computed by the 3D HEATING-7 model ....

20 The R/in. of the Degussa FK-500-LS powder at a density of $7.05 \mathrm{lb} / \mathrm{ft}^{3}$ versus the pressure of $\mathrm{He}$ and $\mathrm{N}$ and the $\mathrm{R} / \mathrm{in}$.

of the PEPs versus the pressure of air and helium $\ldots \ldots \ldots \ldots$

21 Schematic of the CVI glass sphere support system to hold the two stainless steel sheets that form the vacuum enclosure

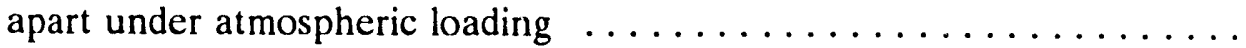

22 Model of spheres in CVI showing boundary conditions used in the HEATING-7 calculations $\ldots \ldots \ldots \ldots \ldots \ldots \ldots \ldots \ldots \ldots \ldots$

$23 \mathbf{R}$ measured by HFMA for CVI/batt composite versus the CVI $\mathbf{R}$, showing the values obtained for the two SERI CVIs $\ldots \ldots \ldots \ldots \ldots$

$24 \quad \mathbf{R}$ Measured by HFMA for CVI/batt composite versus the ideal $\mathbf{R}$ of the CVI, showing the values obtained for the two SERI CVIs ....

25 Increase in $\mathbf{R}$ of a foarn/CVI composite above the $\mathbf{R}$ of foam alone as a function of the size of the composite $\ldots \ldots \ldots \ldots \ldots \ldots$

26 The $\mathbf{R}$ of a wall consisting of a $1 \frac{1}{2}$-in.-thick, $3 \times 3 \mathrm{ft}$ composite of a stainless-steel-clad PEP with foam as a function of the percent of the area covered by the $1 / 2$-in.-thick PEP (8-milthick stainless steel used in place of polymer barrier in a 20 R/in. powder). Polymer-clad PEP shown for comparison. 
Figure

27 Increase in $\mathbf{R}$ in percent above that of foam alone of the stainless steel and polymer-clad PEP,foam composite versus the percent of the area covered by PEP (same data as previous figure but plotted

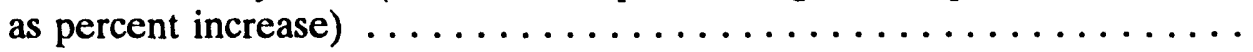




\section{LIST OF TABLES}

Table

Page

1 Ice melting rates of seven Igloo 24 coolers as measured by a standard

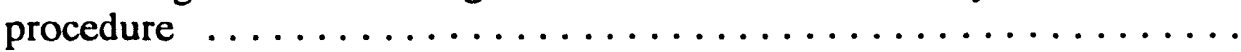

2 Ice melting rates of four Igloo 32 coolers as measured by a standard

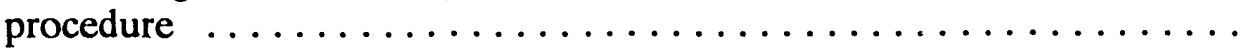

3 Ice melting rates of ten Igloo 48 coolers as measured by a standard procedure

4 Ice melting rates for coolers with taped-in PEPs $\ldots \ldots \ldots \ldots \ldots \ldots$

5 Ice melting rates of Igloo 32 coolers with foamed-in PEPs

$6 \quad$ Ice melting rates of Igloo 32 coolers with and without foamed-in

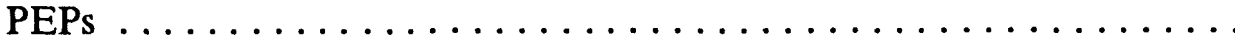

7 Results of HEATING-7 models of Igloo 32 coolers with and without PEPs

8 The $\mathbf{R}$ of a composite wall as affected by the area of coverage

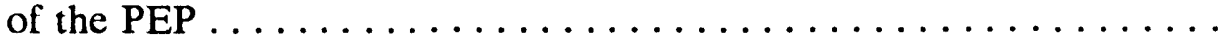

9 Ice melting rates of Igloo 44 coolers with and without foamed-in PEPs

10 Summary of internal pressure measurements by Global, GE, and ORNL on ORNL PEPs $\ldots \ldots \ldots \ldots \ldots \ldots \ldots \ldots \ldots \ldots \ldots \ldots \ldots \ldots$

11 Calculated permeance to achieve 20. and 100-year lifetime PEPs ..... 45

12 Impurtant contacts made during the barrier materials survey $\ldots \ldots \ldots$

13 Permeance of selected materials at $26 \mu$ in. thickness at $73^{\circ} \mathrm{F}$ and $0 \% \mathrm{RH}$

Laminate barrier candidates for PEPs with lifetimes of 20 years at $760 \mathrm{~mm}$ of $\mathrm{Hg}$ pressure or 100 years at $76 \mathrm{mn} \mathrm{Hg}$ pressure $\ldots \ldots \ldots \ldots \ldots$ 
$18 \quad$ Results of accelerated aging tests on PEPs in $\mathrm{He} \ldots \ldots \ldots \ldots \ldots \ldots$

19 Comparison of measured values of internal PEP pressures with those calculated from permeance measurements $\ldots \ldots \ldots \ldots \ldots \ldots \ldots . \ldots . \ldots$

20 HFMA-measured $\mathrm{R} /$ in. of PEPs at $75^{\circ} \mathrm{F} \ldots \ldots \ldots \ldots \ldots \ldots \ldots \ldots$

21 Measured R/in. of Degussa FK-500-LS powder at $80^{\circ} \mathrm{F}$ and $7.05 \mathrm{lb} / \mathrm{ft}^{3} \ldots \quad 66$

22 HEATING-7 model results for infinitely large, "ideal" CVIs

(no shunting through the stainless steel) $\ldots \ldots \ldots \ldots \ldots \ldots \ldots \ldots$ 


\section{ABBREVIATIONS, ACRONYMS, AND INITIALISMS}

1D

one dimensional

3D

ASTM

three dimensional

B\&W

American Society for Testing and Materials

BMG

Babcock and Wilcox

CFC

Building Materials Group

CVI

chlorofluorocarbon

EVOH

compact vacuum insulation

fcc

ethylene vinyl alcohol

GE

face-centered-cubic

HFMA

General Electric Company

HFT

k

LBL

LLDPE

MBB

Heat-Flow-Meter Apparatus

heat flux transducer

conductivity (thermal)

NIST

ORN:

ORNL-7

OTR

$\Gamma$

$\mathrm{p}$

$P$

PEP

PET

PU

Lawrence Berkeley Laboratory

linear-low-density polyethylene

Messerschmidt-Bolkow-Blohm

PVA

PVDC

PVOH

R

National Institute of Standards and Technology

Oak Ridge National Laboratory

$R /$ in.

RH

ORNL's Unguarded Radial-Heat Flow Apparatus

oxygen transmission rate

permeance

permeability

pressure

SERI

SRM

STP

Powder-filled Evacuated Panel

polyethylene

polyurethane

polyvinyl alcohol

polyvinyldene chloride (Saran)

polyvinyl alcohol

thermal resistance

Unguarded Thin-Heáter Apparatus

VIP

VSI

thermal resistivity or thermal resistance per inch

relative humidity

Solar Energy Research Institute

Standard Reference M: :rial

standard temperature and pressure

vacuum isolation panel:

vacuum super insulation 


\section{EDITOR'S NOTE}

Although ORNL has a policy of reporting its work in SI metric units, this report uses English units. The justification is that the insulation industry at present operates completely with English units, and reporting otherwise would lose meaning to the intended readership. To assist the reader in obtaining the SI equivalents, these are listed below for the units occurring in this report.

\begin{tabular}{|c|c|c|}
\hline Property & Unit used & SI equivalent \\
\hline Dimension & in. & $25.4 \mathrm{~mm}$ \\
\hline Dimension & $\mathrm{ft}$ & $0.3048 \mathrm{~m}$ \\
\hline Dimension & mil & $0.0254 \mathrm{~mm}$ \\
\hline Density & $\mathrm{lb} / \mathrm{ft}^{3}$ & $16.02 \mathrm{~kg} / \mathrm{m}^{3}$ \\
\hline Energy & Btu & 1055 Joules \\
\hline Mass & oz. & $0.02835 \mathrm{~kg}$ \\
\hline Mass & lib. & $0.4536 \mathrm{~kg}$ \\
\hline Permeance & $\mathrm{cc} / \mathrm{m}^{2} \cdot 24 \mathrm{~h} \cdot \mathrm{atm}$ & $5.097 \mathrm{f} \mathrm{mol} / \mathrm{m}^{2} \cdot \mathrm{s} \cdot \mathrm{Pa}$ \\
\hline Power & $\mathrm{Btu} / \mathrm{h}$ & $0.2929 \mathrm{~W}$ \\
\hline Pressure & Torr & 133.3 Pascal \\
\hline Pressure & $\mathrm{mm} \mathrm{Hg}$ & 133.3 Pasıal \\
\hline Pressure & psi & 6894.8 Pascal \\
\hline Temperature & ${ }^{\circ} \mathrm{F}$ & ${ }^{\circ} \mathrm{C}=(5 / 9)\left({ }^{\circ} \mathrm{F}-32\right)$ \\
\hline Temperature & ${ }^{\circ} \mathrm{F}$ & $\mathrm{K}=(5 / 9)\left({ }^{\circ} \mathrm{F}-32\right)+273.2$ \\
\hline Temperature difference & ${ }^{\circ} \mathrm{F}$ & ${ }^{\circ} \mathrm{C}=(5 / 9)^{\circ} \mathrm{F}$ \\
\hline Thermal conductivity & $\mathrm{Btu} \cdot$ in. $/ \mathrm{h} \cdot \mathrm{ft}^{2} \cdot{ }^{\circ} \mathrm{F}$ & $0.1442 \mathrm{~W} / \mathrm{m} \cdot \mathrm{K}$ \\
\hline Thermal resistance & $\mathrm{h} \cdot \mathrm{ft}^{2} \cdot{ }^{\circ} \mathrm{F} / \mathrm{Btu}$ & $0.1762 \mathrm{~K} \cdot \mathrm{m}^{2} / \mathrm{W}$ \\
\hline Thermal resistivity & $\mathrm{h} \cdot \mathrm{ft}^{2} \cdot{ }^{\circ} \mathrm{F} / \mathrm{Btu} \cdot \mathrm{in}$. & $6.933 \mathrm{~m} \cdot \mathrm{K} / \mathrm{W}$ \\
\hline
\end{tabular}




\title{
A REVIEW OF VACUUM INSULATION RESEARCH AND DEVELOPMENT \\ IN THE BUILDING MATERIALS GROUP OF THE \\ OAK RIDGE NATIONAL LABORATORY*
}

T. G. Kollie, D. L. McElroy, H. A. Fine ${ }^{\dagger}$,

K. W. Childs ${ }^{\ddagger}$, R. S. Graves, and F. J. Weaver

\begin{abstract}
This report is a summary of the development work on flat-vacuum insulation performed bv the Building Materials Group (BMG) in the Metals and Ceramics Division of the Oak Ridge National Laboratory (ORNL) during the last iwo years. A historical review of the technology of vacuum insulation is presented, and the role that ORNL played in this development is documented.

The ORNL work in vacuum insulation has been concentrated in Powder-filled Evacuated Panels (PEPs) that have a thermal resistivity over 2.5 times that of insulating foams and seven times that of many batt-type insulations, such as fiberglass.

Experimental results of substituting PEPs for chlorofluorocarbon (CFC) foam insulation in Igloo Corporation ice coolers are summarized. This work demonstrated that onedimensional (1D) heat flow models overestimated the increase in thermal insulation of a foam/PEP-composite insulation, but three-dimensional (3D) models provided by a finitedifference, heat-transfer code (HEATING-7) accurately predicted the resistance of the composites. Edges and corners of the ice coolers were shown to cause the errors in the 1D models as well as shunting of the heat through the foam and around the PEPs. The area of coverage of a PEP in a foam/PEP composite is established as an important parameter in maximizing the resistance of such composites.
\end{abstract}

\footnotetext{
* Research sponsored by the U.S. Department of Energy, Assistant Secretary for Conservation and Renewable Energy, Office of Buildings Energy Research, Building Systems and Materials Division, under contract DE-AC05-84OR21400 with Martin Marietta Energy Systems, Inc.

${ }^{+}$Consultant to the Oak Ridge National Laboratory.

${ }^{\ddagger_{K}}$-25 Site, Computing and Telecommunications Division.
} 
The HEATING-7 code was employed in a detailed thermal analysis of Compact Vacuum Insulation (CVI) produced by the Solar Energy Research Institute (SERI). The large reduction in the thermal resistance of the CVI by the 8-mil stainless steel cladding, used to contain the vacuum, is illustrated by direct measurements of the resistance of two CVIs and models of their use in composites with foam. The relatively high thermal conductivity of the stainless steel causes the decreased resistance of the CVI. Effects of ared of coverage of the CVI in a composite insulation and the effects of the size of the CVI are documented by models.

Polymer-clad vacuum insulation, such as the PEPs under study at ORNL, does not experience a decrease in resistance due to its cladding (barrier) material, but its thermal resistance does decrease with time due to permeation of ambient gases through the polymer. This aging phenomenon is caused by the reduction of thermal resistance of the powder as the gas pressure inside the PEP increases. The results of a literature survey to locate low-permeability polymers are presented. The state of the art for measurement of the permeability of barriers is reviewed, and interlaboratory comparisons using a standard reference material (SRM) 1470 from the National Institute of Standards and Technology (NIST) and a typical PEP barrier are discussed. A newly developed method of non-destructive measurement of the internal pressure of a PEP was employed in aging tests that used He to accelerate the gas permeation rate through barriers by several orders of magnitude. Measurements of the thermal resistance of PEPs, as a function of internal pressures of air and $\mathrm{He}$, were made as well as measurements of the pressure dependence of the powder used in the PEP. These resistance measurements are employed, along with the permeability measurements of the barrier, to predict the lifetimes of PEPs. 


\section{INTRODUCTION}

For pressures of $1 \times 10^{-4}$ torr or less, heat is transferred by thermal radiation as the mechanisms of thermal conduction and thermal convection are negligible. Thus, near or below room temperature, a vacuum is one of the best insulators available. This fact has been recognized as far back as the nineteenth century, when Sir James Dewar used the unique insulating capability of a vacuum in his calorimetry experiments ${ }^{1}$. Today, one of the most common uses of Dewar's concept is the Thermos ${ }^{*}$ bottle, which is usually constructed of a highly reflective, double-walled, glass container in the shape of a cylinder or sphere. For example, the thermal resistance $(\mathbf{R})$ provided by two, infinite, parallel, brightly polished, aluminum surfaces of emittance 0.035 that are separated by a vacuum is $54 \mathrm{~h}-\mathrm{ft}^{2}-{ }^{\circ} \mathrm{F} / \mathrm{Btu}$ at a $75^{\circ} \mathrm{F}$ average temperature of the two surfaces. This value is independent of the separation distance of the two surfaces and is typical of that achieved in Thermos bottles. ${ }^{\dagger}$

Often, however, the cylindrical or spherical geometry of a Dewar flask is not desired, such as when designs call for flat plates. For flat plates there is a significant technical problem: how to hold two flat plates apart under the load of the atmosphere without allowing them to touch except at the edges where the vacuum seal is made. Metals and plastics could be used as the plates, but the total conductance of the plates must be small so that heat is not shunted around the vacuum through the vacuum seal of the plates. This requirement mandates that the plates be very thin because the thermal conductivities $(\mathbf{k})$ of metals and plastics are high. Unfortunately, thin sections of these materials cannot support the atmospheric load; therefore, in practice, the plates are supported by a substance of high $\mathbf{R}$ placed within the vacuum space between the plates. Many different materials have been used to provide this support. For example, the Solar Energy Research Institute's (SERI) Compact Vacuum Insulation (CVI) employs glass spheres spaced in a facedcentered-cubic ( $\mathrm{fcc}$ ) array. The majority of other designs use powders, foams, or fibers as filler materials to support the load. The advantage of the latter design is that thin sheets of plastic can provide the vacuum containment and the powder/foam/fiber completely

${ }^{*}$ Registered Trademark fo the Household Industries, Inc., Freeport, Ill.

In this report the units used for $\mathbf{R} / \mathbf{i n}$. are $\mathrm{h}-\mathrm{ft}^{2}{ }^{\circ}{ }^{\circ} \mathrm{F} / \mathrm{Btu}$-in. and for $\mathbf{R}$ are $\mathrm{h}-\mathrm{ft}^{2}-^{\circ} \mathrm{F} / \mathrm{Btu}$. The $\mathrm{R} / \mathrm{in}$. is the thermal resistivity of an insulation and is the reciprocal of the thermal conductivity $(\mathrm{k})$ of the insulation. 
supports the load; the thermal conductance of the plastic in these designs is negligible. On the other hand, the SERI-type design requires sheets of stainless steel or some other metal to contain the vacuum and to help support the atmospheric load. Only for CVIs greater than $20 \times 20 \mathrm{ft}$ is the conductance of the steel sheets small enough so that thermal shunting of the steel is negligible.

This report is a summary of the development work on flat-vacuum insulation in the Building Marerials Group (BMG) of the Metals and Ceramics Division of the Oak Ridge National Laboratory (ORNL) during the last $2 \frac{1}{2}$ years. The principal work of the BMG in vacuum insulation has been development of Powder-filled Evacuated Panels (PEPs). In addition, significant efforts have been devoted to measurements of $\mathbf{R}$ of CVIs. Discussion of this work is included in this report.

\section{BACKGROUND}

\subsection{HISTORY}

During the early twentieth century, numerous attempts were made to fabricate flat insulation using Dewar's vacuum concept. However, none achieved the high Rs of the Thermos ${ }^{\star}$ bottle. ${ }^{1}$ In fact, only the very fine silica aerogels of Kistler ${ }^{2}$ achieved the thermal resistance of still air.

In the early 1950s, scientists at the General Electric (GE) Corporate Research Laboratory experimented with evacuated materials that were capable of supporting the high stress levels encountered in evacuated panels. Their work was not successful because the powder and granular filler materials they used had low Rs when compacted by atmospheric pressure. They were somewhat successful with very fine diameter ( 8 to $550 \mu$ in.) glass fibers that were compacted to a density of 16 to 22 pounds per cubic foot. ${ }^{1}$ This technology was abandoned by GE after many unsuccessful attempts to apply it to refrigerators. The major problems with this technology were: high material and fabrication costs, low reliability, and increased heat leakage caused by a stainless steel vacuum container. Further, about this time, other insulating materials (i.e., polystyrene and polyurethane foam) that were less costly and more adaptable to conventional manufacturing processes became available and were used instead of the flat vacuum insulation.*

*This paragraph is based on information excerpted from Ref. 3. 
Between 1979 and 1987, filler materials were discovered that could support the atmospheric load and still retain a high $\mathbf{R}$. Many of these filler materials attained 20 $\mathbf{R} / \mathbf{i n}$. or higher near-room temperature. During this time period, numerous patents were issued that described the materials, construction, and fabrication processes for flat, evacuated, insulated panels. ${ }^{4-11}$ In general, these panels consisted of a filler material, an outer barrier envelope, and in some designs, an inner porous pouch to retain the filler material during evacuation. The filler materials described in the patents ranged from finely divided particulates to open-celled foam, all having very low solid densities. The outer envelopes or barrier material were either plastic laminates or metallic claddings. The first PEP patent appears to be that of L'Aire Liquide, ${ }^{6}$ which described a panel consisting of very small diameter, fumed, silica filler material in a metallized-plastic envelope.

In the early 1980 s, Japanese refrigerator manufacturers were the first to employ flat evacuated panels in a commercial product. ${ }^{7}$ These panels were foamed into the refrigerators so that the insulation was a composite of the panels and the foam. The panels were constructed of perlite as the filler material and were contained in a metallized-plastic envelope. The superior insulation provided by the panel/foam composite allowed this Japanese manufacturer to market refrigerators with thinner walls. This construction resulted in increased food storage capacity without an increase in the external dimensions of the refrigerator, a distinct competitive advantage in the spaceconscientious Japanese society. Manufacturing of these type refrigerators was discontinued in the mid-1980s because of the high cost of producing and installing the composite insulation in the refrigerators.

Since 1988, international efforts in flat-vacuum insulation have been intensified by two pieces of legislation-the Montreal Protocol, ${ }^{12}$ which will eventually eliminate the use of chlorofluorocarbons (CFCs) due to their detrimental effect on the ozone in the stratosphere, and the recent energy efficiency requirements for appliances, ${ }^{13}$ which may require the use of higher thermal resistance per inch ( $R / i n$.) insulation or an increase in the thickness of lower $\mathrm{R}$ /in. insulation, with the consequent loss in usable space within the appliance. The following is a summary of the recent efforts in vacuum insulation technology (other than the ORNL effort) of which the authors are aware: 
1. A substantial program or the cievelopment of the CVI exists at SERI. As discussed later, the results of two tests of the CVI in refrigerators were disappointing due to the theirmal shunting caused by the CVI design, per se, and the fact that the walls of the refrigerators were only partially covered by the CVIs. ${ }^{14}$

2. Work performed at Messerschmidt-Bolkow-Blohm (MBB) developed a vacuum insulation that is called Vacuum Super Insulation (VSI). This product consists of diatomaceous earth as the filler material and steel as the barrier material. The thermal shunting of the steel is minimized in some applications for the VSI, such as 20-ft-long hollow cylinders used to insulate steam pipes. ${ }^{15}$

3. The staff of the Physikalisches Institut der Universităt Würzburg measured the $\mathbf{k}$ of evacuated materials under compressive loads to simulate those generated by atmospheric pressure on an evacuated panel. ${ }^{16}$ In earlier work, they and Brown, Boveri \& Cie AG developed a high-vacuum insulation to operate near $400^{\circ} \mathrm{C}$ to insulate $\mathrm{Na} / \mathrm{S}$ batteries. The filler material was either a powder ${ }^{17}$ such as opacified fumed silica or a fiber ${ }^{17-18}$ such as glass wool. The metallic foil of the battery wall served as the barrier material.

4. Researchers at Lawrence Berkeley Laboratory (LBL), working in conjunction with Thermalux, Inc., are developing evacuated insulation panels containing silica aerogels in tile or granular form. ${ }^{19}$ The ifhermal properties of these panels are very sensitive to the thickness and the boundary temperatures and emittances as these materials are transparent to thermal radiation at certain wavelengths. Lu et al. ${ }^{20}$ have described efforts to opacify aerogels to reduce thermal radiation transport.

5. Degussa AG (Frankfurt, Germany) recently announced the development of Vacuum Isolation Panels (VIP). "Powdered silica is pressed into panels and vacuum-sealed in a special film. VIF panels have an insulation value about twice that of high-grade PU (polyurethane) foam."21

6. Researchers at the Massachusetts Institute of Technology have worked on glassenclosed compacts of precipitated silica as a component to be distributed in foam boards. The thin glass envelopes may result in lower gas permeability rates without significant increases in thermal shunting, and use of numerous vacuum compacts avoids the problem of a single penetration destroying the high $\mathbf{R}$ of the compact/foam system. ${ }^{22}$ 
The reader is referred to Ref. 23 for a complete review of evacuated panel insulation technology as of 1989.

\subsection{ORNL HISTORY}

The ORNL BMG's interest in flat-vacuum panels began in 1981 with the completion (for ORNL) of an assessment by Lawrence and Ruccia of A. D. Little, Inc. ${ }^{24}$ Their analysis indicated that the use of thermal insulation with $20 \mathrm{R} / \mathrm{in}$. in appliances could save about one quad* of energy annually. Also, they concluded that the most promising systems, from an economic viewpoint, were evacuated, small-diameter-particle insulation. One of the recommendations of this analysis was that measurements of the $\mathbf{R}$ of this type insulation were needed to verify their assumptions about the $R$ values of this type of insulation.

The BMG followed this recommendation and subsequently published seven papers characterizing the $\mathbf{R} / \mathbf{i n}$. of candidate filler materials for flat-vacuum insulation as well as theoretical analysis of the mechanism that contributes to heat conduction in these materials. ${ }^{25-31}$ In addition, the $\mathbf{R}$ of flat-vacuum panels has been measured as a function of time to determine the aging of the panels due to gas permeation of the barrier envelope. ${ }^{29}$

In 1988, R. W. Barito Associates was contracted by ORNL to assess the use of foam/PEP composites to help reduce dependence on CFC insulation as well as to reduce energy consumption, due to the postulated higher $\mathrm{R} / \mathrm{in}$. of the composite as compared to $\mathrm{CFC}$ insulation. The second phase of this assessment involved fabrication and evaluation of PEPs and their application in a composite-foam/PEP insulation system in portable ice coolers. Ice coolers were used as a small-scale experiment to determine the Rs of the composite insulation as compared with the conventionally used foam. CFC foams were used because this project involved "drop-in" replacement in a production environment at the Igloo Corporai:'n; they were not able to use a non-CFC foam on their production line at that time. The first task of this work was the development and verification of a

${ }^{*}$ One quad equals $10^{15}$ Btu. About 85 quads of energy per year (1990) are presently used in the United States. 
repeatable ice melting test for evaluation of the ice coolers. Using this test, the heat transferred into a cooler insulated with the composite system was shown to be less than the heat transferred into a cooler insulated with CFC foam alone. The thermal performance of the coolers with the composite insulation was not as good as predicted by one-dimensional (1D) heat-transfer models but was in excellent agreement with threedimensional (3D) models. Temperature profiles derived with the 3D models showed that heat shunted around the PEPs through regions of the coolers not covered by PEPs, such as edges and corners. The shunting reduced the effectiveness of the PEPs as insulators by about a factor of two. To be most effective, the PEPs must cover the entire heattransfer path so that lower $\mathbf{R}$ parallel paths do not exist. In all, the project demonstrated that drop-in replacement of CFC foams with PEPs is viable in a production setting and that the composite insulation has a higher $\mathbf{R}$, which was in excellent agreement with predictions made with 3D models. This work was completed early in $1990 .^{32}$

The lifetime of PEPs depends on the permeability ( $p$ ) of the PEP's barrier material for the PEP's ambient gases and the $\mathbf{R}$ vs pressure $(\mathbf{P})$ relationship of the PEP's filler material for the ambient gases. In 1990, the BMG developed a simple model to predict useful lifetimes of PEPs using an accelerated aging test. Requisite to this model and test are values of $\mathbf{p}$ and $\mathbf{R}$ vs $\mathbf{P}$ for the PEP's materials of construction. The BMG's accelerated testing procedure for $\mathbf{p}$ uses He as the ambient gas. This test demonstrated that crders-of-magnitude errors existed in currently available values for the $\mathbf{p}$ of $\mathbf{a}$ composite polymer barrier material and that the industry standard for internal $\mathbf{P}$ measurements of PEPs was in error by up to a factor of three. Presently, interlaboratory comparisons using a National Institute of Standards and Technology (NIST) standard reference material (SRM) 1470 and several low $\mathbf{p}$ materials have been initiated to check the accuracy of techniques available to ORNL. To solve the internal $\mathbf{P}$ measirement problem, the BMG developed (and is in the process of obtaining a patent on) a handheld device that has yielded accurate measurements of the internal $\mathbf{P}$ of PEPs.

\subsection{OBJECTIVES OF ORNL WORK}

The future objective of the ORNL work is to develop technology to produce PEPs for less than $\$ 0.50$ /board $\mathrm{ft}$, having a $\mathrm{R} / \mathrm{in}$. greater than 20 , with a useful lifetime of 
greater than 20 years for applications such as refrigerators and 100 years for applications such as buildings. The major emphasis of this task is materials:

1. Development of filler materials that have high $\mathbf{R} / \mathrm{in}$. at high pressure, such as fumed silica (20 $\mathrm{R} /$ in. at $10-\mathrm{mm} \mathrm{Hg}$ pressure), and are relatively inexpensive, like silica dust (\$0.10/board $\mathrm{ft})$;

2. Development of gas barrier materials that are poor thermal conductors, that have low permeabilities and can be sealed at a reasonable cost (e.g., polymers), and that are essentially impermeable to ambient gases as are metals.

Four types of filler materials are to be studied-powders, fibrous insulation, aerogels, and foams. Powder materials that have the desired properties except for cost will be blended with lower cost materiais; new powders will be studied. Fiber insulations will be improved (e.g., by reducing their extinction coefficient by coating them with metals). Promising open-cell foams and aerogels will be studied. The $\mathbf{R}$ vs $\mathbf{P}$ of candidate materials will be measured before fabrication of test PEPs.

Individual polymer and metal barrier materials alone do not appear to offer hope of meeting the objectives of this work. Most polymeric barrier materials have too high a p, are of low strength, are soluble in water, or have other undesirable properties. All metals have too high a $\mathbf{k}$ Polymer/metal and/or polymer/polymer composites that have the desired properties will be developed. Permeability tests will be used to screen candidate barrier materials before they are fabricated into PEPs.

Models will be employed to predict the useful lifetimes of the PEPs fabricated with the barrier and filler materials identified by this project. Finally, PEPs will be fabricated and the $\mathbf{R}$ vs internal $\mathbf{P}$ will be measured.

\section{EQUJPMENT}

\subsection{ICE MELTING TEST}

A standardized, ice cooler test procedure developed in this program is shown in the flowchart in Fig. 1. This procedure employs a chamber* in which the temperature $\left(100^{\circ} \mathrm{F}\right)$

*Standard Environmental Systems, Inc., Model No. LHH/64S, Totowa, NJ; temperature range 32 to $200^{\circ} \mathrm{F}$, control $\pm 0.5^{\circ} \mathrm{F}$; relative humidity range 20 to $95 \%$ from 37 to $185^{\circ} \mathrm{F}$; Honeywell Model 452X21BE-000-00-2274, Relative Humidity and Temperature Recorder. 


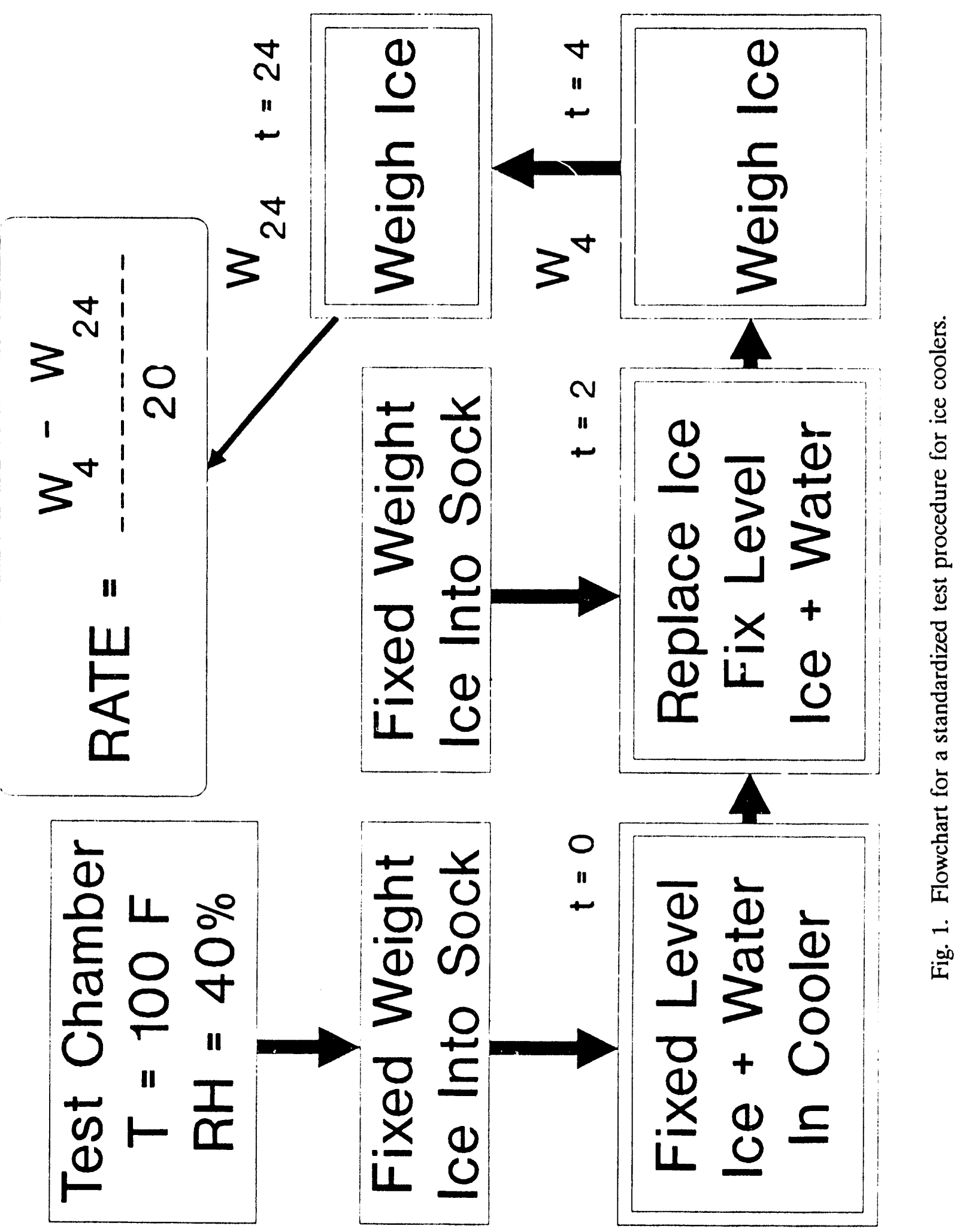


and relative humidity $(40 \% \mathrm{RH})$ are regulated precisely; the volume of the chamber is $64 \mathrm{ft}^{3}(4 \times 4 \times 4 \mathrm{ft})$. When a cooler is being tested, it is placed on a screen mesh about 6 in. off the floor of the chamber, thereby assuring a uniform flow of $100^{\circ} \mathrm{F}$ air over all sides of the cooler. The first step in the procedure is to load "cheese cloth" socks with ice cubes that are approximately $0.7 \times 0.6 \times 0.3 \mathrm{in}$. Each sock contains about $4.4 \mathrm{lb}$ of ice. The socks are placed in the coolers; the coolers are filled with water to a predetermined level and placed in the chamber. After $2 \mathrm{~h}$, the ice-filled socks are replaced with a second set of ice-filled socks, prepared as described above; sufficient water is removed to return the water to the initial level. After $2 \mathrm{~h}$, the ice-filled socks are removed and placed in cold Igloo 24 coolers, the weight of the ice is determined to the nearest $0.002 \mathrm{ib}$, and the ice-filled socks are returned to the coolers. These steps ensure that the cooler has reached steady state and that the ice is at $32^{\circ} \mathrm{F}$. After $20 \mathrm{~h}$, the ice-filled socks are removed and weighed again as described above; the ice use rate is calculated from the reduction in weight of ice during the 20 -h period.

\subsection{THE ORNL UNGUARDED THIN-HEATER APPARATUS}

The Unguarded Thin-Heater Apparatus (UTHA) ${ }^{33,34}$ is shown in Fig. 2 and meets the requirements of the Ame:ican Society for Testing and Materials (ASTM) C 1114-89. ${ }^{35}$ The apparatus is an absolute, longitudinal-heat-flow method and consists of an unguarded, electrically heated, flat, large-area, Nichrome-screen, heat source sandwiched between two horizontal layers of insulation with flat isothermal bounding surfaces. The screen heat source has a low thermal conductance, which reduces unwanted lateral heat flow and minimizes the need for active edge guarding. The heat source provides vertical heat flow in its central region across the subject insulation to two temperature-controlled, water-cooled, copper plates. The screen is large, $3 \times 5 \mathrm{ft}$, and the instrumented area $(3 \times 2 \mathrm{ft})$ has 11 thermocouples for temperature measurement and voltage taps for power measurements. A measured dc passes through the screen, and the heat generated passes through the two layers of insulation, each of thickness ( () . When steady state is reached, potentiometric equipment is used to measure the thermocouple outputs, the current (I), and the voltage (V). These quantities and the known spacing between the plates allow the apparent $\mathbf{k}$ to be calculated for two-sided heat flow from the measured temperature difference $(\Delta T)$ : 


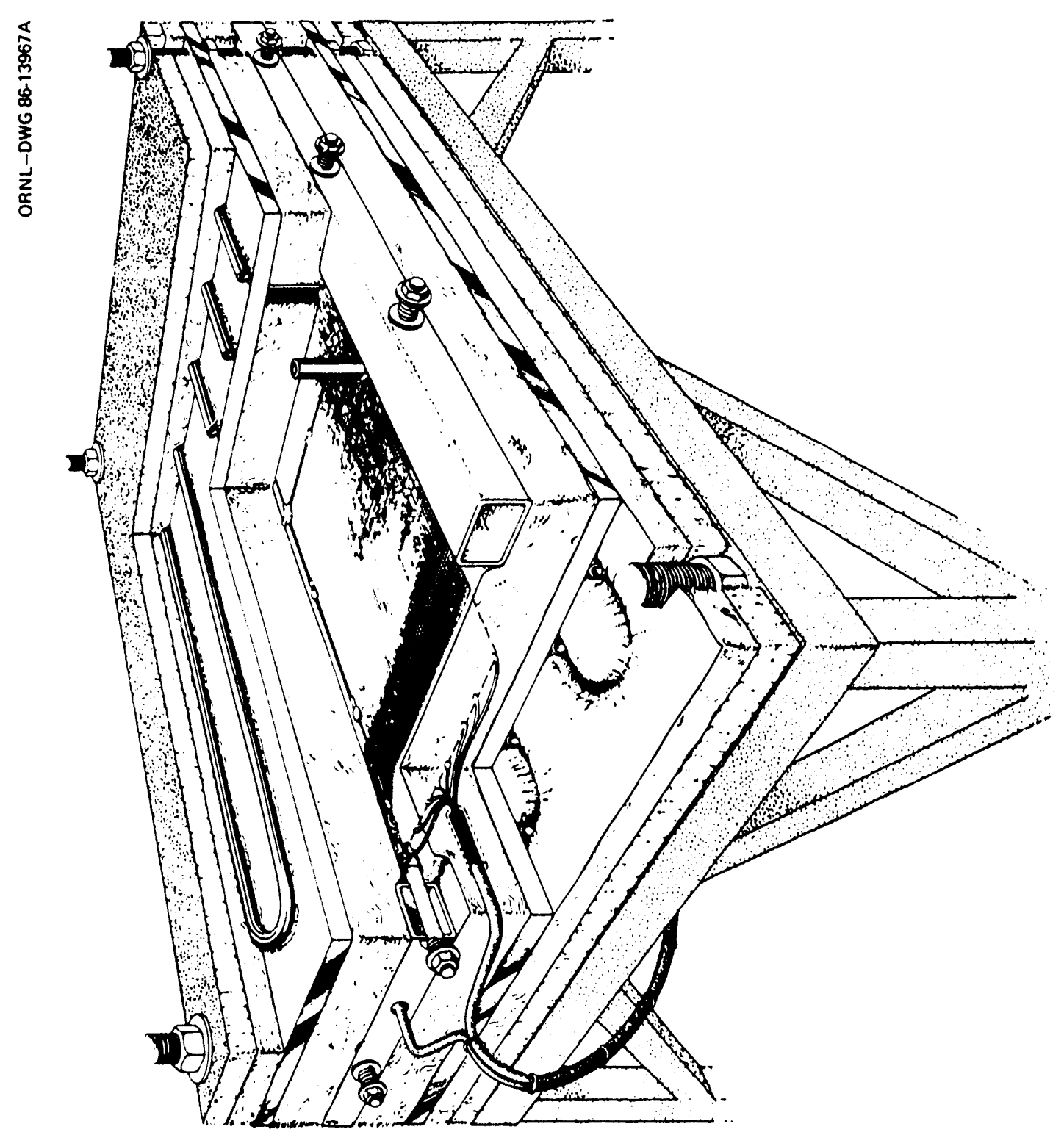

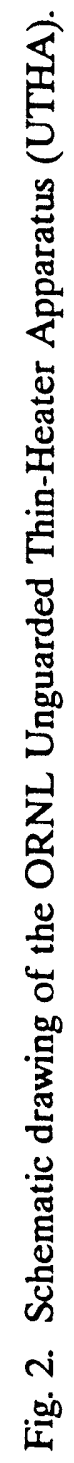




$$
k=\frac{I \times V}{2} \times \frac{\ell}{A_{0} \Delta T}
$$

By changing the screen power and the plate temperatures, mean specimen temperatures from 50 to $122^{\circ} \mathrm{F}$ can be achieved. The independent temperature control for each copper plate allows one-sided heat flow tests. If one plate is controlled to the temperature of the screen heater, the $\mathbf{k}$ of the insulating specimen with an imposed temperature difference is calculated from:

$$
k=\left[I \times V-\frac{k(B) \times \Delta T(B) \times A_{0}}{\ell(B)}\right] \times \frac{\ell}{A_{0} \Delta T}
$$

The B terms provide a heat flow correction for a small temperature mismatch. ${ }^{36}$

The measurement errors of the thin-heater apparatus have been assessed. A determinate error analysis of the quantities in Eq. (1) predicts a maximum uncertainty of $1.7 \%$ if $\Delta \mathrm{T}$ is $9^{\circ} \mathrm{F}$ and $0.7 \%$ if $\Delta \mathrm{T}$ is $54^{\circ} \mathrm{F}$. The most probable uncertainty is 1.2 and $0.4 \%$, respectively, for these $\Delta \mathrm{T}$ values. ${ }^{33,34}$

\subsection{THE ORNL HEAT-FLOW-METER APPARATUS}

Figure 3 is a photograph of the ORNL Heat-Flow-Meter Apparatus (HFMA), which is a comparative heat-flow-meter technique designed to meet ASTM C 518, Configuration B (i.e., two trarsducers, both faces). ${ }^{37}$ The apparatus is the first commercial unit in a new series of HFMAs and includes a computer for test control, data acquisition, and data analysis. The ORNL HFMA was produced by Holometrix, Inc. (Cambridge, MA) and delivered to ORNL in March 1989. The features of the apparatus include:

1. the $24 \times 24$ in. top and bottom plates with $10 \times 10$ in. heat-flow t:ansducers (HFTs) in each and independent plate temperature control to obtain one-sided heat flow, up or down;

2. mean specimen temperatures $(\mathrm{T})$ from 20 to $120^{\circ} \mathrm{F}$ can be obtained by controlling the hot face between 40 and $140^{\circ} \mathrm{F}$ and the cold face between 0 and $100^{\circ} \mathrm{F}$; 


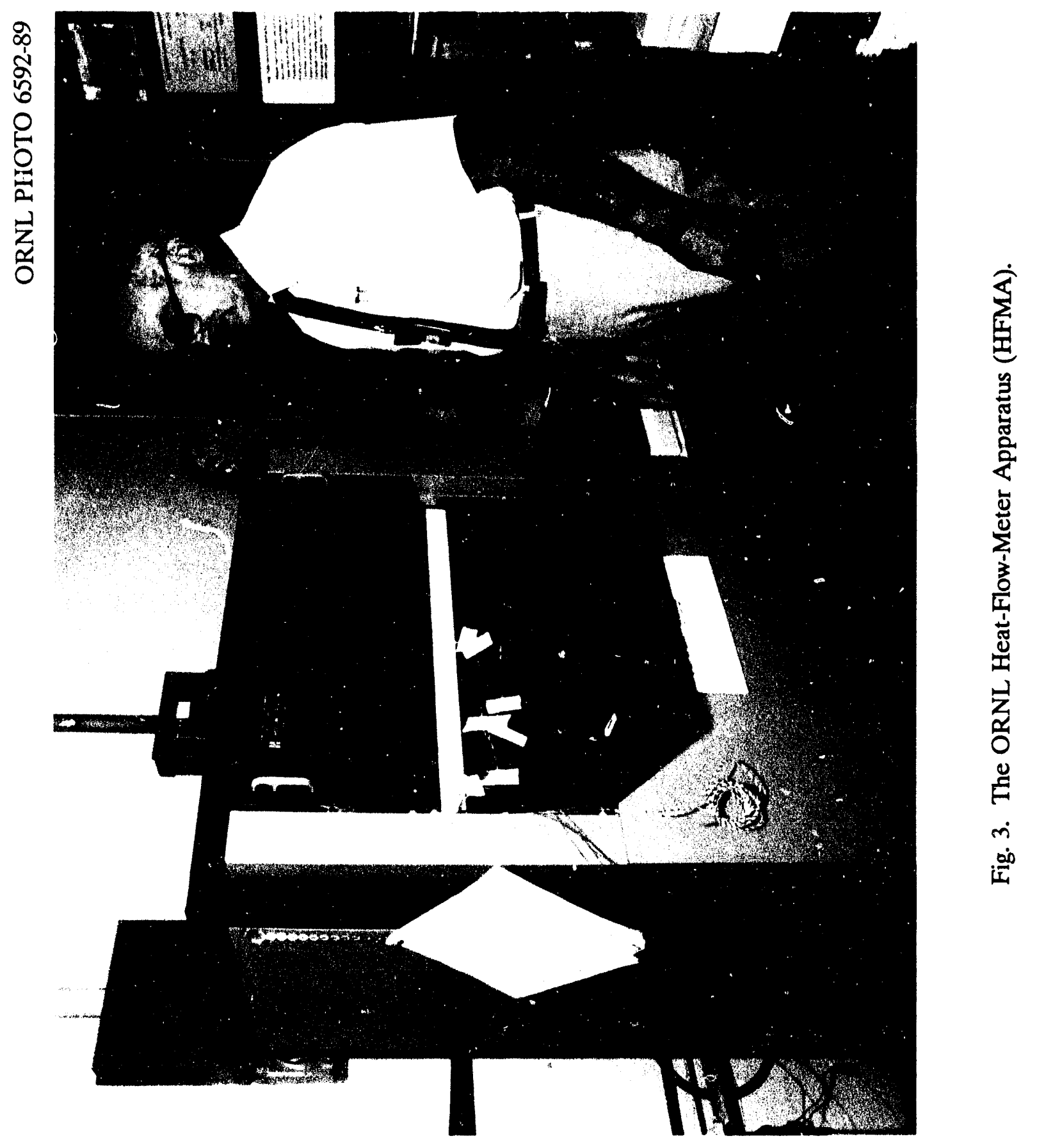


3. the test specimen chamber is surrounded by temperature-conditioned air and accommodates $24 \times 24$ in. specimens with thicknesses between 0.5 and 7 in.;

4. a dedicated computer allows test conditions to be programmed to obtain up to five $\mathbf{k}(\mathrm{T})$ determinations. The programming features compare the sequeniial data sets to selected criteria, such as change in $\mathbf{k}$, to decide when steady state has been cbtained. Thus, multiple determinations of $\mathbf{k}(\mathrm{T})$ can be measured automatically;

5. the apparatus includes circuitry to calibrate embedded HFTs; and

6. as specified by ASTM C 518, the two $10 \times 10$ in. HFTs are calibrated with SRM $1450 \mathrm{~b}$ or SRM 1451 to establish their calibration factors as a function of specimen thickness prior to a measurement campaign.

Because the ORNL HFMA is a comparative apparatus, its accuracy cannot be established by a determinate error analysis. Rather, the uncertainties must be inferred from measurements on materials of known $\mathbf{k}$. McElroy et al. ${ }^{38}$ have established uncertainties of less than ${ }_{ \pm} 5 \%$ by tests on identical specimens in the ORNL UTHA. The $2 \sigma$ value for a set of $\mathrm{C} 518$ measurements in an interlaboratory comparison was $2.2 \%$ for polyisocyanurate boards. ${ }^{39}$

\subsection{THE ORNL UNGUARDED RADIAL-HEAT-FLOW APPARATUS}

Figure 4 depicts the Unguarded Radial-Heat-Flow Apparatus (ORNL-7) used to measure the $\mathbf{k}$ of the powders. ${ }^{30}$ ORNL-7 consists of an unguarded, axially positioned, thin-walled stainless-steel, core heater that is instrumented with three, sinall-diameter, Type E thermocouples welded to holes in the tube wall. These thermocouples span a distance (L) of $20 \mathrm{~cm}$, serve as voltage (V) taps for power determination, and yield the tube temperature $\left(\mathrm{T}_{\mathrm{H}}\right)$ at its diameter. The powder specimen is contained in the annulus between the core heater and a concentric brass cylinder covered with copper tubing over its entire outside surface. Water from a controlled-temperature bath is circulated through this copper coil, and the temperature $\left(T_{c}\right)$ is measured with Type $E$ thermocouples joined to the copper coil with thermally conducting epoxy. The brass cylinder is joined to end flanges and caps that form the outer perimeter of the cell. Power leads exit through these ends to a dc power supply and standard resistor for measuring the current (I) to the core heater. Thermocouples also exit through these ends to join copper wires in an ice bath reference junction. The copper wires extend to 


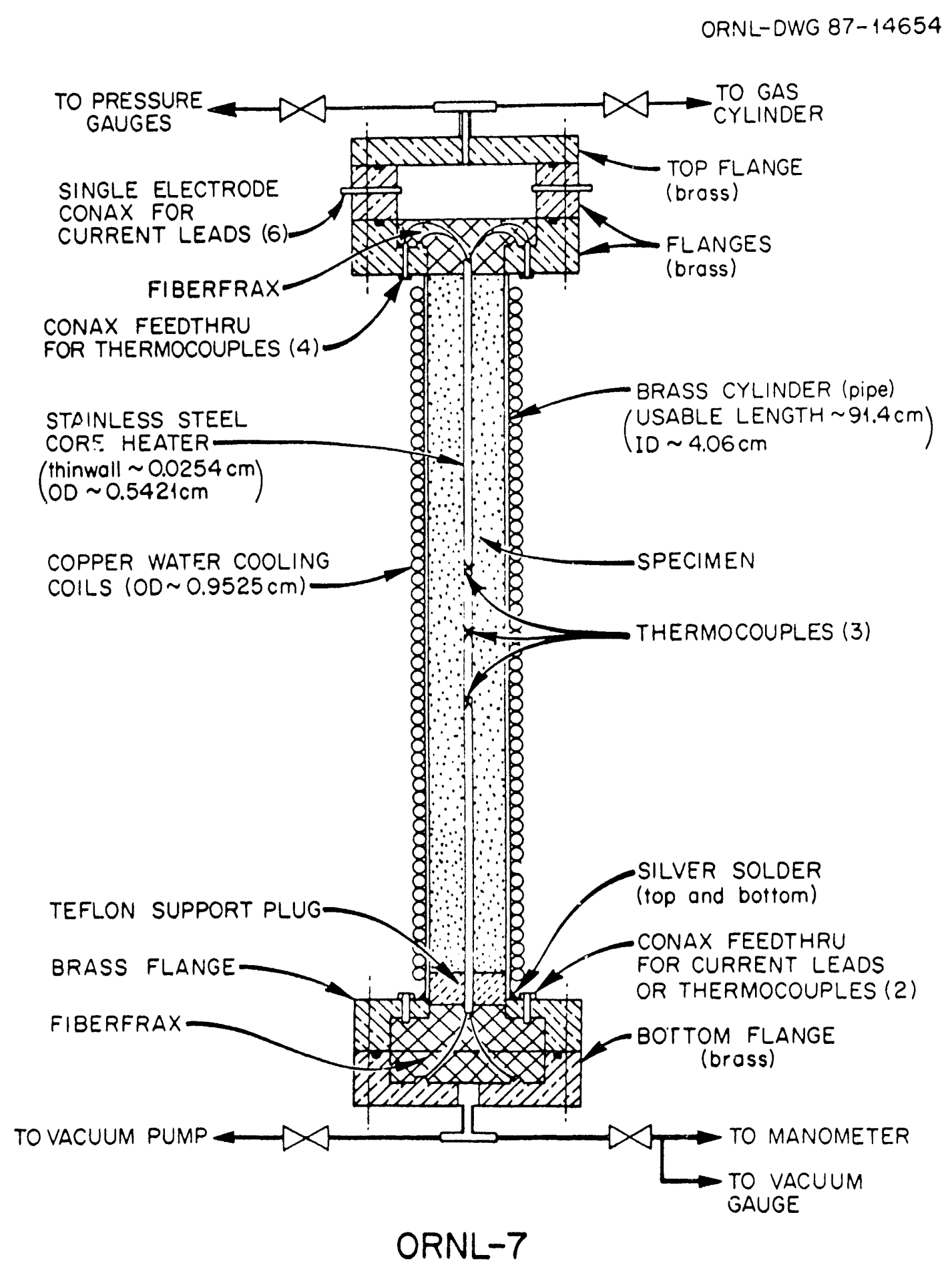

Fig. 4. Schematic drawing of the ORNL Unguarded Radial-Heat-Flow Apparatus (ORNL-7). 
a switching system and a digital voltmeter for measuring all thermal emfs. The end flanges connect to the gas pressure system, vacuum pumps, and gages to read the pressure or vacuum in the cell.

Steady-state $\mathbf{k}$ determinations are based on the temperature difference, $\Delta \mathrm{T}$, across the specimen in the radial direction $\left(\Delta T=T_{H}-T_{c}\right)$; the electrical power dissipated in the stainless steel core heater $(\mathrm{V} \cdot \mathrm{I} / \mathrm{L})$; and the radial dimensions of the annular space $\left(r_{o}\right.$ and $\left.r_{i}\right)$ :

$$
k=\frac{V I}{2 \pi L} \cdot \frac{\ln \left(r_{d} r_{i}\right)}{\Delta T}
$$

The length-to-diameter ratio of ORNL-7 is 22.5 , which makes a correction to $\mathbf{k}$ due to axial heat flow unnecessary. A determinate error analysis for ORNL-7 indicated a total uncertainty in $\mathbf{k}$ of $\pm 3 \%$. $^{30}$

\section{SPECIMENS}

The PEPs for the ice cooler tests were fabricated by R. W. Barito and Associates at a J. M. Huber Corporation facility under a contract between these two firms. Because of the proprietary nature of this work, the materials of fabrication were not identified by the manufacturers. Various sizes of $1 / 2$-in.-thick PEPs were fabricated. In addition, GE fabricated several sizes of $1 / 2$-in.-thick PEPs, which were used in the internal $P$ measurements.

The ice coolers were manufactured by the Igloo Corporation (Houston, TX). Standard Igloo 24, 44, and 48 models were employed and were taken from stock produced over about a one-year period. Igloo 32 coolers, which were actually thermoelectric refrigerators, were also tested. All tests reported herein were performed on the Igloo 32 coolers without the thermoelectric device installed and without the penetrations in the cooler needed to install the thermoelectrics. Production of the Igloo 32 cooler had just begun when this project started. Thus, most of the original Igloo 32 coolers tested were fabricated in January 1989. 
Because of production problems at J. M. Huber and Igloo Corporations, PEPs were only successfully foamed into the walls of Igloo 32 and 44 coolers. Attempts to foam the others were abandoned after attempts to foam into simulated panels failed.

\section{EXPERIMENTAL WORK AND DISCUSSION OF RESULTS}

\subsection{ICE COOLER EXPERIMENTS}

\subsubsection{Preliminary Experiments}

The initial goals of the work were to develop a repeatable ice melting test and to determine the effects of cooler age and manufacturing variability on the ice melting rate. Preliminary experiments were performed in which Igloo 48 coolers were filled with an ice/water mixture to a level $10 \mathrm{in}$. below the top and placed in a room at $72^{\circ} \mathrm{F}$. These simple experiments showed that:

1. below the ice and water mixture, the temperature of the cooler walls increases from $32^{\circ} \mathrm{F}$ near the top of the cooler to about $40^{\circ} \mathrm{F}$ at the bottom of the cooler. (The maximum density of water occurs at about $40^{\circ} \mathrm{F}$ );

2. the temperature distribution in the ice/water mixture is ever-changing, that is, the temperatures of the cooler walls change with time as denser water settles to the bottom of the cooler;

3. removing the ice to make weighings significantly affects the temperature distribution in the cooler because the denser $40^{\circ} \mathrm{F}$ water on the bottom of the cooler is disturbed;

4. the ice melting rate increased if the ice in the cooler was forced to the bottom because the denser water at $40^{\circ} \mathrm{F}$ did not settle to the bottom of the cooler. Thus, a higher temperature difference across the walls of the cooler was maintained throughout the test; and

5. the ice melting rate is a function of the starting weight of ice used.

Tables 1, 2, and 3 show the results of ice melting rates obtained on Igloo 24, 32, and 48 coolers tested by the standard procedure described in the Sect. of this report. Even though the thermal resistance of the foam insulation used in the walls of the coolers decreases with time ${ }^{38}$ after foaming, a correlation between the ice melting rate and the date of cooler manufacture (cooler age) was not found for the Igloo 24 and 48 
Table 1. Ice melting rates of seven Igloo 24 coolers as measured by a standard procedure

\begin{tabular}{ccc}
$\begin{array}{c}\text { Cooler } \\
\text { (number) }\end{array}$ & Manufacture date & $\begin{array}{c}\text { Usage rate } \\
(\mathrm{lb} / \mathrm{h})\end{array}$ \\
\hline 1 & $6 / 25 / 88$ & 0.282 \\
2 & $6 / 25 / 88$ & 0.278 \\
3 & $6 / 25 / 88$ & 0.280 \\
4 & $7 / 01 / 88$ & 0.287 \\
5 & $1 / 01 / 89$ & 0.280 \\
6 & $1 / 01 / 89$ & 0.289 \\
7 & $1 / 01 / 89$ & 0.287 \\
Average & 0.283 \\
Standard Deviation & 0.004 \\
\hline Inside dimensions: length $\times$ width $\times$ height (in.) \\
12.5 7.8 11.5 \\
Water level: 9 in.; ice load: $7 \mathrm{lb}$ in 2 socks \\
\hline
\end{tabular}

Table 2. Ice melting rates of four Igloo 32 coolers as measured by a standard procedure

\begin{tabular}{cc}
$\begin{array}{c}\text { Cooler } \\
\text { (number) }\end{array}$ & $\begin{array}{c}\text { Ice usage rate } \\
(\mathrm{lb} / \mathrm{h})\end{array}$ \\
\hline 1 & 0.315 \\
2 & 0.315 \\
3 & 0.328 \\
4 & 0.340 \\
\hline Average & 0.325 \\
Standard Deviation & 0.011 \\
\hline Manufacture date: $1 / 03 / 89$ & \\
Inside Dimensions: Length $\times$ width $\times$ height (in.) \\
Water level: 10 in.; ice load: $13.7 \mathrm{lb}$ in 3 socks \\
\hline
\end{tabular}


Table 3. Ice melting rates of ten Igloo 48 coolers as measured by a standard procedure

\begin{tabular}{ccc}
\hline $\begin{array}{c}\text { Cooler } \\
\text { (number) }\end{array}$ & Manufacture date & $\begin{array}{c}\text { Usage rate } \\
(\mathrm{lb} / \mathrm{h})\end{array}$ \\
\hline 1 & $11 / 25 / 87$ & 0.635 \\
2 & $05 / 01 / 88$ & 0.529 \\
3 & $11 / 05 / 88$ & 0.498 \\
4 & $12 / 01 / 88$ & 0.518 \\
5 & $06 / 01 / 88$ & 0.586 \\
6 & $10 / 01 / 89$ & 0.498 \\
7 & $11 / 01 / 88$ & 0.492 \\
$\mathrm{~A}$ & $10 / 01 / 88$ & 0.560 \\
$\mathrm{~B}$ & $09 / 01 / 88$ & 0.481 \\
$\mathrm{C}$ & $09 / 20 / 88$ & 0.553 \\
Average & 0.535 \\
Standard Deviation & 0.046 \\
\hline Inside dimensions: length $\times$ width $\times$ height (in.) & \\
Water level: 10 in.; Ice load: $18.1 \mathrm{lb}$ in 4 socks & \\
\hline
\end{tabular}

coolers; the four Igloo 32s were all manufactured on the same day. Later measurements on the Igloo 32s showed aging, however, as discussed later. Lack of correlation between ice melting rate and cooling age is attributed to several factors:

1. For the Igloo $48 \mathrm{~s}$, the standard deviation of $0.046 \mathrm{lb} / \mathrm{h}$ (or about $9 \%$ ) for the ice melting rate masked much of the effect; the large standard deviation is attributed to variations in the foaming process. For example, cooler 1 had the highest ice usage rate and was six months older than all the other coolers. Thus, this high usage rate could be attributed to aging of the foam; however, about one-third of one side of the cooler had no foam, which probably was the cause for most of the increased ice consumption. Inspection of the coolers using radiography and high power lights (the cooler walls are semitransparent in the visible) demonstrated that air pockets existed in the foam of all the coolers.

2. For the Igloo 24s, the top is hollow and is not insulated; thus, a large part of the heat gain occurs through the top. This lack of insulation masked the aging effect, as is demonstrated later when the data for PEPs foamed into Igloo 44 coolers with uninsulated tops is presented. 
3. The plastic inner and outer liners of the coolers could have served to reduce the diffusion of air into the foam and the CFC out of the foam, the processes that cause aging of the foam.

\subsubsection{Tests on Coolers with Taped-In PEPs}

Because of a delay in the delivery of large PEPs, smaller 1/2-in.-thick PEPs were taped to the inner liners of production coolers that had already been tested, and the coolers were retested. Table 4 shows the results of those experiments as well as the area of coverage by the PEPs of the inside surfaces of the coolers.

A 1D heat-transfer analysis was performed on the three types of coolers with and without taped-in PEPs. Heat transfer was treated as an analog to electrical resistors, whereby the thermal resistances were weighted (based on the total inside surface area of the cooler covered by the PEPs) and summed as though they were electrical resistors in series and parallel. (The thermal resistance of the area containing the PEPs was calculated by multiplying the thermal resistivity of the foam and PEPs by their thicknesses and thicknesses and summing. The thermal resistance of the area without PEPs was calculated by multiplying the thickness of the foam by its thermal resistivity; these two resistivities were weighted by the areas and summed as resistors in parallel, resulting in the thermal resistance of the composite insulation.) This analysis predicted heat transfer reductions that were approximately a factor of two too high for all three coolers, as shown in Table 4. As illustrated later, a 1D analysis is generally too simplified to treat the very complex $3 \mathrm{D}$ perturbation in the heat transfer caused by the insertion of the PEPs in walls of the cooler as well as the effects of the corners and edges of the coolers. Thus, the measurements are correct, and the simple 1D model is incorrect.

\subsubsection{Tests on Coolers with Foamed-In PEPs}

Table 5 shows the data obtained on the Igloo 32 coolers that were insulated with the PEP/foam composite. PEPs could only be used in three sides and the bottom of the cooler (i.e., one $10 \times 15 \times 1 / 2$ in. PEP in the two larger sides and the bottom, and one $10 \times 10 \times 1 / 2$ in. PEP in the smaller side). The top and the side molded for the thermoelectric device were too narrow for insertion of PEPs. The average ice melting rate for these coolers was $0.295 \mathrm{lb} / \mathrm{h}$. The average ice melting rate for the control coolers (Table 2) was $0.325 \mathrm{lb} / \mathrm{h}$. This difference translates to an improvement of only 
Table 4. Ice melting rates for coolers with taped-in PEPs ${ }^{a}$

\begin{tabular}{ccccc}
\hline \multicolumn{4}{c}{ Ice melting rate measurements } & \\
\hline Cooler & $\begin{array}{c}\text { As-received } \\
(\mathrm{lb} / \mathrm{h})\end{array}$ & $\begin{array}{c}\text { With PEPs } \\
(\mathrm{lb} / \mathrm{h})\end{array}$ & $\begin{array}{c}\text { Measured } \\
\text { change } \\
(\%)\end{array}$ & $\begin{array}{c}\text { 1D calculated } \\
\text { change } \\
(\%)\end{array}$ \\
\hline 24 & 0.283 & 0.220 & 22 & 43 \\
32 & 0.325 & 0.283 & 13 & 29 \\
48 & 0.535 & 0.445 & 17 & 37 \\
\hline
\end{tabular}

${ }^{a}$ Percent of inside surface area covered by PEPs: 64,59 , and $70 \%$ for 24,32 , and 48 coolers, respectively.

Table 5. Ice melting rates of Igloo 32 coolers with foamed-in PEPs ${ }^{a}$

\begin{tabular}{cc}
\hline $\begin{array}{c}\text { Cooler } \\
\text { (number) }\end{array}$ & $\begin{array}{c}\text { Rate } \\
(\mathrm{lb} / \mathrm{h})\end{array}$ \\
\hline 1 & 0.276 \\
$2^{b}$ & 0.306 \\
$2^{b}$ & 0.306 \\
$2^{b}$ & 0.300 \\
4 & 0.271 \\
5 & 0.335 \\
6 & 0.271 \\
7 & 0.293 \\
8 & 0.304 \\
9 & 0.287 \\
\hline Average & 0.295 \\
Standard Deviation & 0.019 \\
\hline
\end{tabular}

${ }^{a}$ Average melting rate of these coolers is $9.2 \%$ lower than standard production coolers listed in Table 2. Electrical-analog model predicts an 18\% decrease. Total of $55 \%$ of surface area of cooler covered by the PEPs.

${ }^{b}$ Repeat runs.

9.2\% in the cooler performance due to the addition of the PEPs. An electrical-analog, 1D model predicted that insertion of the four PEPs into the foamed wall should have reduced the melting rate $18 \%$.

To provide a better comparison between the coolers with and without the PEPs, two additional ice melting tests were run on production cooler 1 and cooler 2 with the 
foamed-in PEPs. Also, a third run was made after the four PEPs in cooler 2 were punctured. Table 6 lists the measurements obtained on the two types of coolers. Undoubtedly, the most significant result in these data is the large difference between the measurements on cooler 1 in Table 2 and the average presented for cooler 1 in Table 6 (i.e., melting rates of 0.315 and $0.359 \mathrm{lb} / \mathrm{h}$, respectively). This $14 \%$ increase in ice melting rate is believed due primarily to the aging of the foam. The first measurements were made on February 6, 1989, and the second measurements were made on June 27, 1989 ( 34 and $175 \mathrm{~d}$, respectively, after foaming this cooler). In view of this result, direct comparison of the coolers with and without PEPs is not justified unless corrections are made for the aging of the foam, because the date of manufacture of the two types of coolers is different. Another interesting result shown in Table 6 is that after puncturing the PEPs, the ice melting rate of the cooler was essentially the same as the production unit, indicating that the $R / i n$. of a punctured PEP is about equal to that of the foam.

Table 6. Ice melting rates of Igloo 32 coolers with and without foamed-in PEPs

\begin{tabular}{cccc}
\hline & \multicolumn{3}{c}{ Ice Melting Rates $(\mathrm{lb} / \mathrm{h})$} \\
\hline Test & $\begin{array}{c}\text { Production } \\
\text { (cooler 1) }\end{array}$ & $\begin{array}{c}\text { Foamed-in } \\
\text { (cooler 2) }\end{array}$ & $\begin{array}{c}\text { Cooler 2 } \\
\text { (punctured PEPs) }\end{array}$ \\
\hline 1 & 0.368 & 0.306 & - \\
2 & 0.362 & 0.300 & - \\
3 & 0.348 & - & 0.362 \\
\hline Average & 0.359 & 0.303 & 0.362 \\
\hline
\end{tabular}

The differences between the experimental and calculated values of the ice melting rates led to measurements of the thermal conductivity of the PEPs and foam and computer modeling of the heat transfer in the coolers.

\subsubsection{Thermal Conductivity of PEPs and Foam}

The $\mathbf{k}$ of typical PEPs used in this project was measured on July 7, 1989, in the UTHA. Fifteen PEPs were taped together to form a montage specimen $3 \times 5 \mathrm{ft}$ in area. A value of $0.051 \mathrm{Btu}-\mathrm{in} / \mathrm{h}-\mathrm{ft}^{2}{ }^{\circ}{ }^{\circ} \mathrm{F}$ (19.6 R/in.) at $75^{\circ} \mathrm{F}$ was determined; the Ps in the PEPs at the time of this $\mathbf{k}$ measurement were not known because the $\mathrm{J}$. M. Huber pressure-test device was no longer available to the project. At the time of manufacture 
(May 11, 1989), the PEP Ps measured by J. M. Huber averaged about 2.9 torr, and the $k$ was $0.038 \mathrm{Btu}$-in. $/ \mathrm{h}-\mathrm{ft}^{2}{ }^{\circ} \mathrm{F}\left(26 \mathrm{R} / \mathrm{in}\right.$.) at $75^{\circ} \mathrm{F}$. This $\mathbf{k}$ measurement was made at $\mathrm{J}$. $\mathrm{M}$. Huber using Rapid K-Matic (Holometrix, Inc.). The difference in these two sets of measurements is due to the aging of the PEPs and to experimental errors, which are known to be high for materials of such low $\mathbf{k}$. In any event, the $\mathbf{k}$ measured at ORNL should be representative of that of the PEPs during their use in the cooler experiments because the time span between measurements and use was approximately the same.

The $\mathbf{k}$ of foam specimens cut from the walls of Igloo 32 and 48 coolers was measured at ORNL using the ORNL HFMA. A $2 \times 2 \mathrm{ft}$ montage specimen was formed from precisely machined pieces of the foam cut from the walls of the coolers. Values of 0.137 and $0.144 \mathrm{Btu}-\mathrm{in} / \mathrm{h}-\mathrm{ft}^{2}{ }^{\circ}{ }^{\circ} \mathrm{F}$ (7.30 and $6.94 \mathrm{R} / \mathrm{in}$.), respectively, were determined at $75^{\circ} \mathrm{F}$. These measurements were performed approximately $3 \mathrm{~d}$ after final machining of the specimens, which were machined from the centers of the foam extracted from the walls of the cooler. Thus, these values of $\mathbf{k}$ are believed to be representative of newly blown foams.

\subsubsection{Heat Transfer Modeling of the Igloo 32 Coolers}

The finite-difference, heat-transfer code, HEATING-7, was used to model the Igloo 32 coolers using a Cray computer for computation. HEATING-7 is a publicdomain code that is more conveniently run on a super computer such as a Cray because of the memory requirements and especially because of the large number of computations required by the method. Use of less powerful computers is considered impractical for extensive modeling as was performed on the coolers. To reduce the computation time, the heat flow was assumed to be symmetric about the centerline of the coolers, as depicted in Fig. 5.

Modeling was performed for Igloo 32 coolers with foam only, and Igloo 32s having foamed-in PEPs and taped-in PEPs. Analyses were performed for $1 D$ and 3D heat flow using HEATING-7. In each case, the $\mathbf{k}$ of the foam was computed from a model derived by Graves et al. ${ }^{40}$ that corrects for the aging of the foam from time of manufacture. The $\mathbf{k}$ of the PEP measured by the UTHA was used.

The results of the 1D and 3D HEATING-7 models are listed in Table 7. The validity of the $3 \mathrm{D}$ mudels is demonstrated by their excellent agreement with the experimental results, differing by less than ${ }_{ \pm} 5 \%$ from the measured values. In addition, 


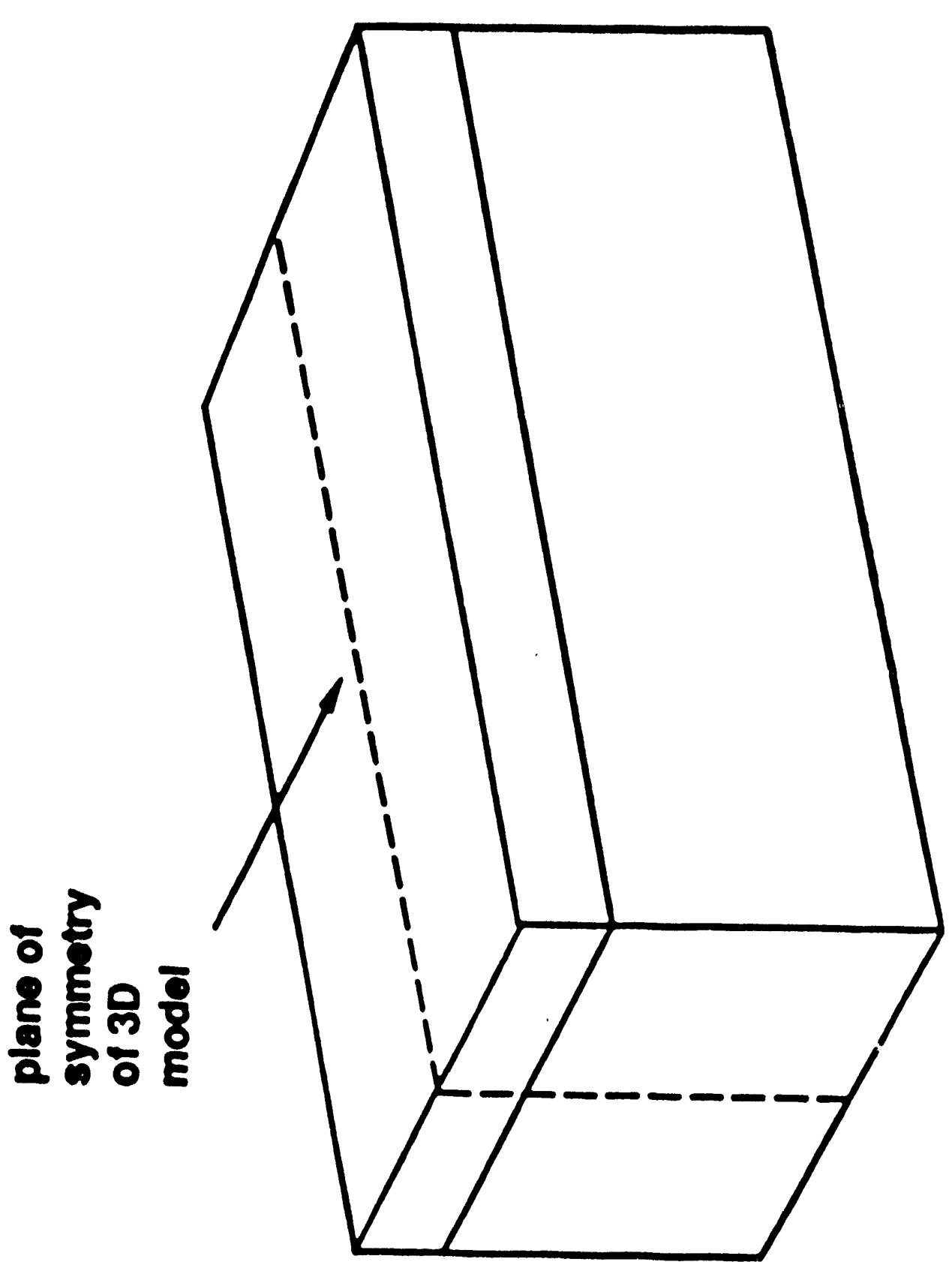

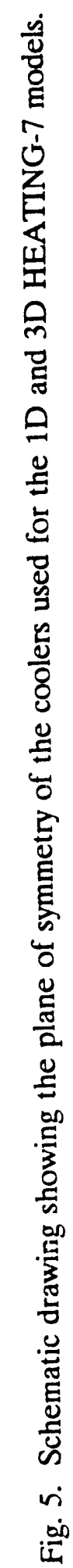


Table 7. Results of HEATING-7 models of Igloo 32 coolers with and without PEPs

\begin{tabular}{lccccc}
\hline & \multicolumn{3}{c}{ Ice melting rates $(\mathrm{lb} / \mathrm{h})$} & \multicolumn{2}{c}{ Comparison } \\
\hline & Calculated & Calculated & & 1D & 3D \\
\hline \multicolumn{1}{c}{ Case } & 1D & 3D & Measured & (diff \%) & (diff \%) \\
\hline Foam $^{a}$ & 0.291 & 0.340 & 0.324 & -10 & +5 \\
Foam $^{b}$ & 0.313 & 0.364 & 0.359 & -13 & +1 \\
Foamed-PEP $^{c}$ & 0.196 & 0.289 & 0.295 & -34 & -2 \\
Taped-PEP $^{d}$ & 0.165 & 0.298 & 0.283 & -41 & +5 \\
\hline
\end{tabular}

${ }^{a} \mathrm{R}=6.93$ for 34 -d-old foam.

${ }^{b} R=6.30$ for 75 -d-old foam.

${ }^{c} R=6.93$ for 34 -d-old foam; $R=20$ for PEPs; $59 \%$ of surface area covered by PEPs.

${ }^{d} \mathrm{R}=6.73$ for 55 -d-old foam; $\mathrm{R}=20$ for PEPs; $55 \%$ of surface area covered by PEPs.

${ }^{e} \mathrm{R}=$ diff $\%=100 \times($ calculated-measured $) /$ measured.

the effect of aging of the foam was accurately predicted by the model as evidenced by the two foam-only results in Table 7.

The 1D HEATING-7 model always underestimated the ice melting rate. In other words, the 1D models overstate the effectiveness of the PEPs. In particular, the calculated ice melting rate for the 1D HEATING-7 model of the taped-in case is $41 \%$ below the measured rate. Similarly, the calculated ice melting rate for the foamed-in case is $34 \%$ too low for the 1D HEATING-7 model. The 1D results for the foam-only cases overestimate the effectiveness of the foam by between 10 and $13 \%$, which is a relatively small error and is due to the inabilities of the ID case tc include the effects of edges and corners of coolers as described in the next section.

The conclusion to be drawn from the results of the HEATING-7 and electricalanalog models is that 1D models do not work well for composite insulation when 3D heat transfer is occurring in an anisotropic manner. The $1 \mathrm{D}$ models do not work because they assume that heat flow is normal to the surfaces of the cooler, i.e., the temperature isotherms are parallel to the surfaces of the cooler, which is definitely a poor assumption for composite insulation. This fact is illustrated in Figs. 6 through 11, which give the temperature profiles obtained from the 3D HEATING-7 models; the temperatures are shown as isothermal contours. 


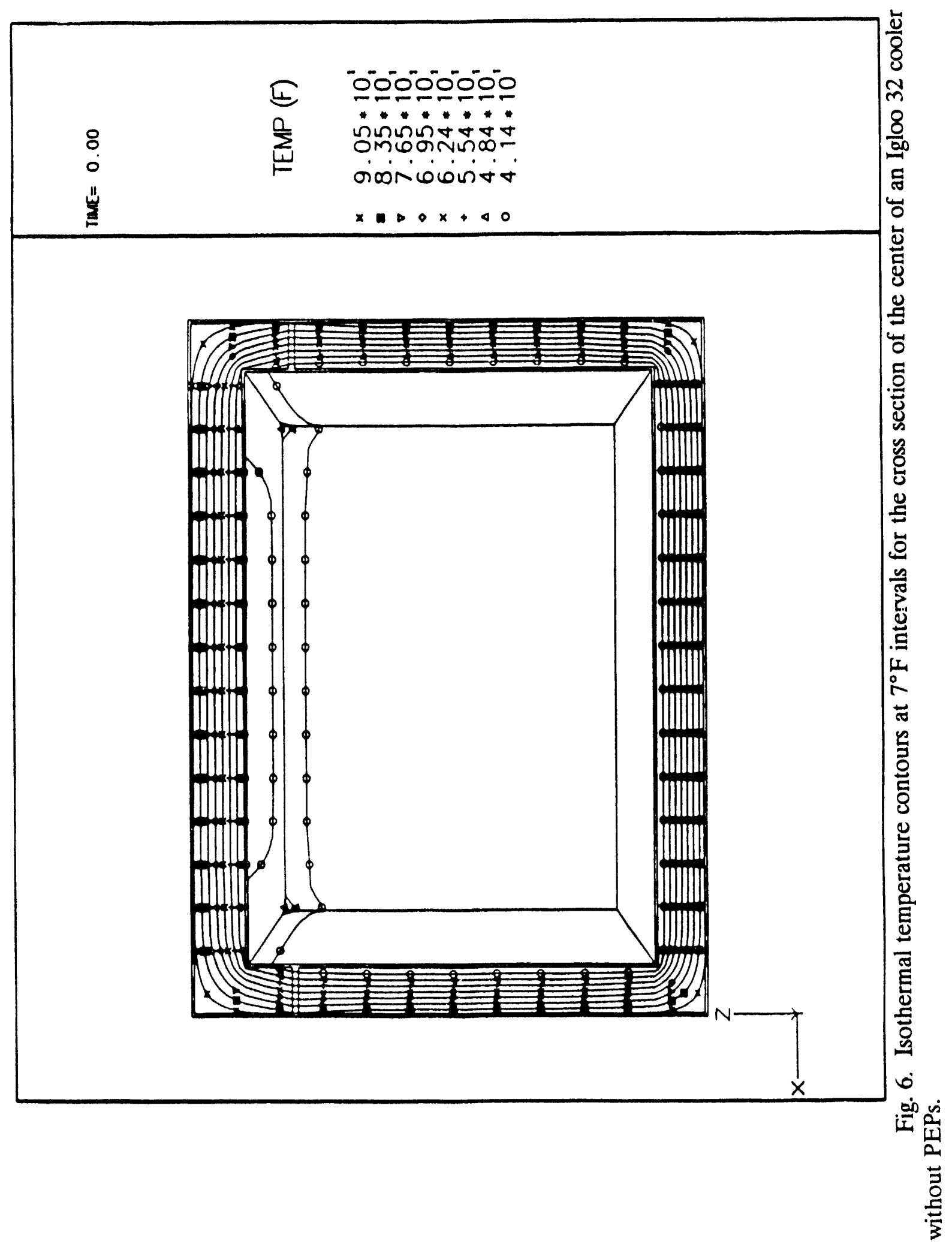




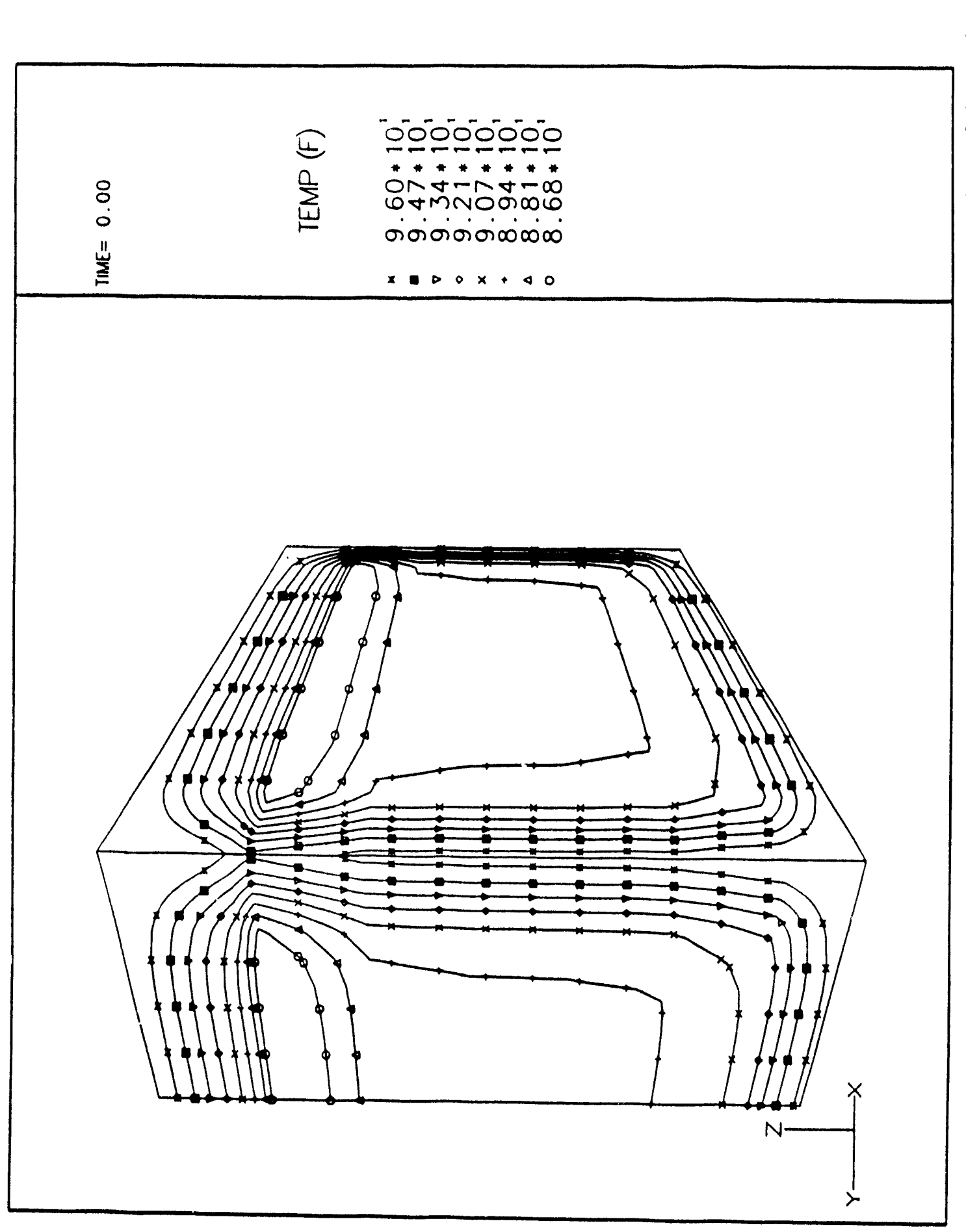

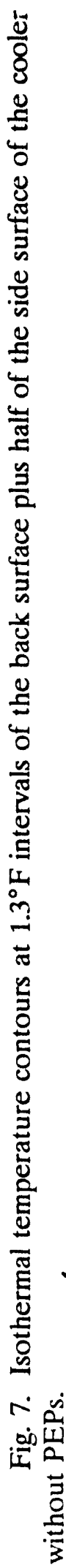



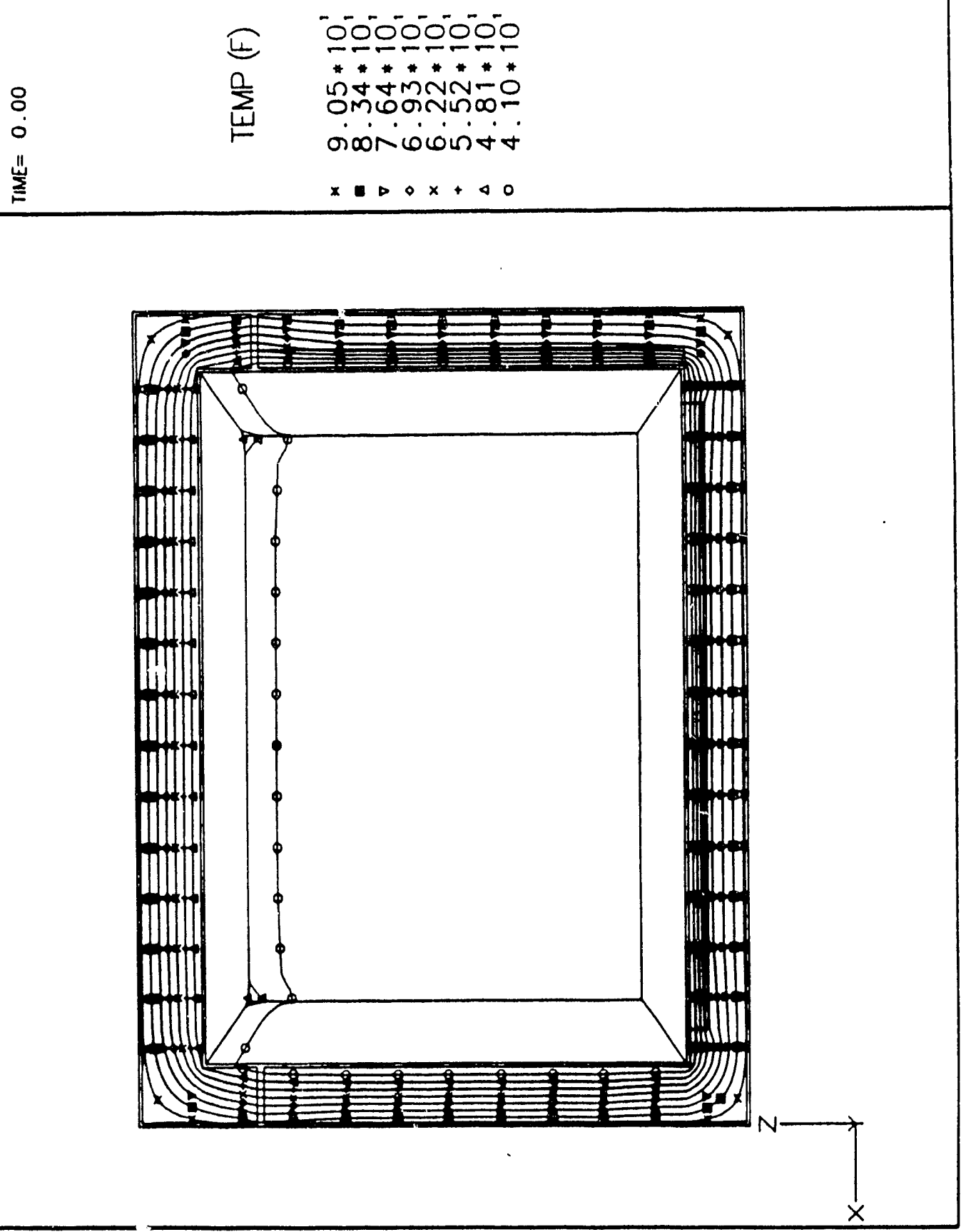

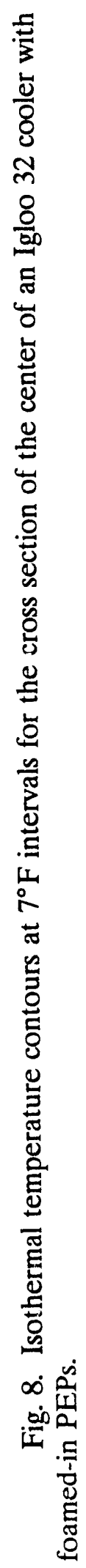



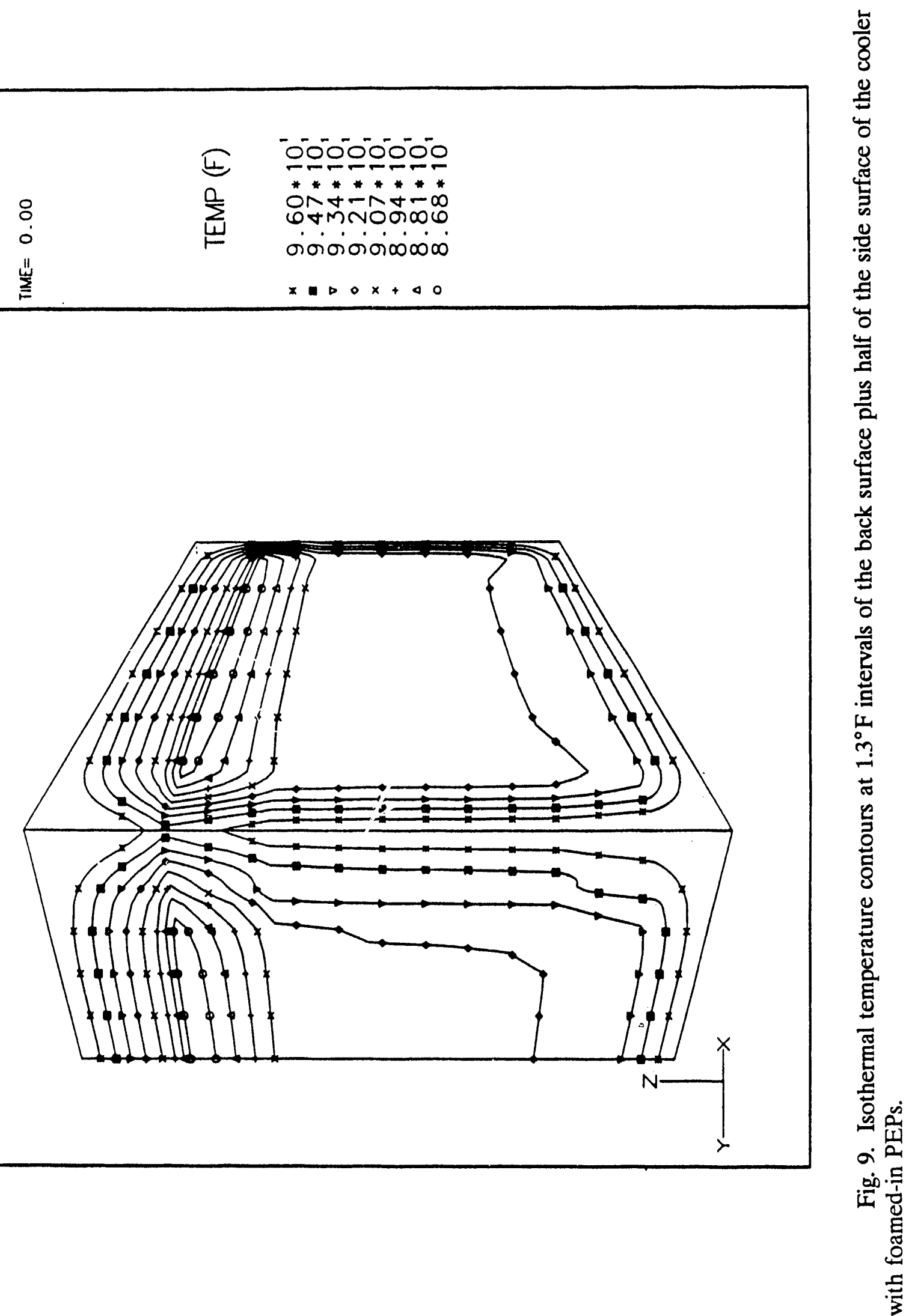

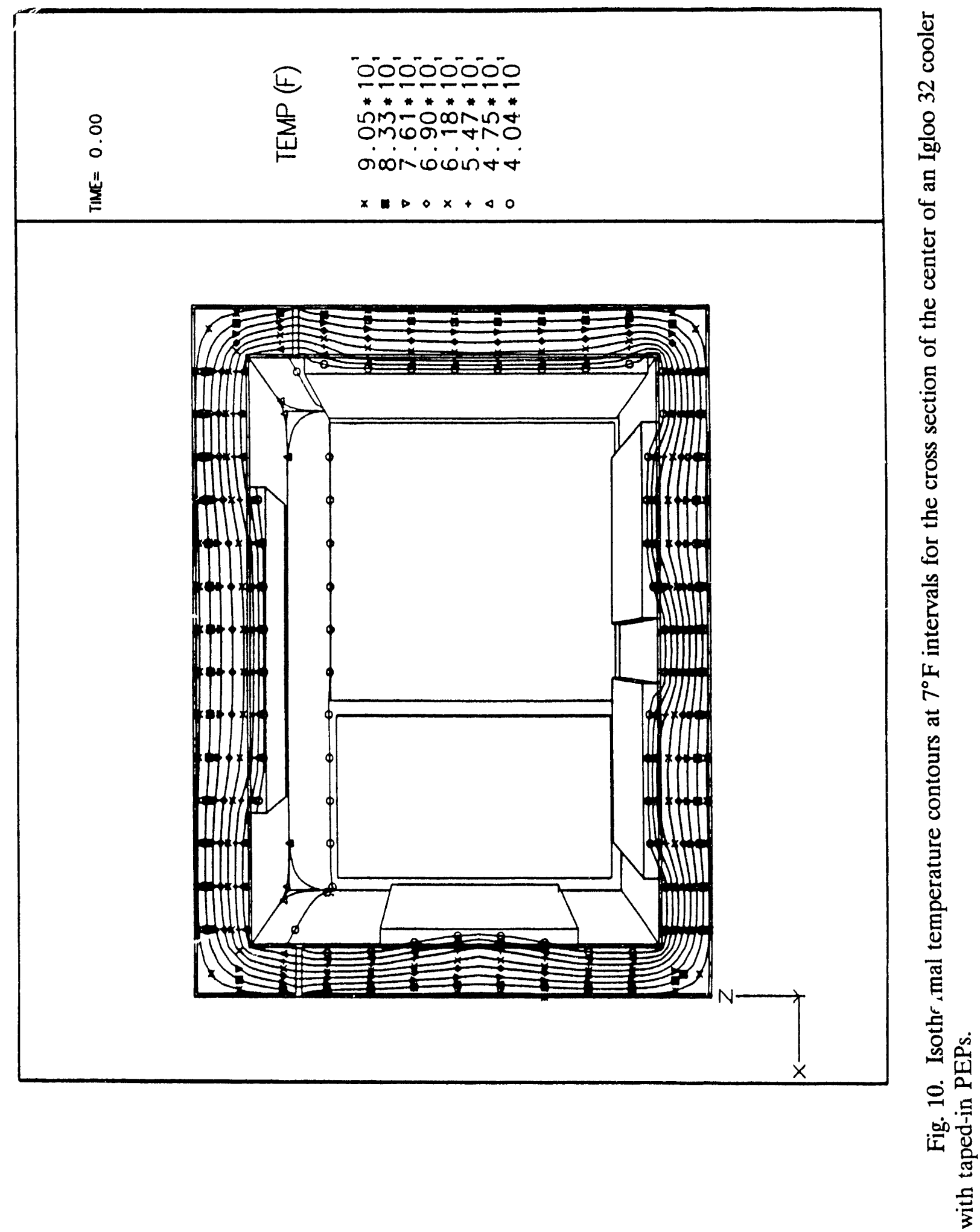


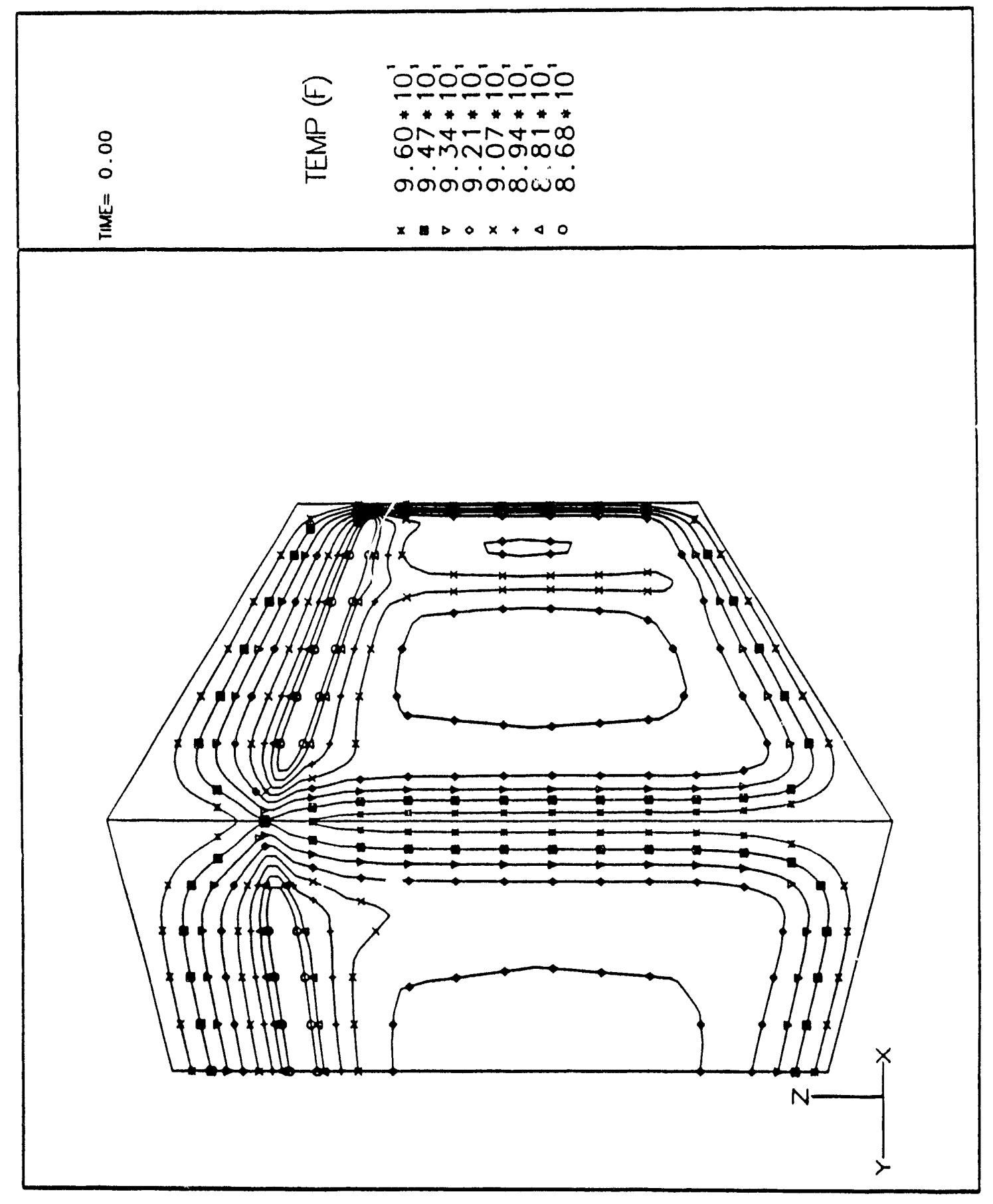

$\frac{1}{8}$

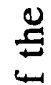

임.

冚

$\frac{\mathscr{g}}{\mathrm{s}}$

를

4

可

$\frac{2}{2}$

䢘

步

递

$\underline{\varrho}$

는

$\frac{n}{3}$

忌

LI

in

ส

号

苞

$\exists .5$

iุ

政

章 
Figures 6, 8, and 10 map the isothermal temperature contours at $7^{\circ} \mathrm{F}$ intervals for the cross section of the center of an Igloo 32 cooler (Fig. 6 without PEPs, Fig. 8 for foamed-in PEPS, and Fig. 10 for taped-in PEPs). Isothermal contours at $1.3^{\circ} \mathrm{F}$ intervals of the back surface plus half of the side surface of the cooler are shown in Figs. 7, 9, and 11 (Fig. 7 without PEPs, Fig. 9 for foamed-in PEPS, and Fig. 11 for taped-in PEPs).

Figure 6 depicts the temperature isotherms for the center cross section of the Igloo 32 without PEPs. The isotherms are parallel to the surfaces of the cooler except at the corners and at the interface between the door and the storage part of the cooler. Figure 10 is the same view as Fig. 6, except it represents taped-in PEPs. The isotherms in this case are extremely distorted; they definitely are not parallel to the surfaces of the cooler, particularly near the edges of each PEP. Figure 8 shows the same view for the foamed-in case for which the distortions of the isotherms, while present, are not as large as for the taped-in case; thus, the overestimate of the 1D calculation is smaller for this case. In 3D, therefore, heat flows around the PEPs and through the foam behind the PEPs, thereby reducing the effectiveness of the PEPs. To prevent this "thermal shunting," the entire surface of the cooler would have to be insulated with PEPs, not just part of the surfaces, as was done in these experiments. Percent coverage of the surface by PEPs, therefore, is an important parameter in reducing the heat flow into the cooler.

As shown in Fig. 7, the center of the surface of the back of the cooler without PEPs is between 89.4 and $90.7^{\circ} \mathrm{F}$. With PEPs foamed in (Fig. 9), the temperature of approximately this same area was substantially higher, being between 90.7 and $92.1^{\circ} \mathrm{F}$. Thus, approximately $9 \%$ less heat could be transferred into the cooler with foamed-in PEPs because the temperature gradient to the ambient $100^{\circ} \mathrm{F}$ air was less. In Fig. 11, the location of the small and large PEPs taped to the inside surface of the cooler is obvious from the temperature contours on the back surface of the cooler. Again, the large area in the center of the back surface is between 90.7 and $92.1^{\circ} \mathrm{F}$.

Figures 7, 9, and 11 illustrate the large heat loss that occurs in the area of the opening of the cooler. In this area, the temperature of the surface drops below $86.8^{\circ} \mathrm{F}$, which provides a significantly larger temperature gradient that increases heat input into the cooler by about $35 \%$ in this area. 


\subsubsection{Effects of Edges and Corners}

As shown in Table 7, the 1D HEATING-7 calculations for the foam-only case of the Igloo 32 coolers overestimated the effectiveness of the foam insulation by 10 to $13 \%$. This overestimate is due to the inability of the 1D computations to include the effects of edges and corners in the coolers. To illustrate this fact, the heat flow through three walls that form one corner of a 2-ft cube was modeled using HEATING-7. The inside wall temperature was set at $50^{\circ} \mathrm{F}$ and the outside wall temperature at $100^{\circ} \mathrm{F}$. The walls were taken as 1.5 in. thicknesses of $7 \mathrm{R} / \mathrm{in}$. foam.

For a $1 \mathrm{D}$ electrical-analog model, the walls have a $\mathbf{R}$ of 10.5 . The 3D HEATING7 model for this case yields a $\mathbf{R}$ for the walls of 9.32 , which is $13 \%$ below that computed with the $1 \mathrm{D}$ model. (The $\mathbf{R}$ of the wall was computed by dividing the temperature difference across the wall by the total heat flux through the wall computed by HEATING-7.)

\subsubsection{Effect of the Area of Coverage of PEPs}

The effect of the percent area of coverage by PEPs of the inside surface of the cube described in the last section was obtained using a HEATING-7 model. For this model, $1 / 2$ in. PEPs of $20 \mathrm{R} / \mathrm{in}$. were positioned at the center of the 1.5 -in.-thick wall with $1 / 2$ in. of foam on each side. The results are listed in Table 8 . To further show the effects of corners, the PEPs were allowed to extend $1 / 2$ in. past the inside surface so that

Table 8. The $\mathbf{R}$ of a composite wall as affected by the area of coverage of the PEPa

\begin{tabular}{ccc}
\hline & \multicolumn{2}{c}{$\mathbf{R}\left(\mathrm{h}-\mathrm{ft}^{2}-{ }^{\circ} \mathrm{F} / \mathrm{Btu}\right)$} \\
\hline $\begin{array}{c}\text { Area of coverage } \\
\text { of inside wall } \\
(\%)\end{array}$ & HEATING-7 & 1D Electric-Analog \\
\hline 117 & & 17.0 \\
109 & 15.7 & 17.0 \\
100 & 15.5 & 17.0 \\
84 & 15.0 & 16.0 \\
69 & 14.2 & 15.0 \\
0 & 13.0 & 10.5 \\
\hline
\end{tabular}

${ }^{a}$ One inch of $7 \mathrm{R} / \mathrm{in}$. foam; PEPs are $1 / 2$ in. thick and $20 \mathrm{R} / \mathrm{in}$; walls form a 2 -ft cube. 
the three PEPs forming the corner just touched, and in a second case were allowed to extend beyond the inside surface to overlap completely and to form a solid PEP wall within the foam, that is, 109 and $117 \%$ coverage of the inside surface, respectively. Figure 12 shows the $\mathbf{R}$ of the wall vs the area of coverage by the PEPs for the 3D HEATING-7 model and the 1D electrical-analog model. The functional dependence of the two models is approximately the same.

Figure 13 shows that the 1D model overestimate of the percentage change in $\mathbf{R}$ of the wall increases as the area of coverage decreases. Again, this effect is due to the inability of the $1 \mathrm{D}$ model to account for $3 \mathrm{D}$ heat flow around the PEPs and through the foam and is larger for lower areas of coverage.

In all, this example emphasizes the need for the PEPs to form a continuous layer within the foam to achieve maximum effectiveness of the PEPs (i.e., the PEP should cover the entire inside surface area of the wall and extend into the corners, if possible).

\subsubsection{Effects of Position of the PEP}

In the previous computations, the PEP was positioned in the center of the foam. For the case of $100 \%$ coverage of the inside surface, $\mathbf{R}$ of the wall listed in Table 8 is 15.0 for the $3 \mathrm{D}$ case. If the PEP is moved to the inside wall from the center of the foam, the $\mathbf{R}$ of the wall increases to 15.2 , only about a $1 \%$ increase in $\mathbf{R}$. If the PEP is moved to the outside wall, the $\mathrm{R}$ of the wall decreases to 14.3 , about a $5 \%$ decrease. These differences are, again, a ramification of allowing heat to circumvent the PEPs and flow through the foam. Thus, placing the PEP on the inside wall yields the best insulation. Also, because the $\mathbf{R}$ of a PEP increases with decreasing temperature, placement of the PEP on the cooler inside will further enhance the $\mathbf{R}$ of the wall.

\subsubsection{Measurements on the Igloo 44 Coolers}

The following data are included in this report for completeness. For several reasons, some of which are outlined below, the data were not analyzed. These measurements do illustrate several points made previously, such as effects of area of coverage of PEPs.

Because of foaming problems with the Igloo 24 and 48 coolers, the Igloo 44 cooler was chosen for installation of the foam/PEP-composite insulation. The Igloo 44 cooler was not an ideal choice because the wall sections were not thick enough to allow 


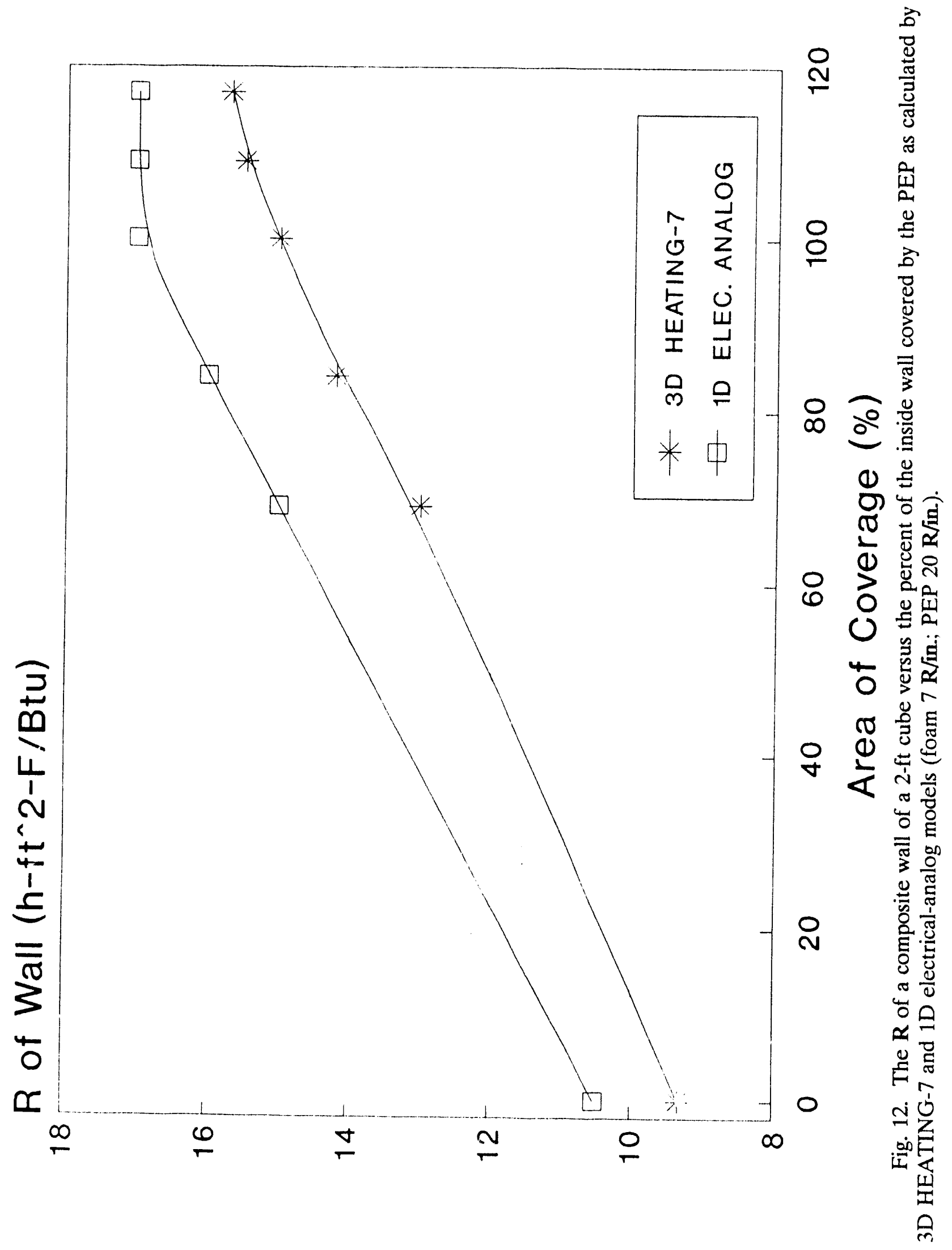




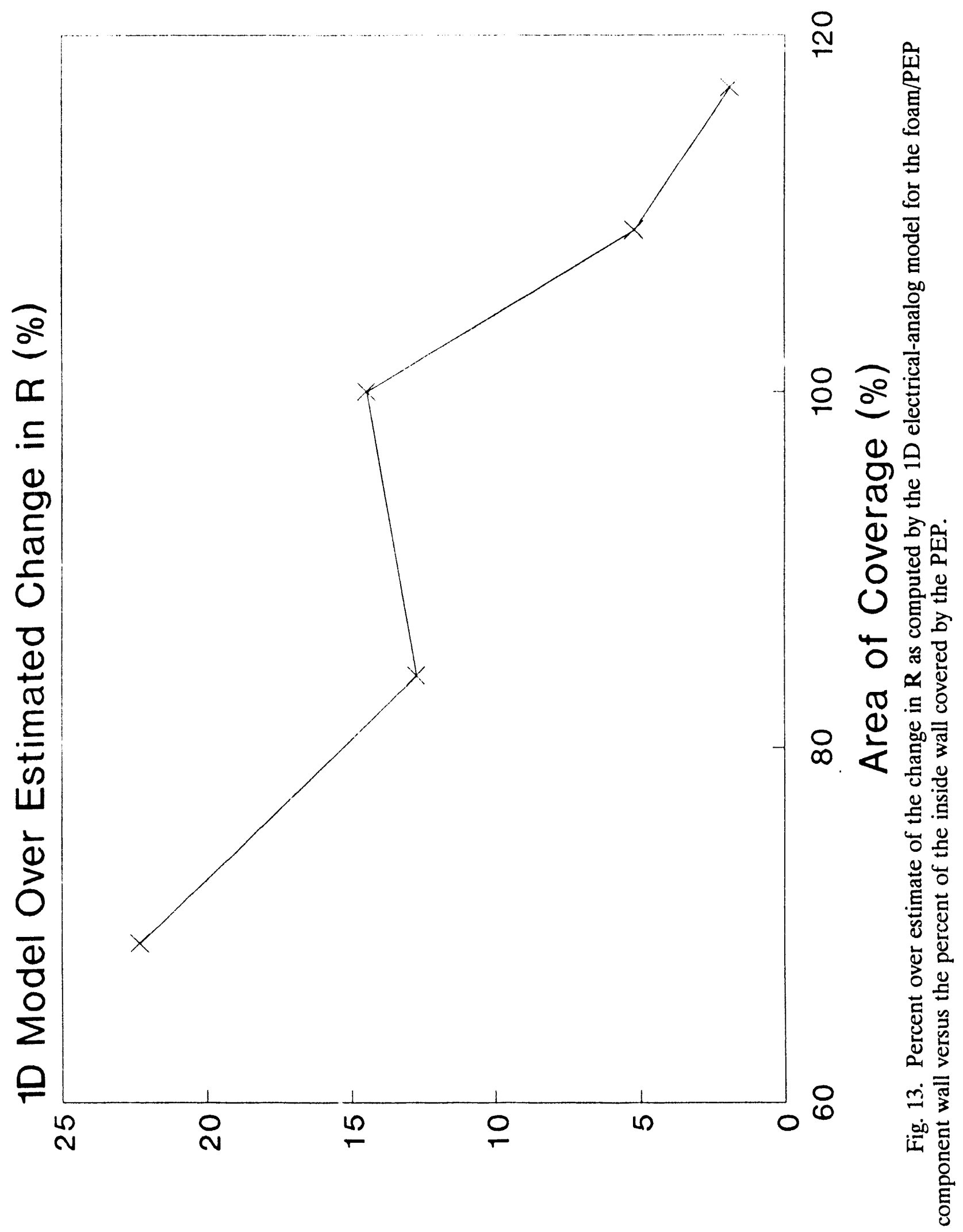


adequate filling of the wall cavity with foam when the PEPs were in place; however, since time was running out on the project, it was decided to go ahead with the paneling and foaming of this model.

Igloo 44 coolers were insulated with three PEPs (one in the bottom and one in each side of the cooler) that were $10 \times 10 \times 1 / 2$ in. Table 9 sets forth the data obtained on Igloo 44 coolers, both production coolers, and those with PEPs foamed in place. Because the PEPs did not fit very well in the walls of the cooler, voids and underpacking of the foam occurred in certain areas of the walls as was demonstrated by sectioning one of the coolers on which measurements were made. This inadequate foam fill would account for part of the poor performance of these coolers. Again, the small $2.1 \%$ reduction in the ice melting rate due to the insertion of PEPs covering $24 \%$ of the surface area was, undoubtedly, a result of "thermal shunting" around the PEPs.

Table 9. Ice melting rates of Igloo 44 coolers with and without foamed-in PEPs

\begin{tabular}{ccccc}
\hline & \multicolumn{5}{c}{ Ice melting rates $(\mathrm{G} / \mathrm{h})$} \\
\hline Cooler & Production & Foamed-in PEPs & Production $^{a}$ & Foamed-in PEPs $^{a}$ \\
\hline $1^{b}$ & 0.628 & 0.615 & - & - \\
$2^{b}$ & 0.617 & 0.613 & - & - \\
$3^{b}$ & 0.635 & 0.615 & - & - \\
$6^{b}$ & 0.624 & 0.606 & 0.514 & 0.493 \\
\hline Average & 0.626 & 0.612 & 0.514 & 0.493 \\
\hline
\end{tabular}

${ }^{a}$ Insulated with R-11 fiberglass.

${ }^{b}$ Manufactured 9/27/89.

Inside dimensions: length $\times$ width $\times$ height (in.).

$18.5 \quad 15.5 \quad 13.5$

Water level: 10 in.; ice load: $17.2 \mathrm{lb}$ in 4 socks.

Another point is the $18 \%$ reduction in ice melting rate resulting from insulating the top of the cooler with R-11 fiberglass batting; the lid of the Igloo 44 is hollow. The surface area of the lid is $18 \%$ of the inside surface area of the Igloo 44 . When the easy thermal shunting path through the top was blocked by the fiberglass, the effectiveness of the PEPs doubled (i.e., a 2.1 vs a $4.1 \%$ decrease in the ice melting rate). 


\subsection{INTERNAL PRESSURE MEASUREMENT OF A PEP}

The $\mathbf{R}$ of a PEP decreases with increasing internal pressure $(\mathbf{P})$ within the PEP. Typically, $\mathbf{P}$ is about 1 to 2 torr after fabrication, and the $\mathbf{R} / \mathbf{i n}$. is about 20 . With time, ambient gases penetrate the plastic-barrier layer, and $\mathbf{R}$ of the PEP decreases. Thus, knowledge of the PEP's $\mathbf{P}$ is critical to its thermal performance.

A nondestructive method of measuring $\mathbf{P}$ was developed by Babcock and Wilcox (B\&W) in 1987 under a contract with GE. This device consists of a vacuum chamber into which the PEP is placed. An infrared, triangulation, optical-displacement sensor is used to detect motion of the barrier material of the PEP as the vacuum chamber pressure is rapidly reduced. When the pressure inside the chamber is less than $\mathbf{P}$, the barrier of the PEP deflects as a diaphragm would under a differential pressure. The outputs of the optical sensor and of a vacuum gauge, which measures the pressure in the chamber, are monitored by a computer. An algorithm is used by the computer to determine $\mathbf{P}$ from these two output signals.

J. M. Huber Corporation purchased one of the B\&W devices, and it was used to determine $\mathbf{P}$ of the panels fabricated for the cooler project. This device was subsequently purchased from J. M. Huber by R. W. Barito and Associates in 1989. Through an agreement with R. W. Barito, ORNL contracted with Global Thermionics, Inc., (Global) for $\mathbf{P}$ measurements on PEPs subjected to accelerated aging tests in $\mathrm{He}$ gas. These measurements of $\mathbf{P}$ as a function of aging time were used to determine the permeability ( $\mathbf{p}$ ) of the barrier material and the effect of pressure on the $R$ of the FEP. The measurements of $\mathbf{p}$ and $\mathbf{R}$ did not correlate well with other measurements of these properties. This disagreement led to an effort by the BMG to develop a hand-held gauge for measurements of $\mathbf{P}$.

At the present time, the hand-held $\mathbf{P}$ gauge is in the process of being patented. Thus, the details of the development of the gauge cannot be described in this report. Numerous tests have been conducted with this device, however, to give the authors confidence in its accuracy. They include:

1. The vacuum gauge of the hand-held device was calibrated vs a mercury manometer; a mercury barometer was used to measure the absolute pressure in these tests. (The $\mathrm{B} \& \mathrm{~W}$ device does not perform this type of calibration. The original calibration by the vacuum gauge manufacturer is used by GE and Global.) 
2. A piece of barrier material was used as a diaphragm in a device (also being patented) that allows measurement of $\mathbf{P}$ on one side of the diaphragm by a mercury manometer and on the other by the hand-held $\mathbf{P}$ gauge. Tests were conducted over the range 0 to 100 torr, and the two pressure readings were within the readability of the instruments, about \pm 1.5 torr. This test demonstrated that the hand-held $\mathbf{P}$ gauge could measure the internal pressure of a PEP.

To establish the magnitude of the pressure measurement errors by the $\mathrm{B} \& \mathrm{~W}$ device, the $\mathbf{P}$ of eight PEPs was measured with the ORNL hand-held $\mathbf{P}$ gauge and with the GE version of the $\mathrm{B} \& \mathrm{~W}$ device; the Global (Barito) version of the $\mathrm{B} \& \mathrm{~W}$ device was used to measure $\mathbf{P}$ on four of these PEPs. Table 10 lists these measurements.

The differences noted in Table 10 were discussed ${ }^{41}$ with the $B \& W$ engineer who developed the device for GE. The device was developed for quality assurance testing, with emphasis on the lower pressure range and speed of measurement. The gauge used is recommended for use in the $1 \times 10^{-2}$ torr to 1 torr range, which is much below that used in the measurements on the ORNL PEPs. B\&W used the manufacturer's calibration of the gauge; it was not calibrated on an absolute basis. A "look-up table" is employed by the computer software to determine the pressure from the voltage output of the pressure gauge; linear interpolation is used, but the voltage is an exponential function of pressure and is very insensitive in the range of pressures of some of the PEPs listed in Table 10. Also, the B\&W engineer believes that the dynamic mode of operation of the $B \& W$ device leads to pressure measurements that are too low. Slow evacuation would be better.

PEPs A, B, E, and F had been aged in He, so the $\mathbf{P}$ of these PEPs should decrease with time during storage in air. Note, however, that the Global measurements were as much as a factor of three less than the GE measurements, even though the GE measurements were made after the Global measurements. The ORNL measurements on these PEPs are in better agreement with the GE measurements, but some are higher (by up to $50 \%$ ), even though the ORNL measurements were made after the GE measurements. The GE measurements on panels $A$ and $F$ were probably adversely affected by the errors in the look-up table for the conversion of gauge voltage to pressure in the computer software's algorithm. 
Table 10. Summary of internal pressure measurements by Global, GE, and ORNL on ORNL PEPs

\begin{tabular}{|c|c|c|c|c|c|c|}
\hline \multirow[b]{3}{*}{ PEP } & \multicolumn{6}{|c|}{ Pressure (torr) } \\
\hline & \multicolumn{2}{|c|}{ Global } & \multicolumn{3}{|c|}{$\mathrm{GE}$} & \multirow{2}{*}{$\frac{\text { ORNL }}{8 / 9 / 90}$} \\
\hline & $5 / 10 / 90$ & $6 / 6 / 90$ & $6 / 15 / 90$ & $6 / 18 / 90$ & $7 / 31 / 90$ & \\
\hline$A^{a}$ & 64.7 & 60.1 & 199.0 & 173.0 & 149.0 & 168 \\
\hline $\mathrm{B}^{a}$ & 34.6 & 35.0 & 47.3 & 47.4 & 44.2 & 61 \\
\hline $\mathrm{E}^{a}$ & 36.4 & 35.4 & 49.6 & 49.2 & 45.2 & 59 \\
\hline \multirow[t]{3}{*}{$F^{a}$} & 74.1 & 70.0 & 191.7 & 188.5 & 155.9 & 172 \\
\hline & & & & GE & \multicolumn{2}{|c|}{ ORNL } \\
\hline & & & & $8 / 2 / 90$ & $7 / 29 / 90$ & $8 / 14 / 90$ \\
\hline GEA-7 $7^{b}$ & & & & 4.7 to 22 & 8.5 & 8.5 \\
\hline GEA-21 ${ }^{b}$ & & & & 3.7 & 8.0 & -- \\
\hline $3^{a}$ & & & & 49.1 & 83 & -- \\
\hline $7^{a}$ & & & & 49.1 & 85.5 & 82.5 \\
\hline
\end{tabular}

${ }^{a}$ Fabricated by J. M. Huber.

${ }^{b}$ Fabricated by GE.

PEPs 3 and 7 were also aged in He so their $\mathbf{P}$ should decrease with time during storage in air. PEPs GEA-7 and GEA-21 were aged in ambient air so their Ps will increase with time during storage in air. In general, the GE measurements are about a factor of two lower on these four panels than the ORNL measurements. Again, look-up table errors and the dynamic mode of operation of the B\&W device must be the cause of these differences.

Figure 14 is a plot of the difference (or error if the ORNL data are considered correct) between the ORNL and GE and ORNL and Global measurements for these PEPs. Corrections for changes in pressure due to differences in the date of measurement were made. These results show that the error in the Global measurements is almost a linear function of the PEP pressure, with errors of almost $70 \%$ at 220 torr. 


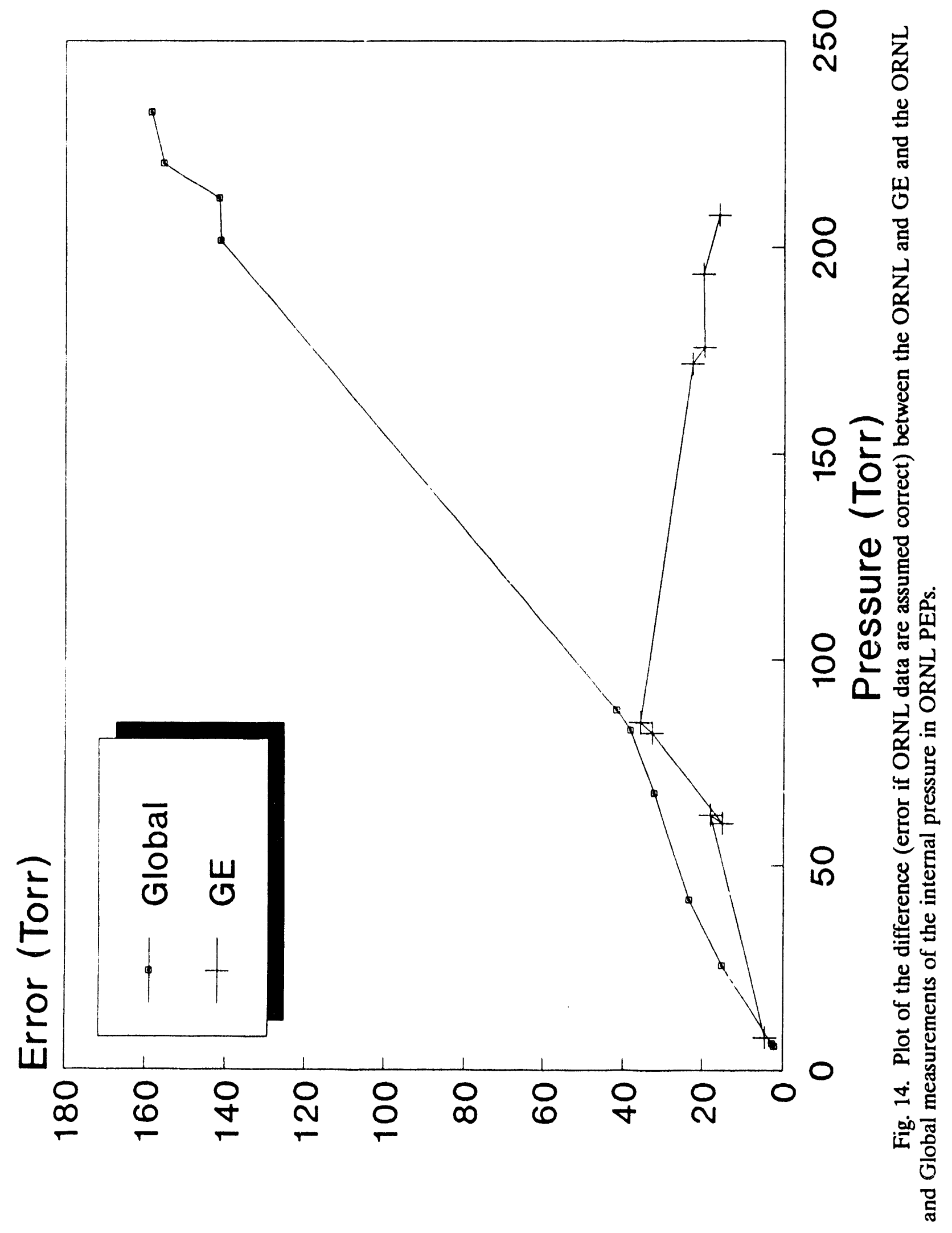


On the other hand, the errors in the GE gauge show a maximum near about 80 torr, where the error is about $40 \%$. These large errors in Global's $\mathbf{P}$ measurements readily explain the lack of correlation between measurements of $\mathbf{p}$ and $\mathbf{R}$ of the PEPs based on the Global measurements and those measurements of $\mathbf{p}$ and $\mathbf{R}$ made by other techniques. All Ps reported herein were measured with the ORNL hand-held gauge, unless otherwise noted.

\subsection{BARRIER MATERIAL SELECTION}

\subsubsection{Selection Criteria}

Many factors effect the selection of a material for use as the barrier of a PEP. Some of the key issues include its strength, toughness, formability, and sealability. Because the goal of this program is the development of PEPs that will last for 20 or 100 years, the most important property of the barrier material is its permeability ( $\mathbf{p}$ ) to its ambient gases.

Permeability is an intensive property of a material, just as are the thermal resistivity and emissivity. A barrier of a PEP has a finite thickness ( 8 ) and its permeance $(\Gamma)$ is equal to the quotient $\mathrm{p} / \delta$ and is an extensive property of a particular piece of barrier material. By definition, ${ }^{42}$ the transmission rate $(G)$ for a gas at STP (standard temperature and pressure) is the volume of gas passing through a barrier of area $A$ in a unit of time and is given by:

$$
G=\Gamma\left(P_{a}-P\right) A,
$$

where $\mathrm{P}_{\mathrm{a}}$ is the pressure outside the barrier's enclosure and $\mathrm{P}$ is the pressure inside the barrier's enclosure. Also, the number of moles dn of gas (assumed to be ideal) that will permeate the barrier of a rectangular PEP with total surface area $\mathrm{A}$ and total volume $\mathrm{V}$ in unit time dt is:

$$
\frac{d n}{d t}=\frac{d}{d t}\left(\frac{P V}{R_{i} T}\right)=\frac{V}{R_{i} T} \frac{d P}{d t}
$$

where $R_{i}$ is the ideal gas constant. Multiplying both sides of Eq. (5) by the ratio of the 
molecular weight $(M)$ to density $\left(\rho_{0}\right)$ at standard temperature $\left(T_{0}\right)$ and pressure $\left(P_{0}\right)$ yields the volume of gas at STP that flows into the PEP in a unit of time*, which is the gas transmission rate into the PEP so that:

$$
G=\frac{M}{\rho_{0}} \frac{d n}{d t}=\frac{R_{i} T_{0}}{P_{0}} \frac{V}{R_{i} T} \frac{d P}{d t}
$$

Thus, setting the right-hand sides of Eqs. (4) and (6) equal yields:

$$
\Gamma\left(P_{a}-P\right) A=\frac{V T_{0}}{T P_{0}} \frac{d P}{d t} .
$$

Rearranging Eq. (7) and integrating from time zero when the internal pressure in the PEP is $\mathbf{P}_{\mathbf{i}}$ to time $\mathbf{t}$ when the pressure is $\mathbf{P}_{\mathbf{f}}$ yields

$$
\frac{\Gamma A T P_{o}}{V T_{o}} \int_{0}^{t} d t^{*}=\int_{P_{1}}^{P_{f}} \frac{d P}{P_{a}-P},
$$

which simplifies to

$$
\frac{\Gamma A T P_{o}}{V T_{0}} t=\ln \left(\frac{P_{a}-P_{i}}{P_{a}-P_{f}}\right)
$$

Assuming that $\mathbf{P}_{\mathbf{i}}=0$ and $\mathbf{P}_{\mathbf{f}}$ must be less than a specified final pressure limit, $\mathbf{P}_{\mathbf{f}}^{+}$, when the PEP is exposed to a selected pressure $\mathbf{P}_{\mathbf{2}}=\mathbf{P}_{\mathbf{a}}^{+}$for time period $\mathbf{t}=\mathbf{t}^{+}$, the maximum allowable permeance, $\Gamma_{\boldsymbol{m}}$, that a barrier can have is:

$$
\Gamma_{m}=\frac{\frac{V T_{o}}{A T P_{o}} \ln \left(\frac{P_{a}^{+}}{P_{a}^{+}-P_{f}^{+}}\right)}{t^{+}} .
$$

*The quantit $M / \rho_{o}$ equals $V_{o} / n$ which equals $R_{i} / P_{o}$ for an ideal gas. 
The results of using Eq. (10) for three $P_{f}^{++}$of 1,10 , or $100 \mathrm{~mm}$ of $\mathrm{Hg}$ and three $\mathbf{P}_{\mathbf{a}}^{+ \text {'s }}$ of 760,380 , or $76 \mathrm{~mm}$ of $\mathrm{Hg}$ for $\mathrm{t}^{+'}$ 's of 20 and 100 years are shown in Table 11 for $12 \times$ $12 \times 1 / 2$-in.- and $12 \times 12 \times 1$-in.-thick PEPs.

Table 11. Calculated permeance to achieve 20- and 100-year lifetime $\operatorname{PEPs}^{a}$

\begin{tabular}{|c|c|c|c|}
\hline \multirow{2}{*}{$\begin{array}{c}\mathrm{P}_{\mathrm{f}}^{+} \\
(\mathrm{mm} \mathrm{Hg})\end{array}$} & \multirow{2}{*}{$\begin{array}{c}\mathrm{P}_{\mathbf{2}}^{+} \\
(\mathrm{mm} \mathrm{Hg})\end{array}$} & \multicolumn{2}{|c|}{$\Gamma_{\mathrm{m}}\left(\mathrm{cm}^{3} / \mathrm{m}^{2}-24 \mathrm{~h}\right.$-atm $)$} \\
\hline & & $1 / 2$-in. panel & 1-in. panel \\
\hline \multicolumn{4}{|l|}{ 20-Year Lifetime } \\
\hline $\begin{array}{r}1 \\
10 \\
100\end{array}$ & 760 & $\begin{array}{l}0.001 \\
0.01 \\
0.1\end{array}$ & $\begin{array}{l}0.002 \\
0.02 \\
0.2\end{array}$ \\
\hline $\begin{array}{r}1 \\
10 \\
100\end{array}$ & 380 & $\begin{array}{l}0.002 \\
0.02 \\
0.24\end{array}$ & $\begin{array}{l}0.004 \\
0.04 \\
0.48\end{array}$ \\
\hline $\begin{array}{c}1 \\
10\end{array}$ & 76 & $\begin{array}{l}0.01 \\
0.11\end{array}$ & $\begin{array}{l}0.02 \\
0.22\end{array}$ \\
\hline \multicolumn{4}{|l|}{ 100-Year Lifetime } \\
\hline $\begin{array}{r}1 \\
10 \\
100\end{array}$ & 760 & $\begin{array}{l}0.0002 \\
0.002 \\
0.02\end{array}$ & $\begin{array}{l}0.0004 \\
0.004 \\
0.024\end{array}$ \\
\hline $\begin{array}{r}1 \\
10 \\
100\end{array}$ & 380 & $\begin{array}{l}0.0004 \\
0.004 \\
0.048\end{array}$ & $\begin{array}{l}0.0008 \\
0.008 \\
0.095\end{array}$ \\
\hline $\begin{array}{r}1 \\
10\end{array}$ & 76 & $\begin{array}{l}0.002 \\
0.022\end{array}$ & $\begin{array}{l}0.004 \\
0.044\end{array}$ \\
\hline
\end{tabular}

${ }^{a} 12 \times 12$ in. square PEPs.

Examination of Table 11 shows that a reasonable criterion for 20-year lifetime for a $1 / 2$-in.-thick PEP exposed to an ambient pressure of $76 \mathrm{~mm} \mathrm{Hg}$ with an internal PEP pressure limit of $10 \mathrm{~mm}$ of $\mathrm{Hg}$ is a $\Gamma_{-}$of $0.11 \mathrm{~cm}^{3} / \mathrm{m}^{2}-24 \mathrm{~h}$-atm. The corresponding value for 20 years at an ambient pressure of $760 \mathrm{~mm}$ of $\mathrm{Hg}$ or 100 years lifetime at $76 \mathrm{~mm} \mathrm{Hg}$ would be a $\Gamma_{\text {. }}$ of 0.01 and $0.022 \mathrm{~cm}^{3} / \mathrm{m}^{2}-24 \mathrm{~h}$-atm, respectively. A literature search was conducted to locate potential barrier materials that would meet these criteria. 


\subsubsection{Literature Search Methodology}

A large collection of information exists for materials employed in the packaging and converting industries. A broad review of this information is given in the Packaging Encyclopedia. ${ }^{43}$ The initial attempts to search this information for data on laminate materials were performed by computer literature searching of the Packaging Science and Technology Abstracts and the Food Science Abstracts. The key words for both searches were "permeability" or "diffusivity," "barrier" and "films," and "polymers" or "laminates." A large number of telephone contacts were also made to identify manufacturers and products that might be of interest.

\subsubsection{Literature Search Results}

Approximately 100 citations were obtained from each of the literature searches. Abstracts were also obtained for each of the citations and sorted by hand. The result was a set of approximately 30 papers that described possible candidate materials. Some of the papers of interest were located in the University of Kentucky's libraries, where the search was performed. Others were ordered by interlibrary loan. Contacts were then made by telephone to the manufacturers of several of the identified laminate films. Because many of the identified materials were no longer manufactured and because obtaining many of the papers was a very time consuming process, direct contact with the various manufacturers proved to be the most time-efficient process. Over 50 contacts were made. A list of the most important contacts is given in Table 12.

The data on some of the potential barrier materials obtained from these contacts are listed in Table 13 and show that the order of permeance at 1 mil thickness is: $\Gamma$ $(\mathrm{He})>\Gamma\left(\mathrm{CO}_{2}\right)>\Gamma\left(\mathrm{O}_{2}\right)>\Gamma\left(\mathrm{N}_{2}\right)$. The data are also very sensitive to the $\mathrm{RH}$ and temperature at which the test is performed (see Figs. 15 and 16, respectively). The vast majority of the data which was obtained from the manufacturers was for oxygen transmission rate (OTR) only. Because the temperature of a PEP will normally be about $73^{\circ} \mathrm{F}$, the OTR at $73^{\circ} \mathrm{F}$ and $0 \% \mathrm{RH}$ is a helpful parameter to use as the selection criterion for a barrier material.

Although not given in Table 13, water vapor $\Gamma$ 's are very high for many films. In fact, some films, such as polyvinyl alcohol (PVOH and/or PVA), are soluble in water. Thus, water vapor can be expected in PEPs exposed to high humidity. (Many filler materials have high surface areas and adsorb large amounts of water that permeates the barrier.) Coatings made of Saran polyvinyldene chloride (PVDC) may be employed on the outer surface of a laminated barrier to reduce moisture permeation. 
Table 12. Important contacts made during the barrier materials survey

\begin{tabular}{|c|c|c|}
\hline Company & Contact & Telephone number \\
\hline \multicolumn{3}{|l|}{$\underline{\text { PVA }}$} \\
\hline $\begin{array}{l}\text { Fres-Co } \\
\text { Merubeni } \\
\text { (Nippon Gohsei) }\end{array}$ & $\begin{array}{l}\text { Mr. Larry Restivo } \\
\text { Mr. Harry Stone }\end{array}$ & $\begin{array}{l}215-721-4600 \\
212-599-3964\end{array}$ \\
\hline $\begin{array}{l}\text { Unitika } \\
\text { Mono-Sol } \\
\text { (Chris Craft) }\end{array}$ & $\begin{array}{l}\text { Mr. M. Kageyama } \\
\text { Mr. Dennis Conley } \\
\text { Ms. Kathy Auksill }\end{array}$ & $\begin{array}{l}212-765-3760 \\
219-762-3165 \\
219-762-3165\end{array}$ \\
\hline \multicolumn{3}{|l|}{ EVOH } \\
\hline $\begin{array}{l}\text { Evalca } \\
\text { Printpack }\end{array}$ & $\begin{array}{l}\text { Mr. Frank Kitchell } \\
\text { Mr. Tony Alvarez } \\
\text { Mr. Nelson Hood }\end{array}$ & $\begin{array}{l}513-860-4806 \\
404-671-5830 \\
800-241-9984\end{array}$ \\
\hline \multicolumn{3}{|l|}{$\underline{\text { Al Films }}$} \\
\hline $\begin{array}{l}\text { Am. Nat. Can. } \\
\text { Fres-Co } \\
\text { James River } \\
\text { DuPont } \\
\text { Ultravac }\end{array}$ & $\begin{array}{l}\text { Mr. Bill Bowen } \\
\text { Mr. Larry Restivo } \\
\text { Mr. Ted Frey } \\
\text { Mr. Roger Richmond } \\
\text { Mr. Frank Magnami }\end{array}$ & $\begin{array}{l}414-727-6975 \\
215-721-4600 \\
513-792-6700 \\
302-999-6774 \\
203-243-3150\end{array}$ \\
\hline \multicolumn{3}{|l|}{ Measurement Technology } \\
\hline $\begin{array}{l}\text { Mocon } \\
\text { University of Toledo } \\
\text { Michigan State University }\end{array}$ & $\begin{array}{l}\text { Mr. Mike Babiraki } \\
\text { Dr. Wendell Kollin } \\
\text { Dr. Jack Giacin }\end{array}$ & $\begin{array}{l}612-569-3222 \\
419-537-5003 \\
517-355-4556\end{array}$ \\
\hline \multicolumn{3}{|l|}{ Converters } \\
\hline $\begin{array}{l}\text { Cadillac Prod. } \\
\text { DRG Med. Packaging }\end{array}$ & $\begin{array}{l}\text { Mr. Bill Havercroft } \\
\text { Mr. Louis Boughner }\end{array}$ & $\begin{array}{l}217-463-1444 \\
609-267-5900 \\
\end{array}$ \\
\hline
\end{tabular}

Table 13. Permeance of selected materials at $26 \mu$ in. thickness at $73^{\circ} \mathrm{F}$ and $0 \% \mathrm{RH}^{44}$

\begin{tabular}{lcccc}
\hline \multicolumn{1}{c}{ Material } & \multicolumn{4}{c}{$\Gamma @ 1 \mathrm{mil}\left(\mathrm{cm}^{3} / \mathrm{m}^{2}-24 \mathrm{~h}\right.$-atm $)$} \\
\hline & $\mathrm{N}_{2}$ & $\mathrm{O}_{2}$ & $\mathrm{C}_{2}$ & $\mathrm{He}$ \\
\hline Evalca F - EVOH & 0.015 & 0.200 & 0.496 & 144.1 \\
Evalca H - EVOH & 0.062 & 0.395 & 1.040 & 257.3 \\
Evalca E - EVOH & 0.124 & 0.935 & 3.32 & 368.9 \\
Oriented Nylon 6 & 10.80 & 51.15 & 102.6 & 1798 \\
& & & & \\
Oriented polyethylene (PET) & 7.1 & 79 & 304 & 2790 \\
\hline
\end{tabular}




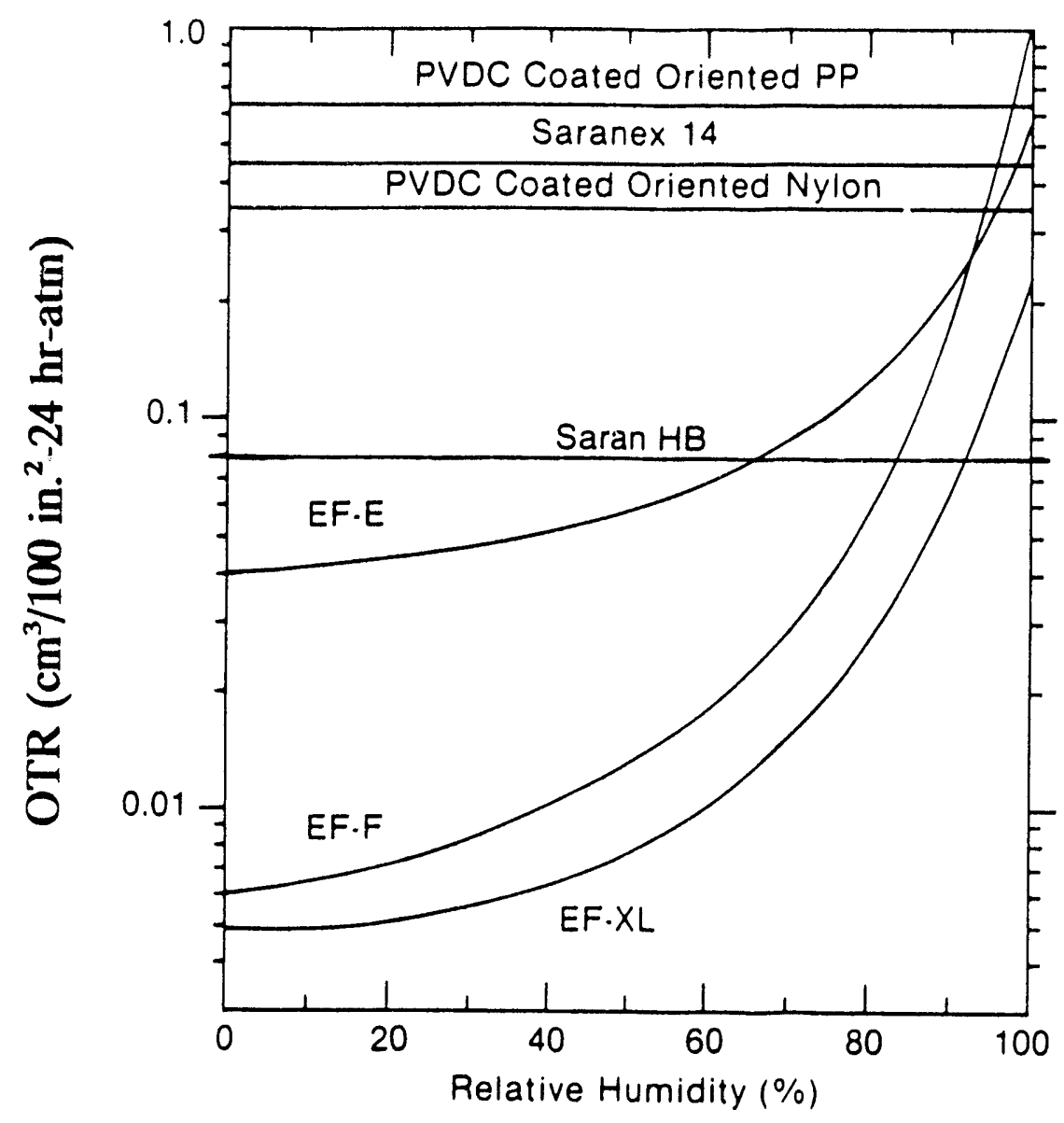

Fig. 15. Oxygen transmission rate versus relative humidity. 


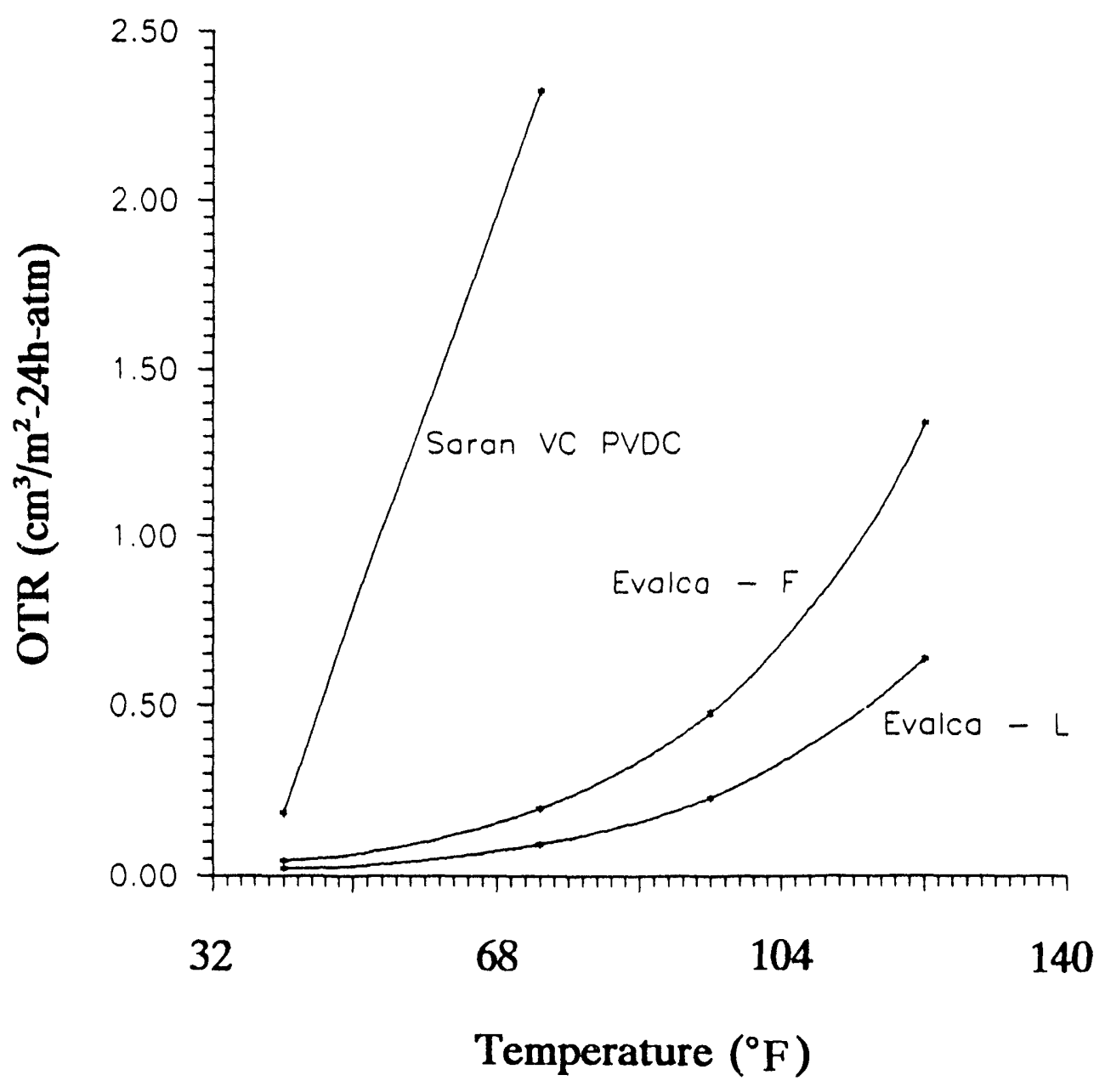

Fig. 16. Oxygen transmission rate versus temperature. 
Because of its high $\Gamma$ for most films, $\mathrm{CO}_{2}$ is normally present in PEPs at very low concentrations, depending on the concentration of $\mathrm{CO}_{2}$ in the ambient atmosphere. For example, high levels of $\mathrm{CO}_{2}$ are expected to permeate a PEP after foaming in place with certain blowing agents; however, the $\mathrm{CO}_{2}$ will leave the PEP rapidly as the $\mathrm{CO}_{2}$ content in the foam decreases. Foams that continuously produce $\mathrm{CO}_{2}$ could degrade the performance of a PEP.

Three groups of materials emerged as candidate materials from the many inquiries that were made. These included PVOH (or PVA) films and laminates, ethylene vinyl alcohol films (EVOH) and laminates, and aluminized films and foil laminates.

PVA - PVA films have the best barrier properties of any polymer material. They are, however, water soluble, and the properties are very sensitive to the relative humidity. PVA is available in biaxially oriented film, BOVLON; Sarancoated (PVDC) film, EMBLAR-OV; and in multi-layer laminates, VECAT and BOVLON. A fully hydrolyzed PVA, which is soluble in hot water, is available from Chris Craft, and they claimed that it has a very low OTR. The authors believe that their value for $\Gamma$ for this material $\left(0.001 \mathrm{~cm}^{3} / \mathrm{m}^{2}-24 \mathrm{~h}\right.$-atm for a 1.5 mil-thick film) was derived from a structural model and not a measurement. Chris Craft does, however, believe that this number is "conservative." The material is available in $20 \times 34$ in. $\times 3$ mil bags and 20 in. diam $\times 2$ mil tubes. The bags arc PVOH to PVOH heat sealed.

$\underline{E V O H}-\mathrm{EVOH}$ is a copolymer consisting of ethylene and vinyl alcohol molecules. The $\Gamma$ decreases as the percentage of ethylene decreases. In the limit of zero ethylene, EVOH would be PVA. Like PVA, EVOH is available as biaxially oriented film, Evalca EF-XL; non-oriented film, Evalca EF-F; laminates from various converters including Cadillac Products and Printpack; and resins which can be made into sheets with thicknesses of ten or more mils, Evalca $\mathrm{L}$ series. EVOH can be sealed to itself; high-frequency sealing is recommended by Evalca.

Al Films - Aluminum is employed in packaging in the form of foil and films. Many of the early laminates used for PEPS contained aluminum and were developed by American National Can. Delamination of the aluminum was a problem with these films. Several contacts indicated that the only way to make a 
100-year lifetime material was with aluminum foil laminates. The recommendations were either 0.7 -mil foil, which would be the thinnest pin-holefree foil, or two layers of 0.25 -mil foil separated by a bonding layer. The thinner foil would have pin holes, but the two layers would make diffusion paths long. A third approach would involve sputtered angstroms-thick layers of aluminum on Saran-coated Mylar (for example, 50- or 100- gauge MMC from DuPont).

Barrier materials for use for 20 years at reduced pressure, 20 years at one atmosphere pressure, or 100 years at reduced pressure were found from each of these three groups. These candidate materials are listed below in Tables 14 and 15. The cost

Table 14. Laminate barrier candidates for 20-year lifetime PEPs at $76 \mathrm{~mm}$ of $\mathrm{Hg}^{a}$

\begin{tabular}{|c|c|c|c|c|c|}
\hline $\begin{array}{l}\text { Barrier } \\
\text { material }\end{array}$ & $\begin{array}{l}\text { Laminate } \\
\text { (structure) }\end{array}$ & $\begin{array}{c}\text { Thickness } \\
\text { (mils) }\end{array}$ & Manufacturer & $\begin{array}{c}\text { OTR } \\
\mathrm{cm}^{3} / \mathrm{m}^{2}-24 \text { h-atm }\end{array}$ & $\begin{array}{c}\text { Cost } \\
\left(\$ / 1000 \text { in. }^{2}\right)\end{array}$ \\
\hline \multirow[t]{3}{*}{ PVA } & BOVLON & 0.55 & Nippon- & 0.3 & $\sim 0.11$ \\
\hline & (B-O. PVA) & 1 & Gohsei & -0.1 & -0.20 \\
\hline & EMBLAR-OV $b$ & 0.6 & Unitika & $<0.5$ & 0.08 \\
\hline \multirow[t]{4}{*}{ EVOH } & EF-F film & 0.5 & Evalca & 0.2 & 0.08 \\
\hline & & 1 & & 0.1 & 0.16 \\
\hline & EF-XL film & 0.5 & Evalca & 0.2 & 0.09 \\
\hline & & 1 & & 0.1 & 0.18 \\
\hline Met. PET & $\begin{array}{c}50 \mathrm{MMC} \\
\text { (Saran/A/PET/Saran) }\end{array}$ & 0.55 & DuPont & $<0.2$ & 0.13 \\
\hline
\end{tabular}

${ }^{a} \mathrm{OTR}$ between 0.01 and $0.1 \mathrm{cc} / \mathrm{m}^{2}-24 \mathrm{~h}$-atm @ 0\% RH and 73. $\mathrm{F}$.

${ }^{b}$ Saran/PVA/Saran. 
Table 15. Laminate barrier candidates for PEPs with lifetimes of 20 years at $760 \mathrm{~mm}$ of $\mathrm{Hg}$ pressure or 100 years at $76 \mathrm{~mm} \mathrm{Hg}$ pressure

\begin{tabular}{cccccc}
\hline $\begin{array}{c}\text { Barrier } \\
\text { material }\end{array}$ & Laminate & $\begin{array}{c}\text { Thickness } \\
(\text { mils })\end{array}$ & Manufacturer & $\begin{array}{c}\text { OTR } \\
\mathrm{cm}^{3} / \mathrm{m}^{2}-24 \mathrm{~h} \text {-atm }\end{array}$ & $\begin{array}{c}\text { Cost } \\
\left(\$ / 1000 \text { in. }^{2}\right)\end{array}$ \\
\hline PVA & Series 1000 & 1.5 & Chris Craft & 0.001 & 0.30 \\
& & 8 & & 0.0002 & 1.70 \\
& VECAT & 5 & Fres-Co & 0.014 & 0.85 \\
EVOH & L sheet & 10 & Evalca & 0.01 & 1.04 \\
Al foil & & 0.7 & Fres-Co & 0 & 0.85 \\
& & $2 \times 0.25$ & James River & 0 & -0.30 \\
\hline
\end{tabular}

${ }^{a}$ OTR equals 0.01 to $0.001 \mathrm{~cm}^{3} / \mathrm{m}^{2}-24 \mathrm{~h}$-atm @ $0 \%$ RH and $23 \cdot \mathrm{C}$.

${ }^{b}$ PET/Saran/PVA/Saran/LLDPE.

data were supplied by the manufacturers for large-lot purchases. The data for film are basically the cost for the resin, generally $\$ 3$ to $\$ 4$ per pound, divided by the yield. The cost figures, therefore, do not include manufacturing costs for using the films as a barrier in a PEP. The data for the laminates, which are generally higher than that for films, do include the manufacturing cost for the film as well as converting it into a laminate.

Several observations on candidate barrier materials are:

1. Films oriented in one direction may have even better barrier properties than isotropic materials. At least one contact for PVA, Chris Craft, is working on this type of concept. Laminates which have "directional" barrier properties may be useful and should be explored, especially when the nature of the environment that the PEP will see is known.

2. Sealing may be a problem. Some of the low- $\Gamma$ barrier materials may be sealed to themselves, but integrity of the seal layer may be suspect for extended lifetimes and hostile conditions such as thermal cycling and vibration. Use of wide seals is possible. High technology sealing, such as using microwaves, may be worth pursuing.

3. The design of the bag, including special aluminum foil configurations only on the large flat sides of the PEP and not along the edges, should be studied. Computer heat-flow modeling of this type design should be performed first. 
4. Several companies have expressed interest in joint development projects. The authors plan to pursue this avenue by visiting these companies and discussing methods of proceeding for prototype development.

5. NASA has done a great deal of work on barrier materials for balloons. The authors plan to contact them to make sure nothing has been missed.

\subsection{MEASUREMENT OF PERMEANCE ( $\Gamma$ ) OF BARRIER MATERIALS}

\subsubsection{Early Attempts to Measure $\Gamma$ in this Program}

Two methods of measuring $\Gamma$ of potential barrier films were employed in 1989 and early 1990. The first was a technique developed at the Oak Ridge K-25 Site, formerly the Oak Ridge Gaseous Diffusion Plant, for measurements of $\Gamma$ of uranium gases through semipermeable membranes used in the gaseous diffusion process for separation of uranium isotopes. In their method, a gas at a preselected pressure is placed on one side of a barrier, and the change in pressure is measured in a calibrated volume on the other side of the barrier. This method is very similar to Procedure M of ASTM D1434. ${ }^{42}$ Unfortunately, these measurements were plagued by several experimental errors, including a leak in the pressure transducer and leaks between the layers of the laminates. The latter problem was solved by sealing the edges of laminate specimens with epoxy. This work, therefore, provided a learning experience for the K-25 Site staff as well as the BMG. For example, effects of water vapor on the measured $\Gamma$ were experienced when water vapor permeation tests preceded those of other gases. Thus, the need for thorough conditioning of the specimen prior to testing was learned the hard way. In general, all their reported values are believed to be too high for $\Gamma$ of the materials measured.

The second technique involved indirect measurements of $\Gamma$ for the barrier material of PEPs used in an accelerated aging test. This procedure consisted of placing PEPs in a chamber that was evacuated several times and backfilled with $\mathrm{He}$ gas at about $860 \mathrm{~mm}$ of Hg. The PEPs were allowed to soak in this atmosphere for extended time periods followed by measurements of the internal pressure in the PEPs by Global. As discussed in a preceding section of this report, these pressure measurements were too low. The erroneous pressure measurements yielded values of $\Gamma$ that were too low for the barrier material. Consequently, the too-high K-25 $\Gamma$ measurements and the too-low $\Gamma$ values of 
this procedure differed by factors of 20 or more. After a brief review of the technology, the approach being pursued now by the BMG is presented.

\subsubsection{Measurement Technology for $\Gamma$}

Several standards exist for the measurement of gas transmission rates for thin laminate materials. ASTM D $1434^{42}$ and DIN $53380^{45}$ are based on measuring a pressure or volume change with time, and ASTM D $3985^{46}$ is based on an oxygen sensor method. The former two standards may be used for any gas; the latter standard is only for oxygen (i.e., OTR). The major, and perhaps only, commercial testing laboratory in this field is Modern Controls, Inc. (MOCON). All questions of the authors regarding testing for $\Gamma$ were referred to MOCON by the manufacturers of barrier materials. Their newest device can measure $\Gamma$ for $\mathrm{O}_{2}$ to a sensitivity of $0.001 \mathrm{~cm}^{3} / \mathrm{m}^{2}-24 \mathrm{~h}$-atm; sensitivities for the other gases are $1 \mathrm{~cm}^{3} / \mathrm{m}^{2}-24 \mathrm{~h}$-atm. Tests at MOCON can be performed at a cost of approximately $\$ 200 /$ gas per material. Tests normally take three to four weeks. Rush tests can be done in two weeks for a surcharge of $50 \%$; however, sample conditioning of at least a week is required by MOCON to bring the barrier to moisture equilibrium.

A standard reference material, SRM 1470 , is available from NIST for $\$ 209$. Because this is a polyester, it has permeability much higher than that desired for a barrier material. The SRM, however, is useful to check the methods employed in this work. Nitrogen has the lowest $\Gamma$ of the gases for the SRM but has the highest temperature coefficient. Experimentally, therefore, $\mathrm{N}_{2}$ will be the most difficult gas to use for measurements on this SRM.

\subsubsection{Present Efforts to Measure $\Gamma$ of Barrier Material}

A three-pronged approach is being pursued by the BMG. First, MOCON was contracted to measure $\Gamma$ of three films at ambient temperature and $0 \% \mathrm{RH}: \mathrm{O}_{2}$ and $\mathrm{He}$, Is for SRM 1470 and a laminate, and the OTR for the Chris Craft hydrolyzed PVA without plastizer. Second, the BMG has asked the K-25 Site staff to measure the $\mathrm{O}_{2}$, $\mathrm{N}_{2}$, and $\mathrm{He} \Gamma \mathrm{s}$ of these same three films. Third, the BMG has repeated our He aging tests on PEPs for which the laminate is the barrier material. 


\subsubsection{Measurements by MOCON}

The $\Gamma$ measurements made by MOCON are listed in Table 16. The difference between their $\Gamma$ measurement for $0_{2}$ on SRM 1470 and the NIST value is $-1.5 \%$; NIST reports a standard deviation of $1.4 \%$. The MOCON OX-TRAN* measurements for oxygen have a sensitivity of $0.001 \mathrm{~cm}^{3} / \mathrm{m}^{2}-24 \mathrm{~h}$-atm and use a coulometric method for detecting the OTR, providing part-per-billion resolution for oxygen even in the presence of water vapor and other common gases. Thus, the excellent agreement with the NIST data is as expected.

The MOCON measurements of the $\Gamma$ of He for SRM 1470 were performed using a MULTI-TRAN ${ }^{\circ}$, which uses a sensing system based on detection of differences in the $k$ of gases, with a sensitivity of $1.0 \mathrm{~cm}^{3} / \mathrm{m}^{2}-24 \mathrm{~h}$-atm. The difference between their $\Gamma$ measurement for $\mathrm{He}$ and the NIST value is $+7.7 \%$; NIST reports a standard deviation of $1.2 \%$. Thus, the difference is more than six times the NIST standard deviation and over 200 times the sensitivity of the MULTI-TRAN, indicating a possible positive absolute bias for the MULTI-TRAN for He.

The $\Gamma\left(\mathrm{O}_{2}\right)$ value of $0.0541 \mathrm{~cm}^{3} / \mathrm{m}^{2}-24 \mathrm{~h}$-atm for the Chris Craft PVA specimen is 54 times higher than that quoted to the authors by Chris Craft as discussed earlier. Obviously, the structural model that Chris Craft employed to obtain this value gave a result almost two orders of magnitude too low.

The $\Gamma$ for $\mathrm{O}_{2}$ for the laminate barrier material is essentially the same as that for the Chris Craft PVA specimen.

\subsubsection{Measurements by K-25 site}

The $\Gamma$ measurements made at the $\mathrm{K}-25$ site are listed in Table 17. The difference between their $\Gamma$ measurements for SRM 1470 and the NIST value is $+17 \%$ for $\mathrm{He}$, $+49 \%$ for $N$, and between -57 and $+4 \%$ for oxygen. These results were quite discouraging. Further improvements in the K-25 site equipment are being made, including an analysis of temperature measurments and the use of better pressure sensors. The measurements of $\Gamma$ for $\mathrm{O}_{2}$ and $\mathrm{N}_{2}$ for the laminate represent only upper limits for

*OX-TRAN is a registered trademark of Modern Controls, Inc., Minneapolis, Minn.

${ }^{\dagger}$ MULTI-TRAN is a registered trademark of Modern Controls, Inc., Minneapolis, Minn. 
Table 16. Permeance measurements made by $\operatorname{MOCON}$ at $73^{\circ} \mathrm{F}$

\begin{tabular}{lcccc}
\hline & & \multicolumn{3}{c}{ Permeance $\left(\mathrm{cm}^{3} / \mathrm{m}^{2}-24 \mathrm{~h}\right.$-atm $)$} \\
\cline { 2 - 5 } Material & Gas & NIST & MOCON & Diff (\%) \\
\hline SRM 1470 & $\mathrm{O}_{2}$ & 69.1 & $68.1^{a}$ & -1.5 \\
& $\mathrm{He}$ & 2706 & $2914^{a}$ & +7.7 \\
Chris Craft PVA & & & $0.054124^{a}$ & -- \\
& $\mathrm{O}_{2}$ & -- & $0.0530^{a}$ & - \\
Laminate & & & $30.2^{a}$ & - \\
& $\mathrm{O}_{2}$ &.- & & \\
\hline
\end{tabular}

Average of two specimens.

${ }^{b}$ NIST stated value.

Table 17. Permeance measurements made at the K-25 Site

\begin{tabular}{lccccc}
\hline & \multicolumn{3}{c}{ Permeance $\left(\mathrm{cm}^{3} / \mathrm{m}^{2}-24\right.$ h-atm $)$} & & \\
\cline { 2 - 4 } Material & K-25 Site & NIST & Diff $(\%)$ & Gas & Temperature $\left({ }^{\circ} \mathrm{F}\right)$ \\
\hline SRM & 3610 & 3085 & +17 & $\mathrm{He}$ & 81.7 \\
& 34.8 & & -57 & & \\
& 73.9 & 81.1 & -9 & 0 & 81.0 \\
& 84.5 & & +4 & & \\
Laminate & 15.5 & 10.4 & +49 & $\mathrm{~N}_{2}$ & 81.3 \\
& 29.2 & - & - & $\mathrm{He}$ & 83.1 \\
& $0.096^{\circ}$ & - & - & 0 & 83.1 \\
& $0.19^{\circ}$ & - & - & $\mathrm{N}_{2}$ & 83.1 \\
\hline
\end{tabular}

${ }^{a}$ Flow about equal to leak rate-not reliable number.

${ }^{b}$ NIST stated value.

this quantity as the flow rates measured were near the leak rates (i.e., the $\Gamma$ s of the laminate for $\mathrm{O}_{2}$ and $\mathrm{N}_{2}$ are about the same as the sensitivity of the K-25 equipment).

The $\Gamma$ for He for the laminate is $3 \%$ below that measured by MOCON, but the temperature of the $\mathrm{K} \cdot 25$ data is $9.7^{\circ} \mathrm{F}$ higher. While the temperature coefficients of the Is of the laminate are not known, activation-type phenomenon often increase by a factor 
of two for every $18^{\circ} \mathrm{F}$ rise in temperature. For example, for SRM 1470, the $\Gamma s$ for $\mathrm{N}_{2}$, $\mathrm{O}_{2}$, and $\mathrm{He}$ increase by a factor of $1.7,1.5$, and 1.3 , respectively, for an $18^{\circ} \mathrm{F}$ temperature change. Thus, the $\mathrm{K}-25$ datum would be expected to be above that of the MOCON datum rather than below it. The authors note that the $\Gamma$ for $\mathrm{He}$ of the laminate lies between the $\Gamma$ s for $\mathrm{O}_{2}$ and $\mathrm{N}_{2}$ of SRM 1470 for which the K-25 Site measurements were erratic and erroneous.

\subsubsection{Aging studies}

Six $9 \times 9 \times 1 / 2$ in. PEPs that were fabricated on $3 / 9 / 89$ were chosen for aging tests. The pressure in each PEP was measured using the ORNL hand-held gauge, and then the PEPs were placed in a chamber which was evacuated to about 250 torr and backfilled five times with $\mathrm{N}$ gas at a pressure of about 895 torr. The PEPs were conditioned in $\mathrm{N}$ for $8 \mathrm{~d}$ followed by remeasurement of the pressure in the PEPs. The PEPs were returned to the chamber which was evaciated to 250 torr and backfilled five times with $\mathrm{He}$ gas at about 895 torr pressure. After $32 \mathrm{~d}$, the PEPs were removed from the chamber and the pressure remeasured. These measurements are shown in Table 18.

Frorn the pressure measurements listed in Table 18 and Eq. (9), the $\Gamma$ for the barrier material was calculated. The $\Gamma$ values of $\mathrm{He}$ for the six panels are given in Table 18. The mean of the six measurements was $14.9 \mathrm{~cm}^{3} / \mathrm{m}^{2}-24 \mathrm{~h}$-atm with a standard deviation $\pm 1.0 \mathrm{~cm}^{3} / \mathrm{m}^{2}$-atm- $24 \mathrm{hr}$. The mean temperature during these measurements was that of the ambient, about $70^{\circ} \mathrm{F}$. Using the pressure measurements made by the fabricator on $3 / 9 / 89$ and the pressures measured on $8 / 16 / 90$ listed in Table 18 , a value of $0.40 \mathrm{~cm}^{3} / \mathrm{m}^{2}-24 \mathrm{~h}$-atm was computed assuming the diffusing gas was $\mathrm{O}_{2}$ at a pressure of 150 torr. These PEPs were stored in the ambient of about $70^{\circ} \mathrm{F}$ and 50 to $60 \% \mathrm{RH}$.

\subsubsection{Comparison of $\Gamma$ measurements for He through laminate barrier}

The specimens of the laminate used in the $\Gamma$ measurements were from a set of PEPs fabricated in 1989. The specimen sent to MOCON was from one side of a PEP and thespecimen sent to the K-25 Site was from the other side of the same PEP. The six PEPs used by ORNL in its aging studies were from the same lot of PEPs. Thus, differences due to specimens would not be expected to be more than that represented by the six PEPs of Table 18, having a standard deviation (o) of $1.0 \mathrm{~cm}^{3} / \mathrm{m}^{2}-24 \mathrm{~h}$-atm, or $7 \%$. Yet, both the MOCON and K-25 site data are a factor of two (100\%) higher than the 
Table 18. Results of accelerated aging tests on PEPs in He

\begin{tabular}{ccccc}
\hline \multicolumn{3}{c}{ PEP pressure (mm Hg) } & $\begin{array}{c}\text { Permeance } \\
\left(\mathrm{cm}^{3} / \mathrm{m}^{2}-24 \mathrm{~h} \text {-atm }\right)\end{array}$ \\
\hline PEP & $8 / 16 / 90^{\circ}$ & $8 / 24 / 90^{b}$ & $9 / 25 / 90^{\circ}$ & \\
\hline 1 & 7.8 & 9.5 & 97.1 & 15.4 \\
2 & 8.0 & 9.4 & 92.5 & 16.4 \\
3 & 8.7 & 9.5 & 100.8 & 14.8 \\
4 & 10.3 & 9.6 & 86.7 & 13.5 \\
5 & 9.2 & 9.2 & 91.5 & 14.4 \\
6 & 7.6 & 10.4 & 92.0 & Mean $\frac{14.4}{14.9}$ \\
& & & & Std dev \pm 1.0 \\
\hline
\end{tabular}

${ }^{a}$ PEPs fabricated on $3 / 9 / 89$ and stored at about $70^{\circ} \mathrm{F}$ and 50 to $60 \% \mathrm{RH}$ (average of at least three measurements).

${ }^{b}$ Eight days in $895 \mathrm{~mm}$ of $\mathrm{Hg}$ pressure of $\mathrm{N}_{2}$ at about $70^{\circ} \mathrm{F}$ (average of at least three measurements).

Thirty-two days in $895 \mathrm{~mm}$ of $\mathrm{Hg}$ pressure of $\mathrm{He}$ at about $70^{\circ} \mathrm{F}$ (average of at least five measurements).

than the ORNL measurements (made at an average temperature of $70^{\circ} \mathrm{F}$ ), which is $3.4^{\circ} \mathrm{F}$ below the MOCON experimental temperature and $13.1^{\circ} \mathrm{F}$ below the $\mathrm{K}-25$ Site experimental temperature. One possible explanation for the ORNL data being low is adsorption of the He by the powder in the PEP. This effect will be studied in the future. The influence of adsorbed water on the He adsorption will also be studied.

\subsection{EXAMPLE OF USE OF TS MEASURED AT ORNL}

Use of the $\Gamma$ s measured during the ORNL aging tests is illustrated by the calculations shown in Table 19. In this table, the internal pressures of the PEPs used in the comparison study of the hand-held gauge and the B\&W gauge (Table 10) were corrected for the diffusion out of/into these PEPS of air or He. The comparison on PEPs A, E, and F with the ORNL measurements listed in Table 10 is quite impressive; the pressure in PEP B is only about 5 torr off. Increasing the $\Gamma$ of the barrier material for He by one standard deviation would decrease the difference for PEP B to 3 torr. Thus, the comparison between the calculated and measured values validates the 


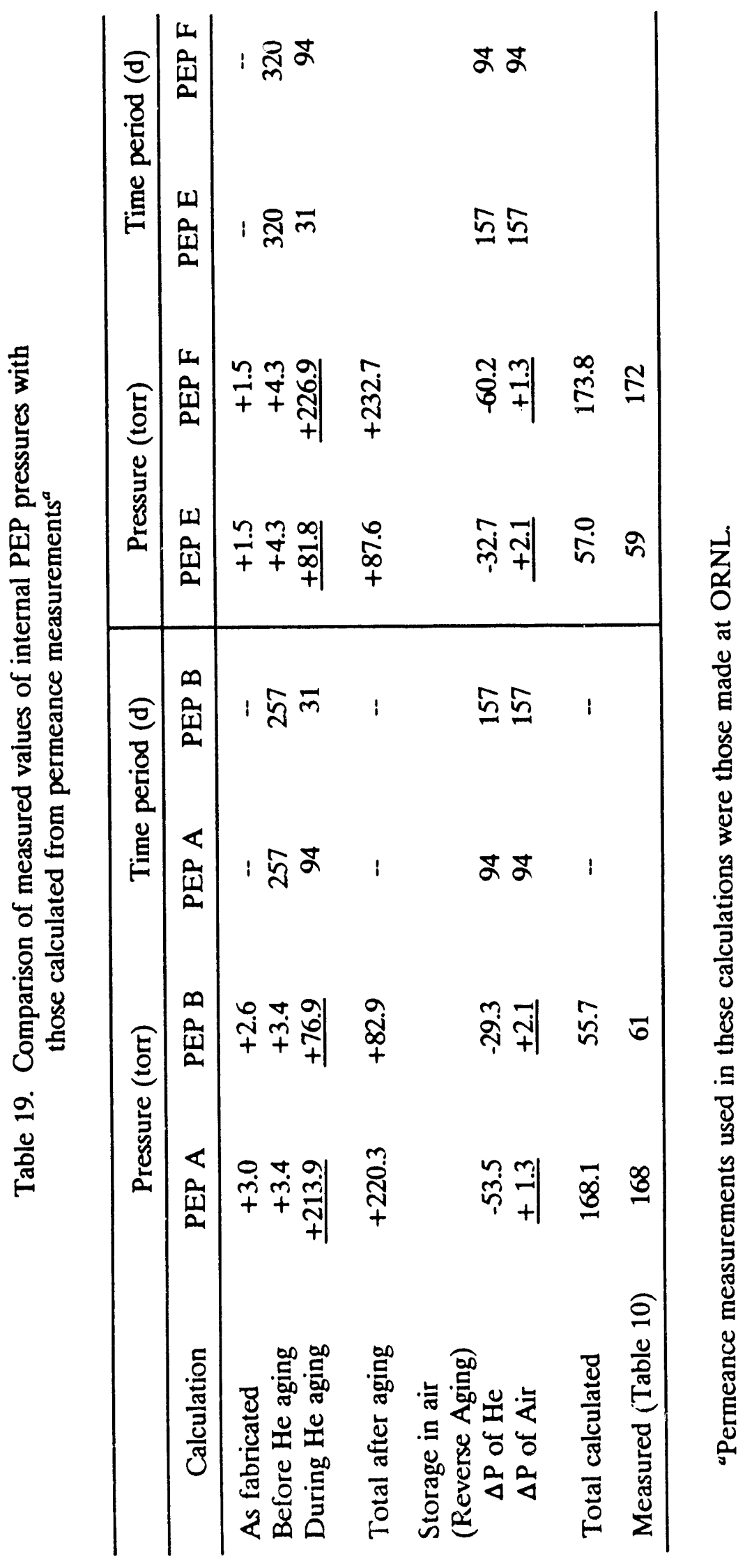


ORNL calculated values of $\Gamma$ of the barrier, especially when one considers that time periods of 31 and $94 \mathrm{~d}$ were involved in the He aging and 94 to $320 \mathrm{~d}$ in air.

\subsection{MEASUREMENT OF $\mathbf{R}$ OF PEPS}

Most methods of measurement of $\mathbf{R}$ require experimental apparatuses that cause heat to flow in one direction. This experimental arrangement allows analytic solutions of the heat transfer equations in a simple, closed form. In some methods, guard heaters are used to create adiabatic surfaces in all but one direction, whereas in others, the dimensions are increased to reduce the heat flow to negligible levels in two directions; the latter are called unguarded techniques. Both the HFMA and the UTHA apparatuses, described in an earlier section, are unguarded, although the HFMA does operate in a temperature-controlled cabinet.

Measurements of $\mathrm{R}$ of the PEPs were performed in the ORNL HFMA apparatus. The PEFs were placed in the HFMA in the center of a nominally $24 \times 24 \times 4$ in.-thick batt of fiberglass with a nominal $R /$ in. of 4.2 . The PEPs are nominally $12 \times 12$ in. squares. The HFT of the HFMA is $10 \times 10 \mathrm{in}$. Thus, the HFT of the apparatus is directly above the center 100 in. $^{2}$ of the PEP, (an area of $\sim 144$ in. $^{2}$ ). The HFT, however, has some peripheral sensing of the other $44 \%$ of the area of the PEP. Because the PEP/batt-composite specimen is anisotropic and inhomogeneous, the heat flow is not normal to the sensor's surface (i.e., heat flow is not 1D). Consequently, modeling of the heat flow to determine the $\mathbf{R}$ of the PEP is required to avoid large errors.

Figure 17 shows the calculated area-averaged heat fluxes for the PEP/battcomposite specimen as a function of the distance from the center of the HFT for several values of the $\mathrm{R} / \mathrm{in}$. of the PEP. These data were calculated using HEATING-7 for a $\Delta T$ of $39.6^{\circ} \mathrm{F}$. For PEP Rs near that of the batting, the heat fluxes measured by the HFT are unaffected by the anisotropy of the PEP/batting-composite specimen. At higher PEP Rs, the measured heat flux would be too high, thereby giving too low a $\mathbf{R}$ measurement for the PEP if $1 D$ heat flow is assumed and the $\mathbf{R}$ of the batt is subtracted from the measured $\mathbf{R}$ of the composite to compute $\mathbf{R}$ of the PEP.

Figure 18 is a plot of the $\mathrm{R} / \mathrm{in}$. of the composite specimen as measured by the HFT vs the R/in. of the PEP as computed by the 3D HEATING-7 model and as 


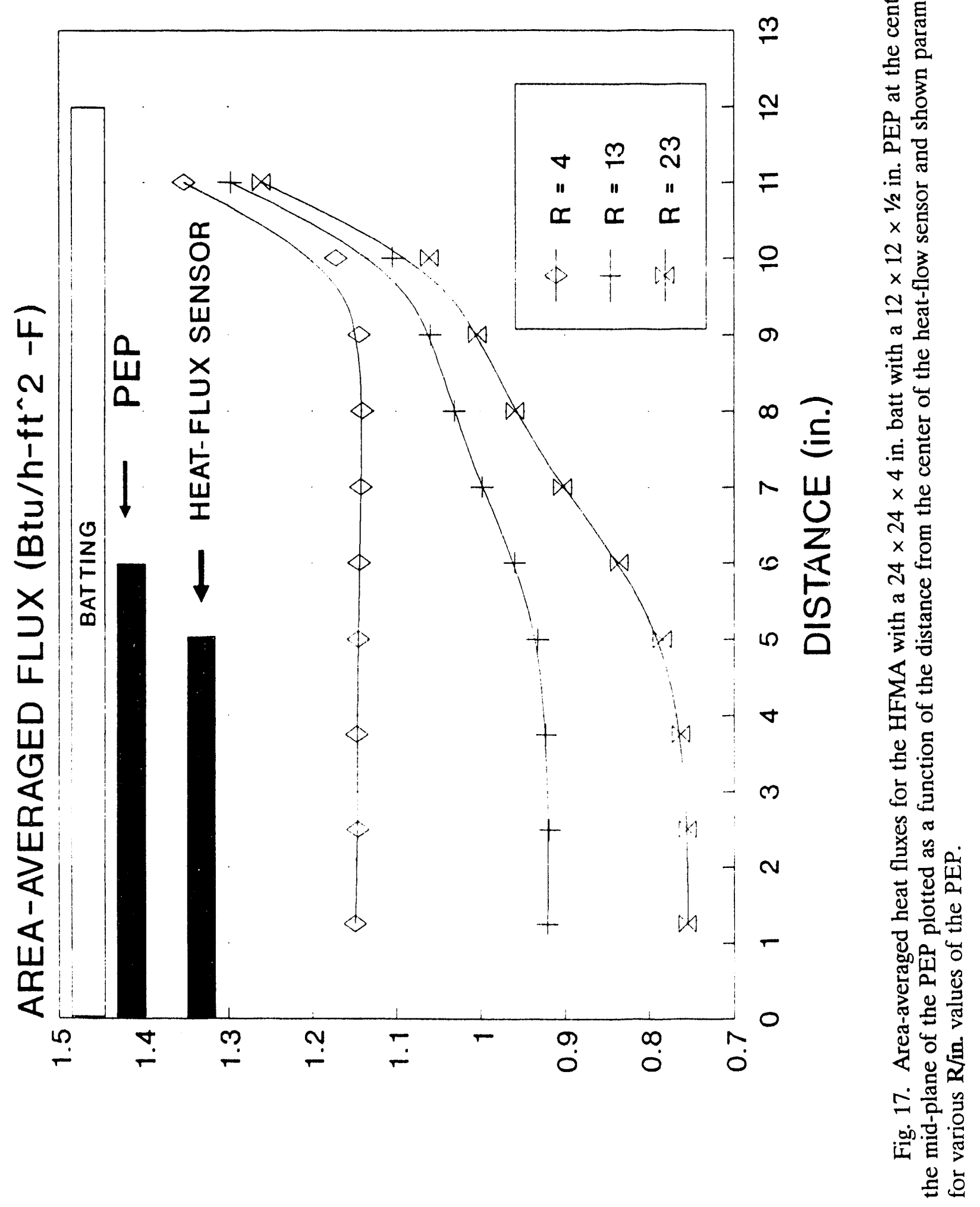




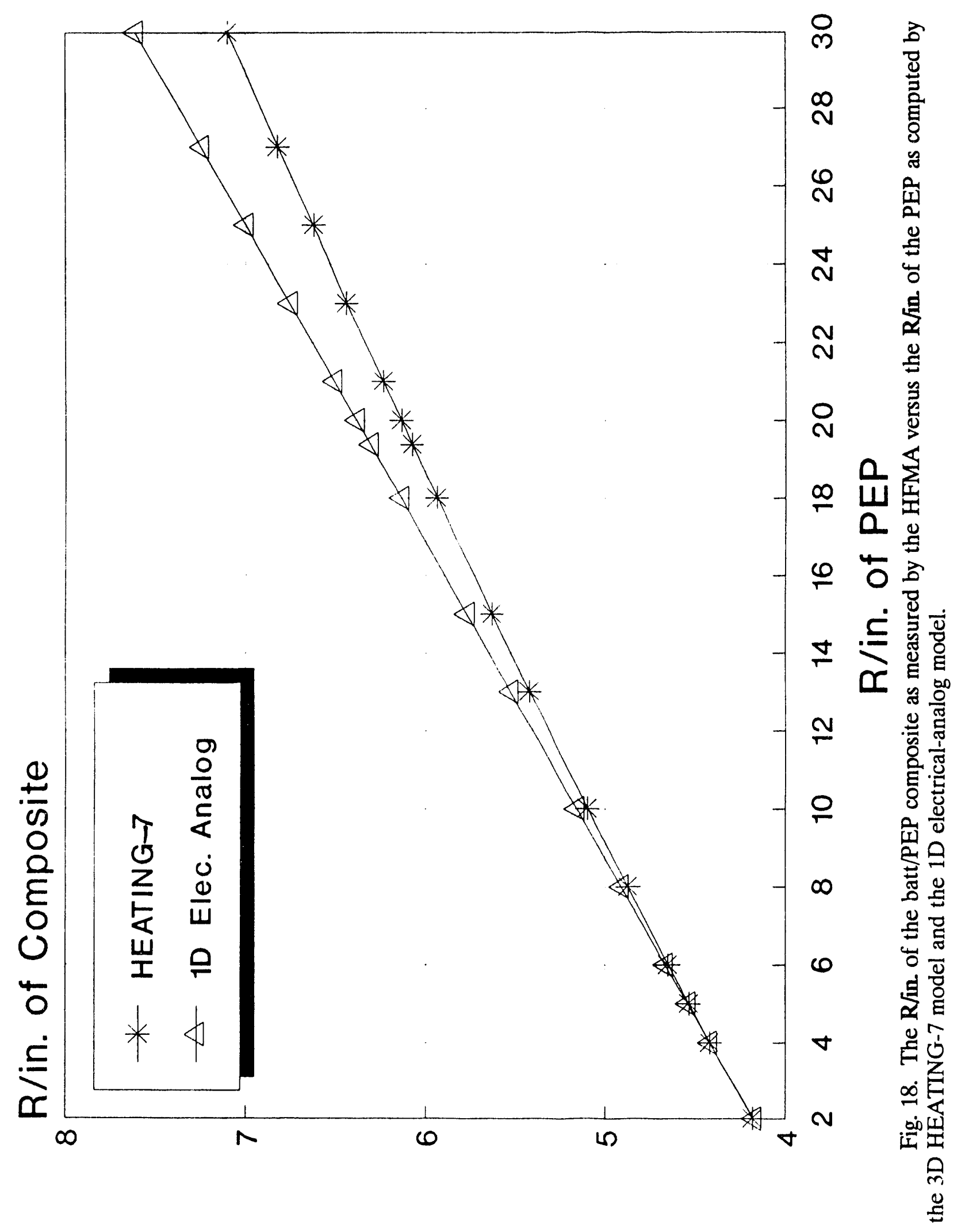


computed by subtracting the resistance of the batt from the measured composite $R$ (1D model). Again, when the batting and PEP Rs are comparable, the difference is small. At about a PEP R/in. of 20 , the two models differ by about $10 \%$.

Figure 19 shows the $\mathbf{k}$ of the composite as measured by the HFT as a function of the $R$ /in. of the PEP. A least-squares fit of these data was used to compute the $R / i n$. of a PEP from the HFT output. Table 20 shows the values measured on seven PEPs at an average temperature of $75^{\circ} \mathrm{F}$. Three of the PEPs had only been exposed to air; the one at 47 torr internal pressure of air had a small leak in the seal. Four of the PEPs had been aged in He. All the internal air pressures (P) were computed from the initial measurements made at J. M. Huber at the time of manufacture plus the increase in $\mathbf{P}$ that resulted from air or He permeation of the barrier material as computed with the measured $\Gamma$ s of air and He; the $P$ of the PEP with the seal leak was estimated from the error curve of Fig. 14 and the measurement made at Global.

\subsubsection{Comparison of Rs Measured in the UTHA and the HFMA}

The $\mathrm{R} / \mathrm{in}$. for the first PEP listed in Table 20 was the center PEP in the montage specimen used in the UTHA, as discussed previously. The UTHA R/in. value for the PEPs was 19.6, which is to be compared with the HFMA value of 21.8. This $10 \%$ difference must be attributed to experimental errors because the measurements were made a few days apart, so the pressure change in the PEP was negligible.

Because the UTHA is an absolute technique, assuming it to give the correct $\mathbf{R}$ value is the conservative approach. Several yet-to-be-evaluated experimental errors, however, could have caused the UTHA to give low values of $\mathbf{R}$. For example, 15 PEPs were taped together to form the UTHA specimen; heat leakage at the joints could have reduced the measured $\mathbf{R} / \mathbf{i n}$. Secondly, for such a high $\mathbf{R}$ specimen, heat losses through the unguarded edges of the montage specimen may have caused too low an $\mathbf{R}$ to be measured. These experimental uncertainties in the UTHA will be evaluated in the future. 


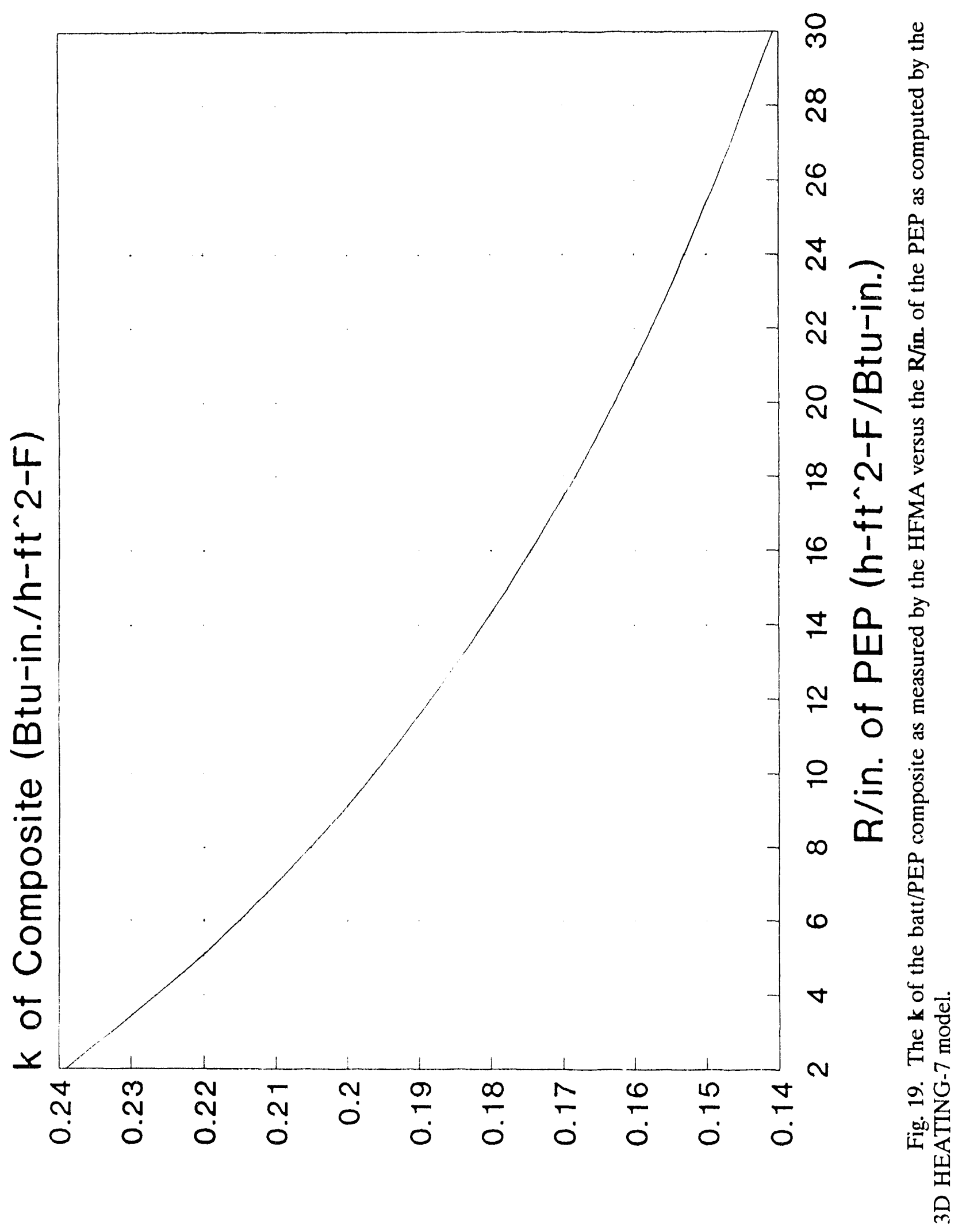


Table 20. HFMA measured R/in. of PEPs at $75^{\circ} \mathrm{F}$

\begin{tabular}{cccc}
\hline & & \multicolumn{2}{c}{ R/in. $\left(\mathrm{ft}^{2}-\mathrm{h}-{ }^{\circ}\right.$ F/Btu-in.) } \\
\hline $\begin{array}{c}\text { Pressure air } \\
\text { (torr) }\end{array}$ & $\begin{array}{c}\text { Pressure } \mathrm{He}^{a} \\
\text { (torr) }\end{array}$ & 1D & 3D \\
\hline 3.6 & - & 19.4 & 21.8 \\
6.5 & - & 16.3 & 17.9 \\
47.0 & - & 10.7 & 11.5 \\
7.0 & 18.4 & 12.8 & 14.0 \\
5.7 & 36.7 & 9.73 & 10.2 \\
6.0 & 76.9 & 6.30 & 6.53 \\
6.4 & 213.9 & 3.30 & 3.32 \\
\hline
\end{tabular}

${ }^{a}$ All pressures computed from J. M. Huber or Global measurements and corrected by computations for errors in their measurements.

\subsubsection{Resistivity Measurements of $\mathrm{SiO}_{2}$ Powder}

Table 21 lists the R/in. of Degussa FK-500-LS powder measured in ORNL-7 at an average temperature of $80^{\circ} \mathrm{F}$ as a function of both $\mathrm{N}$ and He pressure. The density of this powder was $7.05 \mathrm{lb} / \mathrm{ft}^{3}$, which was achieved by tamping the powder during filling ORNL-7. The density of the PEPs is $12.6 \mathrm{lb} / \mathrm{ft}^{3}$, which is approximately $9.1 \%$ of the theoretical density of $\mathrm{SiO}_{2}$. For comparison, the data of Table 20 for the PEPs and Table 21 for the powders are plotted in Fig. 20; the pressure of $\mathrm{He}$ is used to plot the points for the four PEPs aged in He.

The $\mathbf{k}$ of powders can be expressed as a sum of three contributions

$$
k=k_{c}+k_{r}+k_{g}
$$

with the terms being the contributions due to conduction through the powder, due to thermal radiation, and due to gaseous conduction, respectively. The $R / i n$. of the powder is, of course, the reciprocal of $\mathbf{k}$ As shown in Table 21, the $\mathbf{R}$ /in. of tamped powder at 0.03 torr pressure is 43.7 , which is approximately the contribution due to the $k_{c}+k_{r}$ terms of Eq. (11). Thus at $75^{\circ} \mathrm{F}$ and pressures higher than 0.03 torr, the major contribution to $\mathbf{k}$ is that due to gaseous conduction. 
Table 21. Measured R/in. of Degussa FK-500-LS powder at $80^{\circ} \mathrm{F}$ and $7.05 \mathrm{lb} / \mathrm{ft}^{3}$

\begin{tabular}{ccc}
\hline & & R/in. $\left(\mathrm{ft}^{2}\right.$-h- $\left.{ }^{\circ} \mathrm{F} / \mathrm{Btu}-\mathrm{in}.\right)$ \\
\hline Pressure (torr) & In He & In N \\
\hline 0.03 & -- & 43.7 \\
2.8 & -- & 19.2 \\
10.3 & -- & 12.4 \\
23.4 & -- & 9.46 \\
140.3 & -- & 5.82 \\
812.1 & -- & 4.62 \\
2.3 & 20.3 & -- \\
9.6 & 10.5 & -- \\
26.0 & 5.38 & -- \\
48.0 & 3.98 & -- \\
136.6 & 2.34 & -- \\
811.1 & 1.43 & -- \\
\hline
\end{tabular}

The following observations are derived from Fig. 20:

1. At low pressure ( $<3$ torr), the $\mathbf{R} / \mathrm{in}$. of the powder is essentially independent of the type gas present.

2. The R/in. of the PEPs is higher than that of the powder, which has a lower density, indicating that the smaller size pores of the filler powder of the PEPs are more effective in limiting the gaseous conduction.

3. Near one atmosphere pressure, the $\mathbf{R} /$ in. of the powder approaches that of the gases, that is, $\sim 5$ for $\mathrm{N}$ and $\sim 1$ for He.

4. The R/in. of the PEPs approaches the same value at low pressures of He or air.

5. The $R /$ in. versus pressure curve of the PEPs with air is approximately parallel to that of the tamped powder in $\mathrm{N}$. (The $\mathbf{k}$ of air and $\mathrm{N}$ only differs by a few percent.)

6. Although the effects of mixing He with 7 torr of air were not evaluated, it appears that the presence of air reduced the $\mathbf{k}$ of the He/air mixture in the PEPs.

\subsection{THERMAL ANALYSIS OF SERI CVI PANELS}

The $\mathbf{R}$ of SERI CVI panels could not be measured directly in the ORNL HFMA because the CVIs are not homogenous and isotropic specimens as required by ASTM C 518 procedures for the HFMA. Consequently, the effective $\mathbf{R}$ averaged over the 


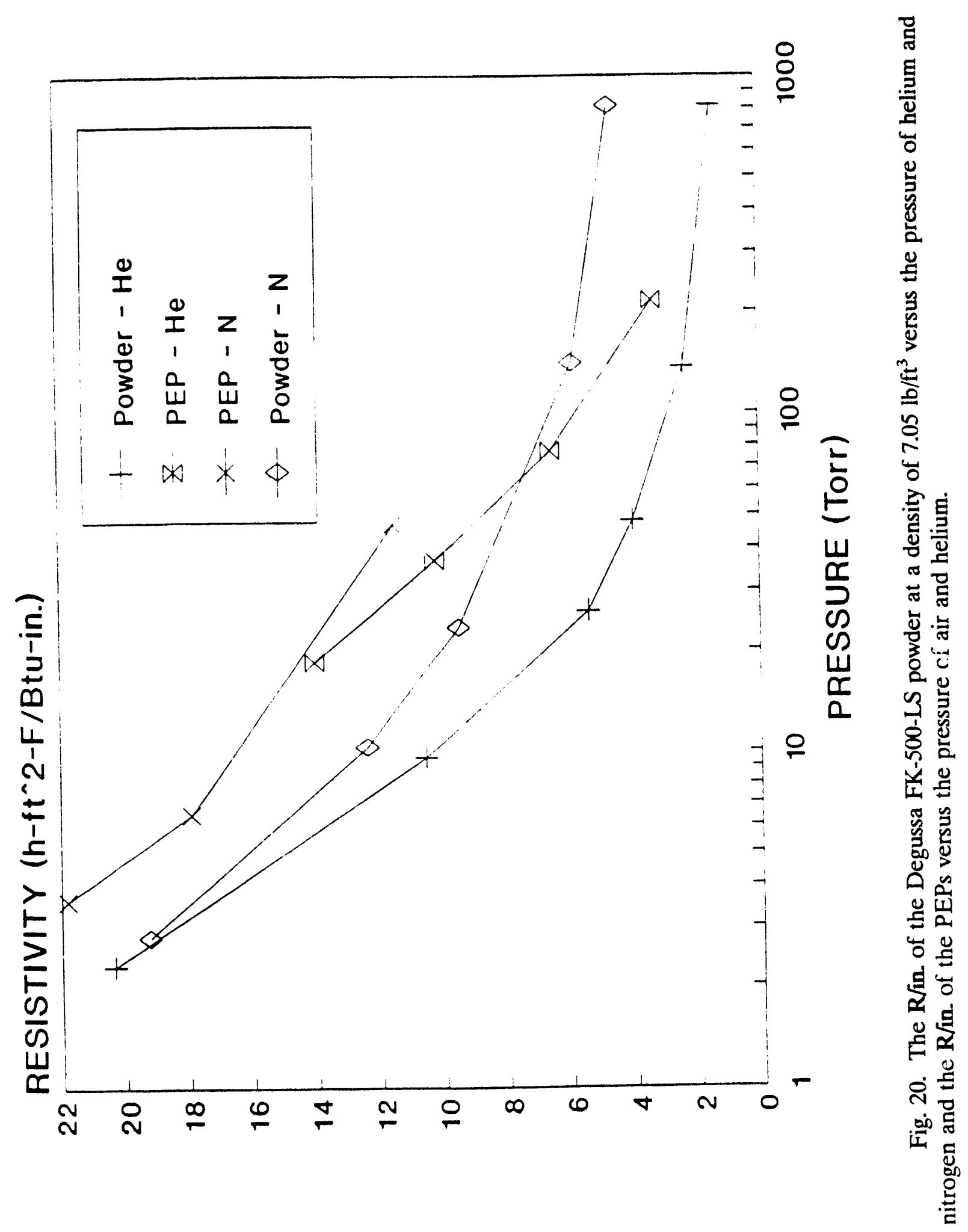


surface area of each CVI was computed from the HFMA measurements using the HEATING-7, heat-transfer code. In addition, a detailed thermal analysis of the heat transport within the CVI was performed to allow calculations of the effective $\mathbf{R}$ of a CVI in two applications. This model of heat transfer in a CVI is presented first.

\subsubsection{Thermal Model of CVI}

First, consider two parallel, infinitely large plates of stainless steel with a vacuum between them. The heat flux/unit area is: ${ }^{47}$

$$
\frac{Q}{A}=\frac{\sigma\left(T_{1}^{A}-T_{2}^{A}\right)}{\left(\frac{1}{\epsilon_{1}}+\frac{1}{\epsilon_{2}}-1\right)},
$$

where $\sigma$ is the Stefan-Boltzmann constant and the $\epsilon_{i} \mathbf{s}$ and $T_{i} \mathbf{s}$ are the total hemispherical emittances and absolute temperatures of the two plates, respectively. Assuming no gaseous convection or conduction (which is true if the pressure between the plates is $\sim 1 \times 10^{-4}$ torr or less), the "ideal" resistance $\mathrm{R}_{1}$ of these two plates for a temperature difference $\Delta T$ is:

$$
R_{I}=\frac{\Delta T}{\frac{Q}{A}}=\frac{T_{1}-T_{2}}{\frac{Q}{A}}
$$

Combining Eqs. (12) and (13) yields

$$
R_{I}=\frac{\left(\frac{1}{\epsilon_{1}}+\frac{1}{\epsilon_{2}}-1\right)}{\sigma\left(T_{1}^{2}+T_{2}^{2}\right)\left(T_{1}+T_{2}\right)}-\frac{\frac{2}{\varepsilon_{a}}-1}{\sigma 4 T_{a}^{3}}
$$

where the approximate expression to the right is true for small $\Delta \mathrm{Ts}$ and average properties $\epsilon_{\mathrm{a}}$ and $\mathrm{T}_{\mathrm{a}}$.

Equation (14) represents the maximum $R$ that can be achieved between two parallel plates. For example, Eq. (14) yiclds $R=17.6 \mathrm{~h}-\mathrm{ft}^{2}-^{\circ} \mathrm{F} / \mathrm{Btu}$ for $\epsilon_{\mathrm{a}}=0.1$ and 
$\mathrm{T}_{\mathrm{a}}=300 \mathrm{~K}\left(80^{\circ} \mathrm{F}\right)$. From a design standpoint, high Rs are achieved at low temperatures (being eight times higher at $80^{\circ} \mathrm{F}$ than $620^{\circ} \mathrm{F}$ ), and for low emittance (being slightly more than twice as high for an $\epsilon$ of 0.1 than 0.2 ). Because the $\mathbf{R}$ is not dependent on the thickness of the CVI, the $\mathbf{R}$ per unit thickness can be increased by stacking several thin assemblies rather than having one thick assembly for a given application.

The significant technical problem is holding two plates (separated by a vacuum) apart, with an atmospheric load of 14.7 psi trying to push the plates together. Such loads are most easily supported by metal plates with spacers placed judiciously between the plates. The spacers will transmit heat by conduction, thereby reducing the $\mathbf{R}$ of the panel. The metal also reduces the $\mathbf{K}$ of the panel by shunting heat along the surfaces of the assembly. Thus, the spacers should be as few and as small as possible, the metal as thin and as brightly polished as possible, and the plates must not touch each other. For the ideal case, the plates are assumed to be infinitely large so that the heat transferred through the vacuum seal where the plates are in contact can be ignored.

Figure 21 is a representation of the CVI support system that was used to model the SERI CVI; the representation is based on the ORNL understanding of the design. Glass spheres (1/8 in. diam) were assumed to separate 8-mil-thick stainless steel plates, yielding a maximum panel thickness of 141 mils. Thicknesses up to 138 mils were measured on the two CVIs. Some thinning of the metal is to be expected due to plastic flow in the area of contact. The "valleys" were as thin as 75 mils in places. Panel S1 had a total of 246 spheres ( 9 rows of 14 spheres and 8 rows of 15 spheres arranged in a fec geometric structure, having $\sim 0.98$ spheres/in. ${ }^{2}$ and a measured diameter of contact less than 76 mils). Panel $M$ had a total of 304 spheres (16 rows of 9 spheres and 16 rows of 10 spheres on a fcc structure, having $\sim 1.16$ spheres/in. ${ }^{2}$ and a measured diameter of contact less than 62 mils). The area of contact between the plate and sphere of Fig. 21 is:

$$
\operatorname{arca}=2 \pi r^{2}(1-\cos \theta)
$$

where $r$ is the radius of the sphere and $\theta$ is the contact angle shown in Fig. 22. The diameter of the contact area shown in Fig. 22 is: 


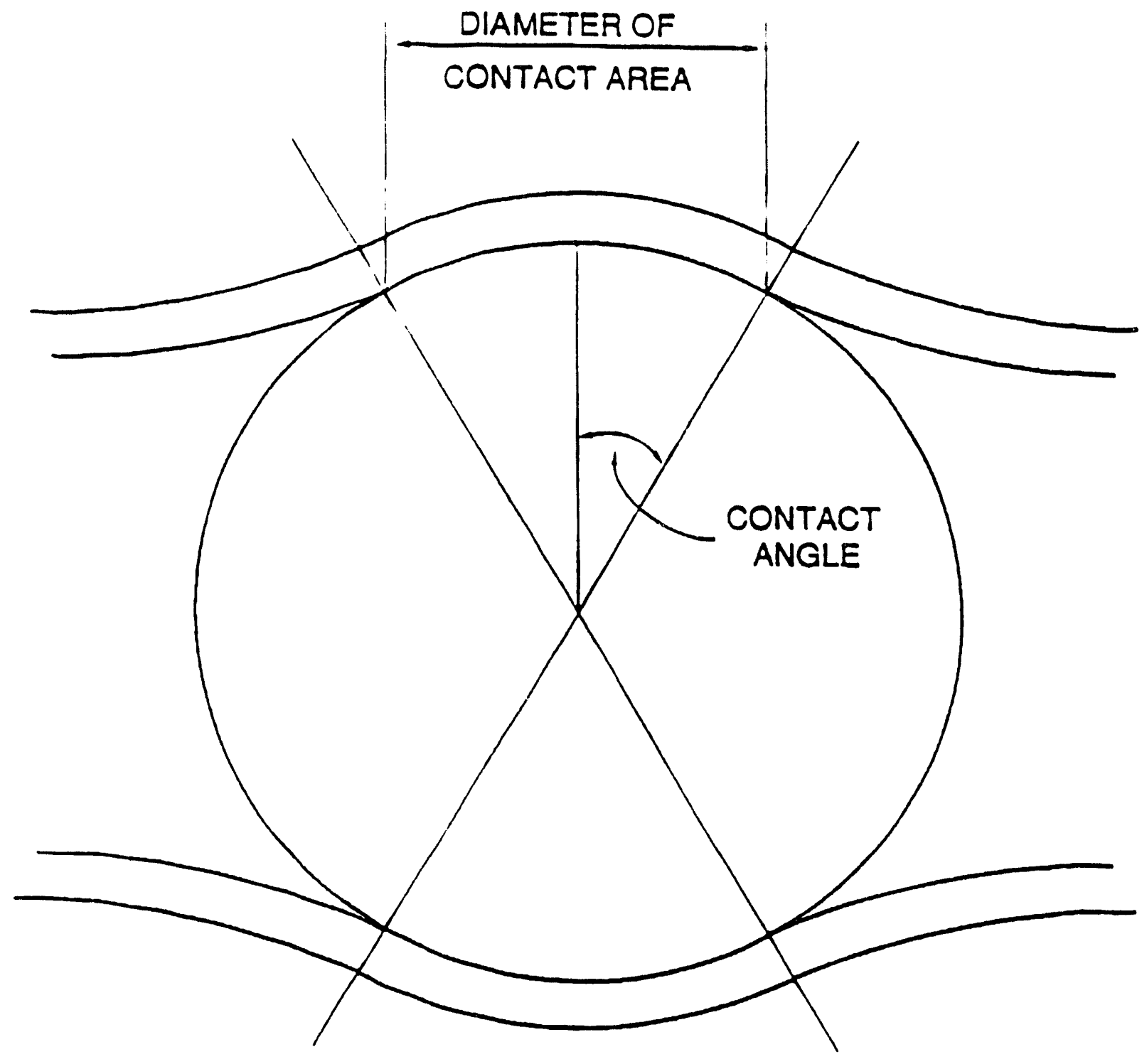

Fig. 21. Schematic of the CVI glass sphere support system to hold the two stainless steel sheets that form the vacuum enclosure apart under atmospheric loading. 


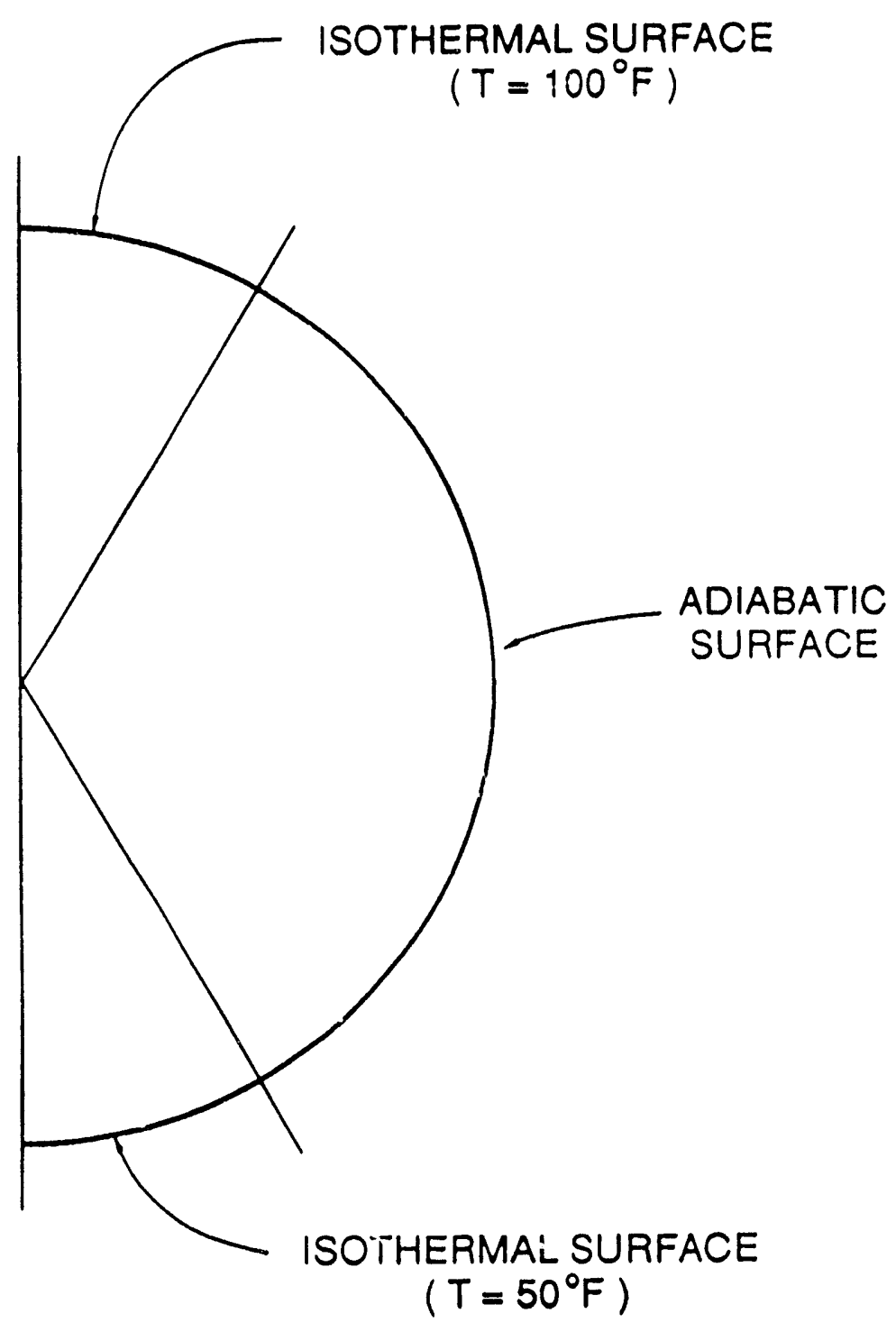

Fig. 22. Model of spheres in CVI showing boundary conditions used in the HEATING-7 calculations. 


$$
\mathrm{d}_{\mathrm{c}}=2 \mathrm{r} \sin \theta
$$

Thus, the area of contact of the sphere of pane! S1 is less than:

$$
A_{s}<2 \pi\left(\frac{125}{2}\right)^{2}\left(1-\cos \left[\sin ^{-1}\left(\frac{76}{125}\right)\right]\right) .
$$

The ratio of the areas of contact for the spheres and plates for the two panels is:

$$
\frac{A_{s 1}}{A_{m}} \sim \frac{1-\cos \left(\sin ^{-1}\left[\frac{76}{125}\right]\right)}{1-\cos \left(\sin ^{-1}\left[\frac{62}{125}\right]\right)}=\frac{0.206}{0.132}=1.56
$$

Because of the larger number of spheres for panel $\mathrm{M}$, the ratio of the total area of contact is:

$$
\frac{\sum A_{s 1}}{\sum A_{m}}-1.56 \times \frac{246}{304}=1.26
$$

Thus, because the radiant energy transfer is the same for the two panels and because the conduction through the spheres was thought to be the dominant heat transfer mechanism, panel $\mathrm{M}$ was expected to be of higher $\mathrm{R}$ by about a factor of 1.26 . The actual measured $\mathrm{R}$ ratio was 1.23 .

The HEATING-7, finite-difference, heat-transfer code was used to model the "ideal" SERI panels, allowing the contact angle to vary. The heat flows obtained are given in Table 22 for the model in Fig. 22. Heat transfer by shunting through the stainless steel was ignored (i.e., the plates were assumed to be infinitely large-the "ideal" case). The $\mathbf{k}$ of the glass spheres was assumed to be $6.24 \mathrm{Btu}-\mathrm{in} \cdot / \mathrm{hr} \cdot \mathrm{ft}^{2}-^{\circ} \mathrm{F}$. As to the total hemispherical emittance for Eq. (14), a computer search of the literature and the CINDAS data base at Purdue were used to select a value for the $\varepsilon$ of Type 304 stainless 
Table 22. HEATING-7 model results for infinitely large, "ideal" CVIs (no shunting through the stainless steel)

\begin{tabular}{|c|c|c|c|c|c|c|}
\hline \multirow[t]{2}{*}{$\begin{array}{l}\text { Angle of } \\
\text { contact } \\
(\theta) \\
{[\mathrm{deg}]} \\
\end{array}$} & \multirow[t]{2}{*}{$\begin{array}{l}\text { Diameter } \\
\text { of contact } \\
\text { (dc) } \\
\text { [in.] }\end{array}$} & \multicolumn{2}{|c|}{$\begin{array}{l}\text { Heat flow by } \\
\text { conduction }^{a} \\
{[\mathrm{Btu} / \mathrm{hr}]}\end{array}$} & \multirow{2}{*}{ 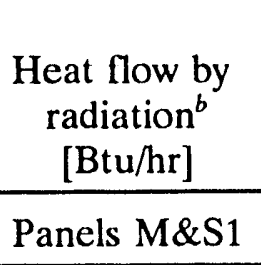 } & \multicolumn{2}{|c|}{$\begin{array}{c}\text { Thermal resistance } \\
(\mathbf{R}) \\
\mathrm{hr}-\mathrm{ft}^{2}-^{\circ} \mathrm{F} / \mathrm{Btu}\end{array}$} \\
\hline & & Panel $\mathrm{M}$ & Panel S1 & & Panel $\mathrm{M}$ & Panel S1 \\
\hline 5 & 0.0109 & 0.0326 & -- & 0.0186 & 6.77 & -- \\
\hline 10 & 0.0217 & 0.0556 & -- & 0.0186 & 4.68 & -- \\
\hline 15 & 0.0324 & 0.0783 & 0.0658 & 0.0186 & 3.58 & 4.12 \\
\hline 20 & 0.0428 & 0.1012 & 0.0850 & 0.0186 & 2.89 & 3.35 \\
\hline 25 & 0.0528 & 0.1245 & 0.1046 & 0.0186 & 2.43 & 2.82 \\
\hline 30 & 0.0625 & 0.1488 & 0.1250 & 0.0186 & 2.07 & 2.42 \\
\hline 35 & 0.0717 & -. & 0.1451 & 0.0186 & -- & 2.12 \\
\hline
\end{tabular}

${ }^{a}$ Surface heat flow per in. ${ }^{2}$ surface area with surface temperatures of 50 and $100^{\circ} \mathrm{F}$ for plates.

${ }^{b}$ Total hemispherical emittance of 0.097 .

steel. The lowest $\varepsilon$ values found were those of Roger et al. ${ }^{48}$ Their values were in excellent agreement with the theoretical equation of Davisson and Weeks: ${ }^{49}$

$$
€=0.754(\rho T)^{0.5}-0.632(\rho T)+0.670(\rho T)^{1.5}-0.607(\rho T)^{2},
$$

where $\rho$ is the electrical resistivity in ohm-cm and T is the absolute temperature in Kelvin. From ORNL $\rho$ measurements on Type 304 stainless steel, ${ }^{50} \varepsilon=0.094$ at $50^{\circ} \mathrm{F}$ and $\epsilon=0.099$ at $100^{\circ} \mathrm{F}$ were calculated; thus, $\epsilon=0.097$ was used for the averige value.

The Table 22 expected values of $\mathbf{R}$ of the CVIs without thermal shunting due to the stainless steel cladding (i.e., the ideal case) ranged from about 2 to 7 . Based on the maximum thickness of 141 mils, the $\mathbf{R}$ per unit thickness of the panels could approach 50/in. As discussed later, such values would only be achieved when the CVIs were significantly over $5 \mathrm{ft}^{2}$.

\subsubsection{Measurement and HEATING-7 Models of the $\mathbf{R}$ of the CVIs}

Measurements of $\mathbf{R}$ of the CVIs were performed by placing them in the ORNL HFMA in the center of a nominally $24 \times 24 \times 4$ in.-thick batt of fiberglass of a R/in. of 


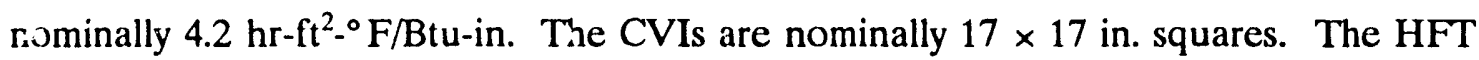
of the HFMA is $10 \times 10$ in. Thus, the HFT is directly above the heat flux to the center 100 in. $^{2}$ of the CVI, which has an area almost three times as large $\left(-294\right.$ in. $\left.^{2}\right)$. The HFT, therefore, only has some peripheral sensing of about two-thirds of the area of the panel. Because the panel/batt composite is anisotropic and inhomogeneous, the heat flow is not normal to the HFT's surface. Modeling of the heat flow to determine the $\mathbf{R}$ of the panel is, the efore, necessary to avoid large errors. To simplify the modeling, $\mathbf{R}$ of the vacuum-sphere-plate assembly was represented as being uniform and isotropic and of values between 1 and $10 \mathrm{hr}-\mathrm{ft}^{2}{ }^{\circ} \mathrm{F} / \mathrm{Btu}$, thereby spanning the expected values computed for Table 22. A value of $120 \mathrm{Btu}$-in. $/ \mathrm{hr}-\mathrm{ft}^{2}-{ }^{\circ} \mathrm{F}$ was selected for the thermal conductivity of stainless steel. Then, the R measured by the HFT of the HFMA for the $\mathrm{CVI} /$ batt composite (as a function of the $\mathrm{R}$ of the $\mathrm{CVI}$ ) was calculated to obtain the effective $\mathbf{R}$ of the CVI over its total surface, including the effect of the shunting $r$, the stainless stcel. Figure 23 shows a plot of the computed relationship between the $\mathbf{R}$ measured by the HFMA for the CVI/batt composite versus the $\mathrm{R}$ of the panels; data points for the two CVIs are plotted in this figure. Figure 24 shows the computed relationship between the HFMA measurement of $\mathbf{R}$ for the panel/batt composite versus the ideal (infinite) panel $\mathbf{R}$; points for the two CVIs are plotied in this figure.

From Fig. 23, the Rs of panels $\mathrm{M}$ and $\mathrm{S} 1$ are 2.84 and 2.30, respectively. Without shunting of the stainless steel, Fig. 24 shows that the Rs of panel M and S1 would have been 5.9 and 4.1, respectively. By linear interpolation of these values in Table 22 , the effective diameter of contact of the spheres in panel $\mathrm{M}$ is 15.4 mils and that of panel $\mathrm{S} 1$ is 32.5 mils. Thus, the effective diameters of contact are substantially less than those observed from the outside, which must be due to the effect of the dimple observed in the center of the spheres of panel $\mathrm{M}$ and ori one side of the spheres of panel S1.

\subsubsection{Uncertainties of the Measurement of $\mathbf{R}$ of the CVIs}

The uncertainties in the measured Rs were estimated from measurements on PEPs in the UTHA versus those in the HFMA that were performed with the same HEATING-7 model and setup as for the CVIs. The two sets of measurements on the PEPs differed by $10.1 \%$. The total error was attributed to uncertainties in the HFMA and modeling, a conservative approximation. The $\mathbf{R}$ of the CVIs was much smaller than the $R$ of the $\operatorname{REPs}(\mathbf{R}=9.52)$; thus, the same $10.1 \%$ uncertainiy was proportioned to 


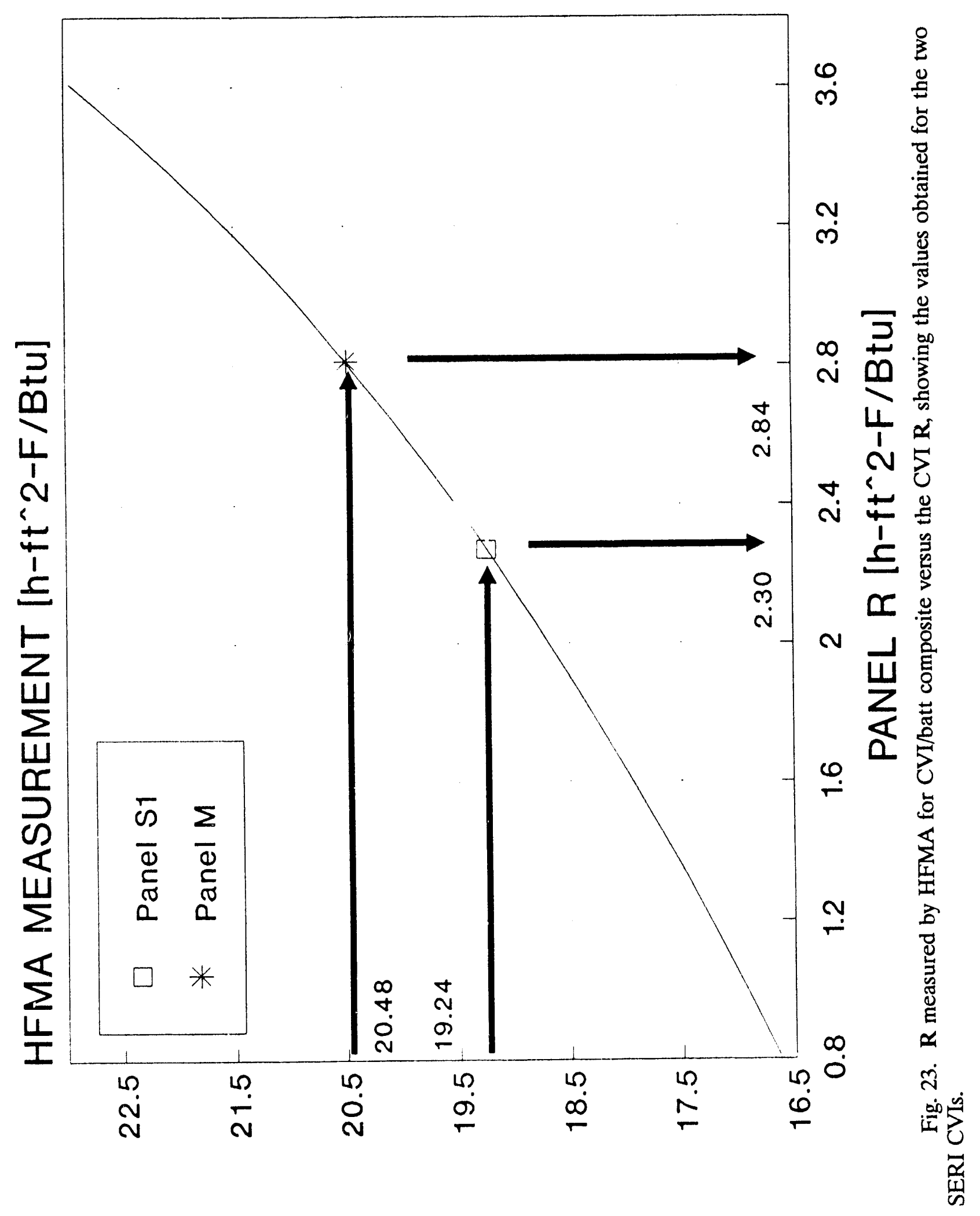




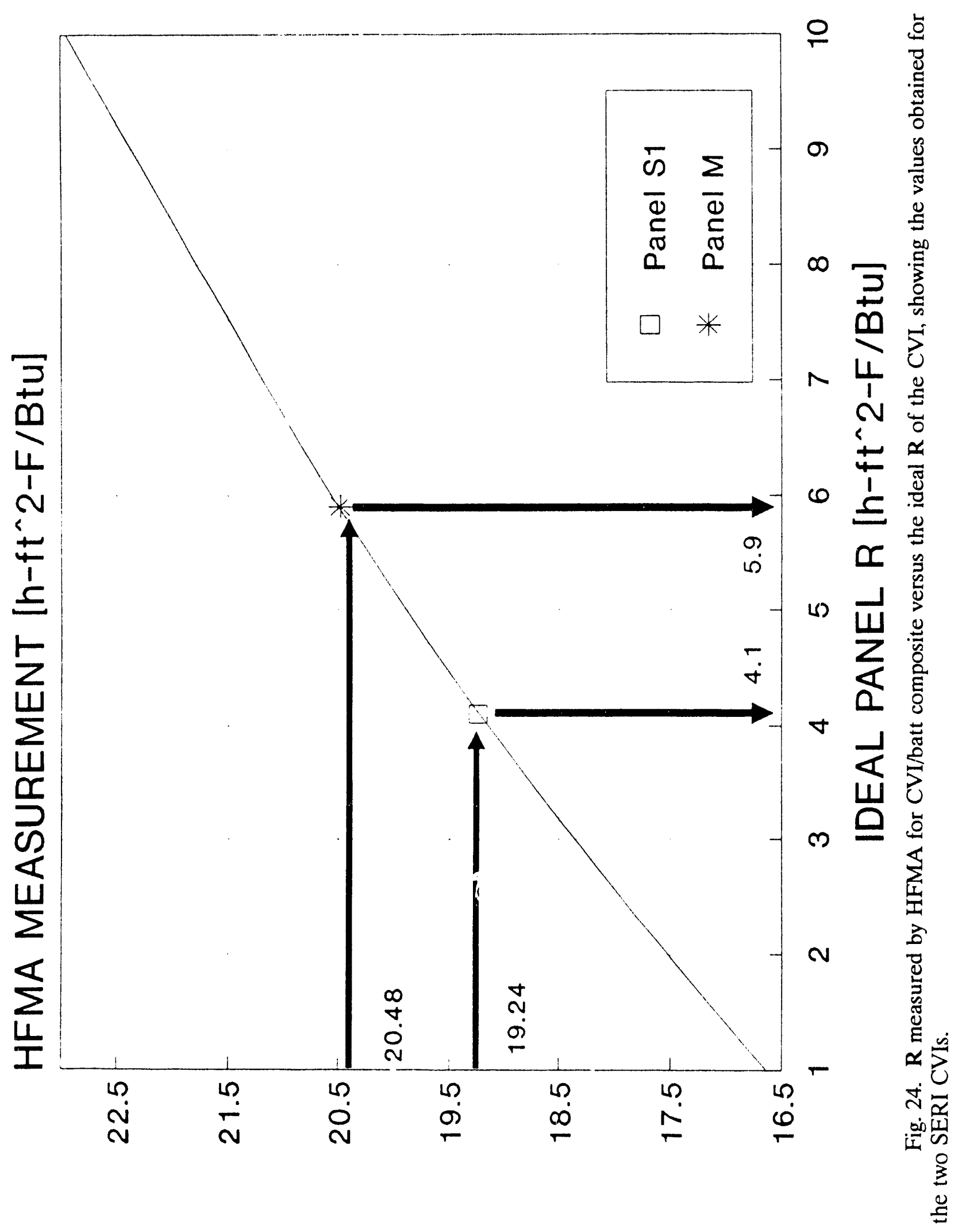


the total $\mathbf{R}$ of the composite (PEP/batt or CVI/batt) to arrive at uncertainties of ${ }_{ \pm} 0.73$ and $\pm 0.77 \mathrm{~h}-\mathrm{ft}^{2}{ }^{\circ} \mathrm{F} / \mathrm{Btu}$ for panels $\mathrm{S} 1$ and $\mathrm{M}$, respectively. These approximately $30 \%$ uncertainties are due to the fact that the Rs of the CVI contributed only about $12 \%$ of the HFMA-measured Rs of the composite. Accuracy could be improved by decreasing the thickness of the batt. There was concern, however, about the effect of the low emittance of the CVI on radiation through the batt. Measurement on the as-received CVIs and the CVIs with a high-emittance coating applied could help to fix the magnitude of this effect.

\subsubsection{The Effective $\mathrm{R}$ of Two, Identical, Stacked CVIs}

As discussed above, thin CVI panels should be stacked one upon the other to achieve a higher total $\mathbf{R}$ rather than using one thick panel. When CVIs are stacked, the shunting effect of the stainless steel further reduces the effective $\mathbf{R}$ of each CVI. The $\mathbf{R}$ of two, Type M CVIs stacked with a $\mathbf{R}$ of 0.6 between them was computed using HEATING-7. This arrangement reduced the effective $\mathbf{R}$ of the CVIs from 2.84 to 2.65, a further reduction of $6.7 \%$ in $\mathbf{R}$ of the CVIs. As more are stacked, further reductions would be expected. Also, the better the panels "nest" into each other, the lower the contact resistance will be and the more the effective $\mathbf{R}$ will be reduced.

\subsubsection{Calculations of $\mathrm{R}$ of a CVI/Foam Composite}

The HEATING-7 code was used to compute the effective $\mathbf{R}$ of a composite consisting of a $2 \times 3 \mathrm{ft} \mathrm{CVI} \mathrm{foamed} \mathrm{into} \mathrm{a} \mathrm{typical} \mathrm{refrigerator} \mathrm{wall} \mathrm{section} \mathrm{of} 1.5 \mathrm{in}$. thickness. The effective width of the zero-resistance lip of stainless steel cladding is 1 in., and the thickness of the CVI is set at 0.14 in. The CVI is assumed to have an R of 5 without thermal shunting of the cladding, the $\mathbf{k}$ of the stainless steel is assumed to be $120 \mathrm{Btu}-\mathrm{in} . / \mathrm{h}-\mathrm{ft}^{2}-{ }^{\circ} \mathrm{F}$, and the foam has a $\mathrm{R} / \mathrm{in}$.. of 7 . For these conditions, the effective $\mathbf{R}$ is 12.85 vs 10.5 for the foam alone, a $22 \%$ increase in $\mathbf{R}$ for the composite over that of the foam alone. A 1D, electrical-analog model (same type of model as used for the taped-in PEPs in the ice coolers), which consists of area-weighted resistances in parallel and series for the direction perpendicular to the CVI of this composite, would predict an effective $\mathbf{R}$ of 13.8 , a $31.4 \%$ increase in $\mathbf{R}$ for the composite over that of the foam alone. This approximately $50 \%$ overestimate of the effectiveness of the CVI is due to the inability of a $1 \mathrm{D}$ model to account for the significant heat flow in the cladding parallel to 
the surface of the CVI. Such overestimates are typical of attempts to model 3D heat flow using a 1D model, as discussed previously.

The effect of the thermal shunting of the cladding of a CVI decreases as the size of the CVI increases. Figure 25 is a plot of the increase in $\mathbf{R}$ of the above composite over that of the foam alone as a function of the size of the composite. Also shown is the theoretical maximum increase of 4.01 , which would occur for an infinitely large composite. The size dependence of the increase in $\mathbf{R}$ is obvious, that is, over a factor of three increase from 0.95 to 3.13 as the composite is increased from a $1 \times 1 \mathrm{ft}$ to $5 \times 5 \mathrm{ft}$ square. Even at a size of $5 \times 5 \mathrm{ft}$, the increase in $\mathrm{R}$ of the composite is only $75 \%$ of that of an infinitely large composite.

\subsubsection{Effects of High-Conductance Claddings}

From the foregoing discussion, the shunting effect of the 8-mil stainless steel cladding decreases with the size of the CVI (Fig. 25). Also, the effective R of the CVI can be increased by the design of the spacers holding the sides of the cladding apart (e.g., the difference between the $M$ and $S 1$ designs. Improvement in the design of the weld closure (e.g., by reducing its size from the present 1 -in. lip), will have only marginal effects on the performance. In the previous calculations, the stainless steel was assumed to be a continuous sheet around the CVI; the effect of the lip was only included in calculation of the area of the panel, which increased the area by $11 \%$. Thus, expenditures of significant research funds to reduce the size of the lip seem ill advised.

The performance of the SERI CVI is limited by the very high thermal conductance of the 8-mil stainless steel cladding employed in the design. This shunting effect reduced the $\mathbf{R}$ of the Type M CVI by a factor of two. It is this shunting effect that limits the usefulness of CVIs for small-sized applications, such as refrigerators and freezers. For example, the authors are aware that CVIs have been foamed into refrigerator walls by two manufacturers. In one case, only a $3 \%$ reduction in energy usage was noted, and in a second case, a $6 \%$ reduction; ${ }^{14}$ engineers who performed the latter test told the authors that the $6 \%$ change was not statistically significant. Some of this poor performance was due to not achieving high areas of coverage with the CVIs, but the majority of the lack of effectiveness was due to the shunting by the stainless steel.

Figure 26 brings home the effect of the stainless steel. These are computations made for the $3 \times 3 \mathrm{f}$ composite panel section as a function of the area of coverage of 


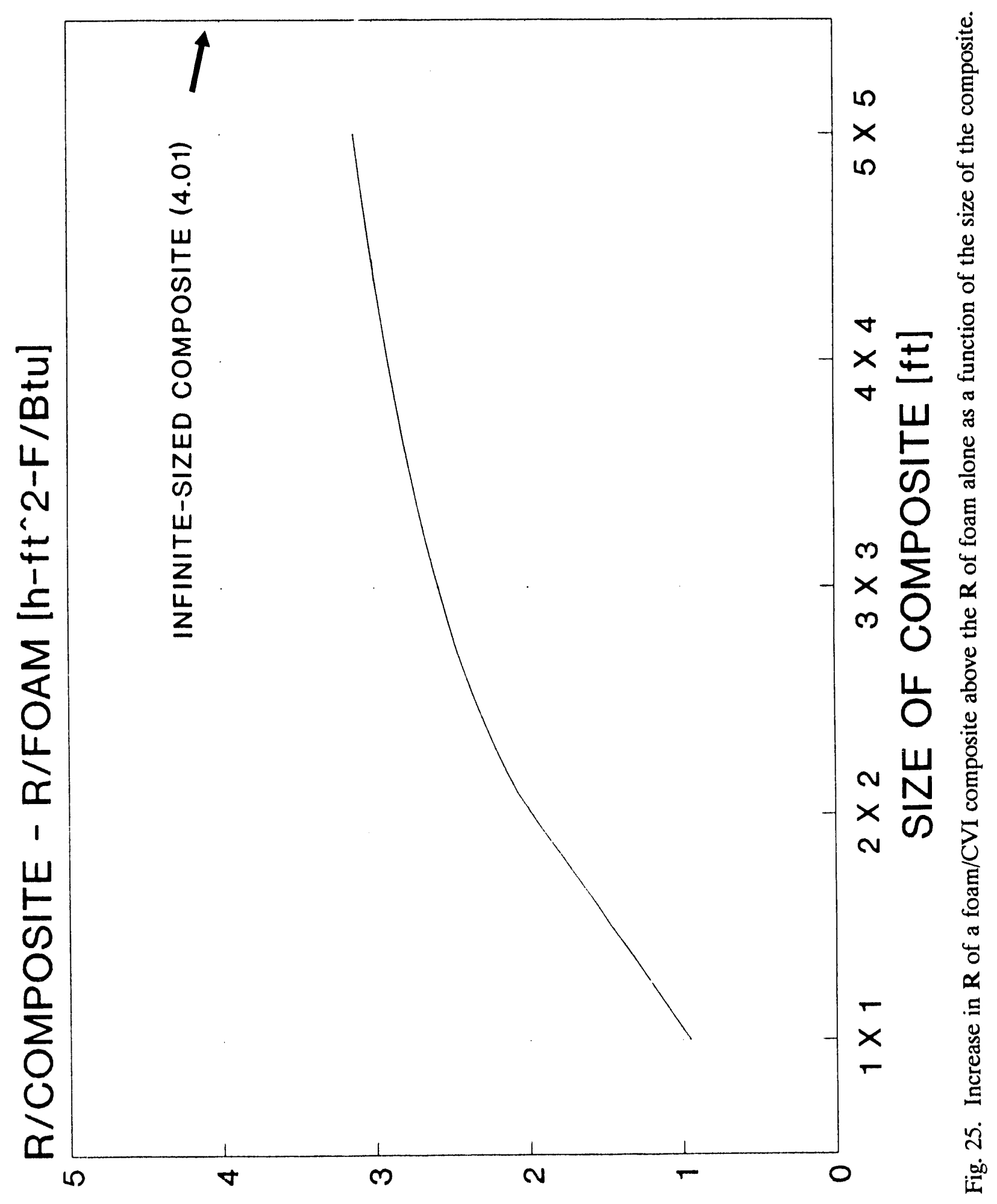




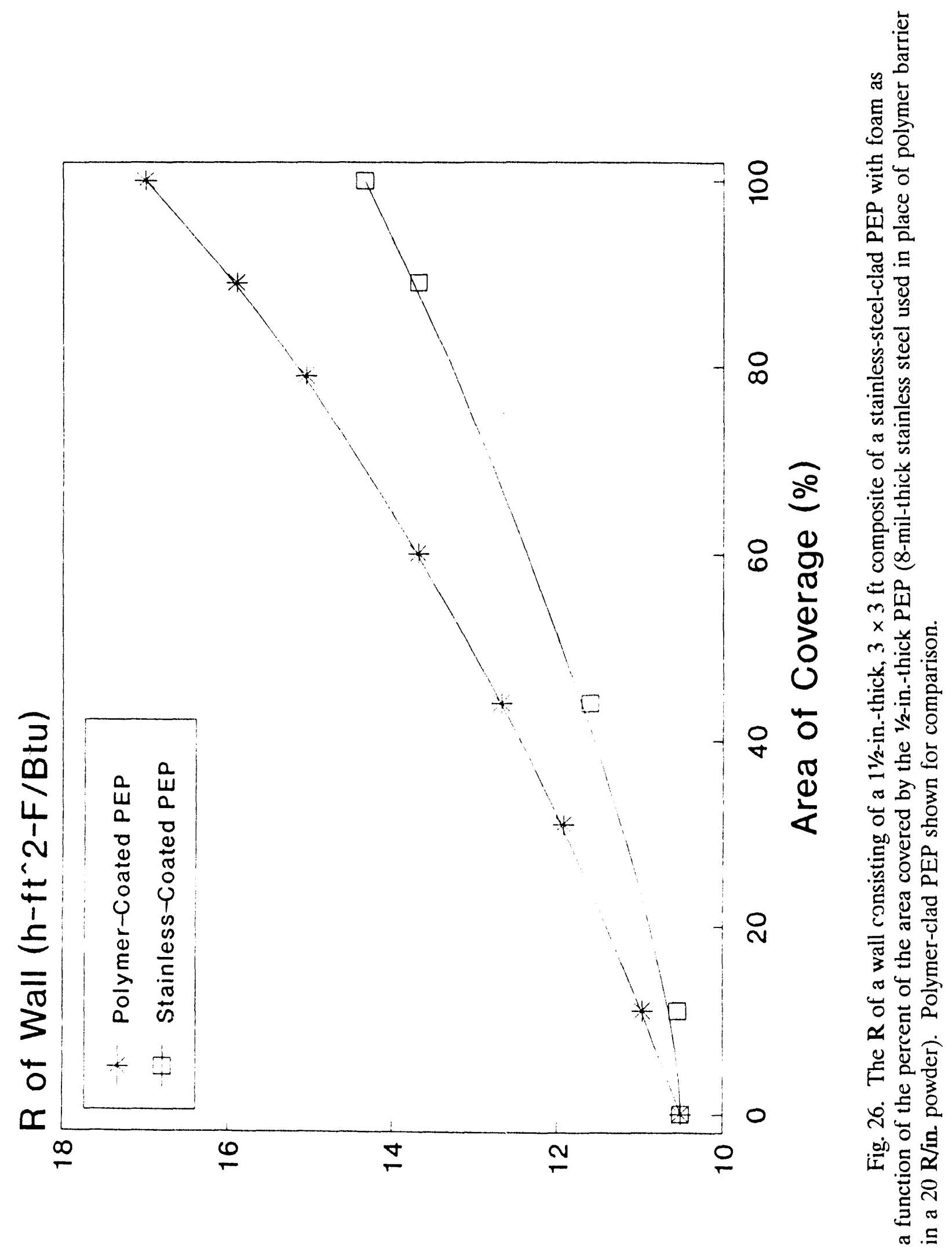


PEP. The parameters are the same as for the $2 \times 3 \mathrm{ft}$ composite in the last section. In this figure, the effect of cladding a $20 \mathrm{R} / \mathrm{in}$. PEP in 8-mil stainless steel was computed using the HEATING-7 code. The reduction in the effective $\mathbf{R}$ of the wall is a compelling reason for not using high-conductance claddings for PEPs. Figure 27 presents these calculations as the percentage change in $\mathbf{R}$ versus the area of coverage. Even at $100 \%$ coverage, the $\mathbf{R}$ of the composite with a stainless steel-clad PEP only increases about half as much as for a polymer-clad PEP.

In summary, in the search to find a solution to the permeation problem of thin plastic sheets for PEPs, one must not be lulled into acceptance of high-thermalconductance barrier materials. For example, a plastic barrier metallized with a continuous coating of 0.6 -mils-thick aluminum would have the same conductance as 8 mils of stainless steel.

\section{CONCLUUSIONS}

1. A reproducible ice melting test was developed for portable coolers.

2. The portable coolers with PEPs foamed-in-place did not give the thermal insulating performance that was predicted by $1 \mathrm{D}$ models but did yield performances in excellent agreement with $3 \mathrm{D}$ models.

3. Two 1D models overestimated the effective $\mathbf{R}$ of a foam/PEP composite; thus, it is generalized and concluded that $1 \mathrm{D}$ models should not be used for these type calculations.

4. Two 1D models overestimated the effective $\mathbf{R}$ of a homogeneous wall of a cube, such as in ice coolers, because of the $3 \mathrm{D}$ effects of edges and corners.

5. The small increment in thermal perform ince of the coolers with the PEP/foam composite is not attributed to any loss of thermal resistance in the PEPs, but rather to t/1ermal shunting around the PEPs and, to a much lesser exteni, to the inadequate filling of the insulation cavity by the foam when the PEPs were in place.

6. PEPs should form a continuous layer in foam/PEP-composite insulation to achieve the highest $\mathbf{R}$. Less than $100 \%$ area of coverage reduces the effectiveness of the PEP. 

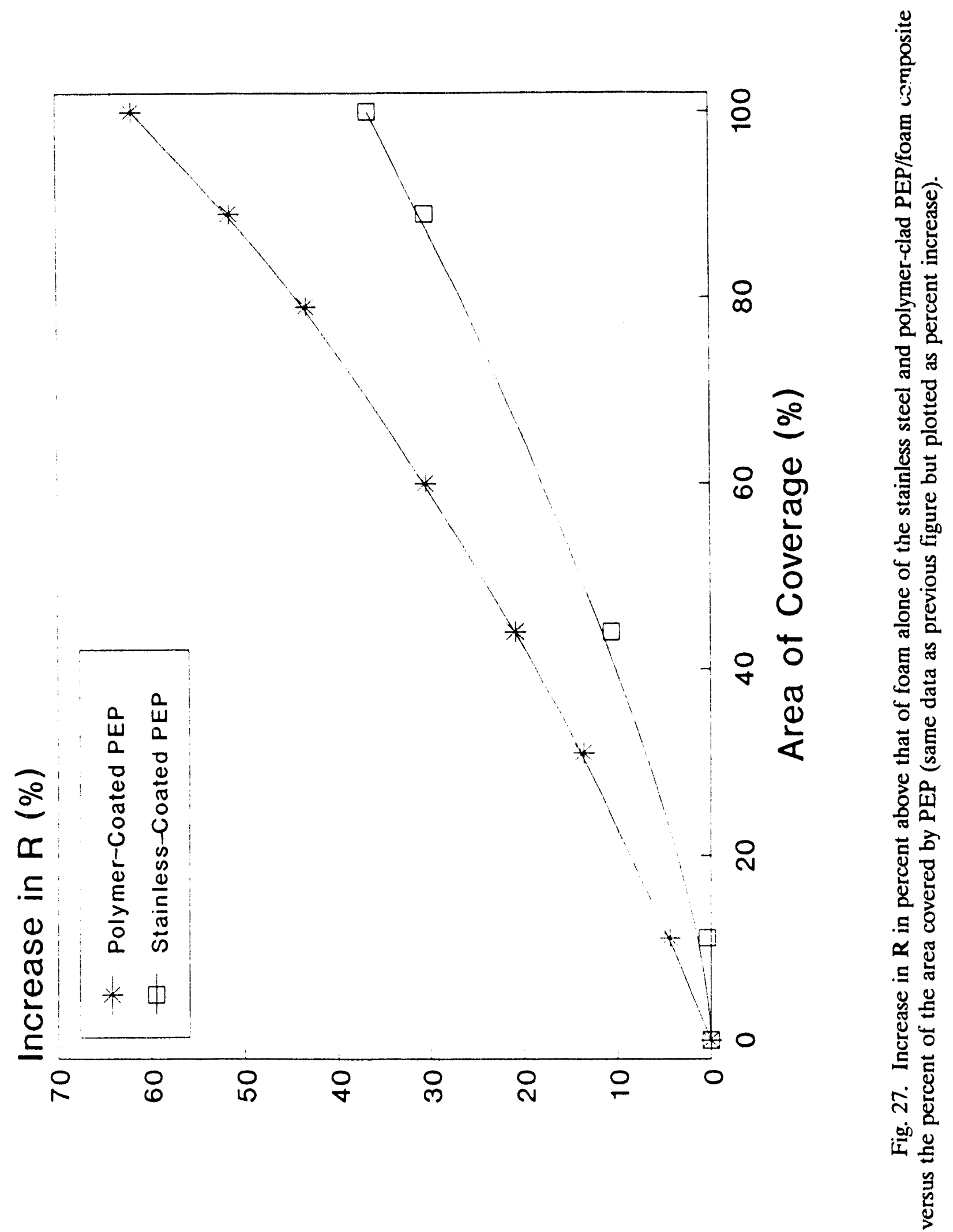
7. A fixcd-size PEP provides the highest $\mathbf{R}$ composite insulation if it is on the inside wall of a hollow cube, such as an ice cooler.

8. ORNL has developed a hand-held gauge for accurately and nondestructively measuring the internal pressure inside a PEP.

9. Three groups of materials were identified as possible candidates for barrier films for 20- to 100-year lifetimes, depending on the environment: PVOH (or PVA), EVOH, and $\mathrm{Al}$-coated films.

10. An interlaboratory comparison of $\Gamma$ measurements on SRM 1470 and a laminate barrier demonstrated:

a. MOCON's accuracy for measurement of the $\Gamma$ of $\mathrm{O}_{2}$ is excellent.

b. MOCON's accuracy for measurements of He and especially $\mathrm{N}_{2} \Gamma \mathrm{s}$ will probably not be good enough on barrier materials needed for 20 - and 100-year lifetimes.

c. The K-25 Site measurement accuracy for $\Gamma$ still needs further improvement.

d. The ORNL accelerated-aging test yielded $\Gamma$ s for He that allowed accurate calc:lation of pressures in PEPs exposed to He.

11. The R/in. of the Degussa FK-500-LS powder is higher at $12.6 \mathrm{lb} / \mathrm{ft}^{2}$ than at 7.05 $\mathrm{lb} / \mathrm{ft}^{3}$ for $\mathrm{He}$ and $\mathrm{N}$.

12. At low pressures, the R/in. of the Degussa FK-500-LS powder approaches the same value for $\mathrm{He}$ or $\mathrm{N}$. This value depends on the density of the powder.

13. Near $1 \mathrm{~atm}$ pressure, the R/in. of the $7.05 \mathrm{lb} / \mathrm{ft}^{3}$ Degussa FK-500-LS powder approached that of the gas for $\mathrm{N}$ and $\mathrm{He}$.

14. The Rs of two SERI CVIs were measured. Their stainless steel cladding reduced the $\mathrm{R}$ by about a factor of two for these $17 \times 17 \mathrm{in.} \mathrm{CVIs.}$

15. The shunting effect of the 8-mil stainless steel cladding decreases as the size of the CVI increases. For a $5 \times 5 \mathrm{ft} P E P$, the reduction in $\mathrm{R}$ due to the stainless steel cladding is still $25 \%$.

16. Cladding a PEP with stainless steel instead of a polymer significantly reduces the effectiveness of the PEP. Thus, use of high-conductance barrier materials, such as 0.6 mils of aluminum, would have the same effect on PEPs as it does on CVIs. 


\section{REFERENCES}

1. H. M. Strong et al., J. Appl. Phys. 31(1), 39-50 (1960).

2. S. S. Kistler, Nature, 127, 741 (1931); J. Phys. Chem. 39, 79-85 (1935).

3. R. W. Barito, Assessment of Composites to Eliminate Chlorofluorocarbon's and Reduce Energy - Case \#1, Letter to D. L. McElroy, dated December 17, 1988, Report on Subcontract No. 41X-SC493V with Martin Marietta Energy Systems, Inc.

4. R. W. Barito and K. L. Downs, "Precipitated Silica Insulation," U. S. Patent 4,636,415, January 13, 1987.

5. R. W. Barito and K. L. Downs, "Insulation Formed of Precipitated Silica and Fly Ash," U. S. Patent 4,681,788, July 21, 1987.

6. P. P. Gervais and D. Goumy, "Insulating Material with Low Thermal Conductivity, Formed of a Compacted Granular Structure," U. S. Patent 4,159,359, June 26, 1979.

7. K. Uekado et al., "Heat Insulating Body," U. S. Patent 4,668,555, May 26, 1987.

8. W. Walles, "Apparatus for Filling and Hermetically Sealing Thermoplastic Containers under Vacuum," U. S. Patent 3,824,762, July 23, 1974.

9. W. Walles, "Thermal Insulating Panel for Use in a Insulative Container and Method of Making Said Panel," U. S. Patent 3,993,811, Nov. 23, 1976.

10. W. Walles, "Open Cell Composition and Method of Making Same," U.S. Patent 4,647,498, March 3, 1987.

11. W. Walles, "Open Cell Composition and Method for Making Same," U.S. Patent 6,613,524, Sept. 23, 1986.

12. "Montreal Protocol on Substances that Deplete the Ozone Layer," United National Environment Programme, Final Act, September 1987.

13. "National Appliance Energy Conservation Act of 1987," Public Law 100-12 [583] March 17, 1987.

14. "Summary of the June 1990 Meeting of SERI's Compact Vacuum Insulation (CVI) Industry Review Panel for Refrigerator/Freezer Applications," Solar Energy Research Institute, Golden, Colo., Aug. 2, 1990. 
15. L. Schilf, "Experience from Development and Five Years Application of a New German Vacuum Insulation," 1990 ASHRAE (American Society of Heating, Refrigeration, and Air-Conditioning Engineers, Inc., Atlanta, GA) Annual Meeting, June 9-13, 1990, St. Louis, Mo.

16. O. Nilsson et al., "Thermal Conductivity Of Evacuated Porous Media Under Compression," Proceedings XXI International Confere ${ }^{\prime} c e$ On Thermal Conductivity, October 15-18, 1989, Lexington, Ky. (in press).

17. D. Büttner et al., "Measurement of the Thermal Conductivity of Evacuated, Load-Bearing, High Temperature Powder and Glass Board Insulation Using A $700 \mathrm{X}$ $700 \mathrm{~mm}^{2}$ Guarded Hot Plate Device," Proceedings 8th European Thermophysics Conference, Baden-Baden, FRG, 1982, in High Temp. - High Press. 15, 1983.

18. H. Reiss, J. Energy, 7(2), 152-59 (1983).

19. M. R. Martin, "Fabrication and Packaging of Soft-Vacuum Aerogel Insulation," 1990 ASHRAE (American Society of Heating, Refrigeration, and Air-Conditioning Engineers, Inc., Atlanta, GA) Annual Meeting, June 9-13, 1990, St. Louis, Mo.

20. X. Lu et al., "Thermal Transport in Opacified, Monolythic Asrogels," Proceedings of the XII European Conference on Thermophysical Properties, Vienna, Austria, September 1990 (in press).

21. "Degussa's Silica-Based Foam Replaces PU," p. 14 in Plastic News, April 16, 1990.

22. L. R. Glicksman, "Two-Dimensional Heat Transfer Effects on Vacuum and Reflective Insulations," Proceedings of the XXI ICHMT Symposium, Dubrovnik, Yugoslavia, September 1989.

2.3. H. A. Fine, J. Therm. Insul. 12, 183-208 (1989).

24. W. T. Lawrence and F. E. Ruccia, Development of Advanced Insulation for Appliances, Task I, ORNL/Sub-81/13800/1, Martin Marietta Energy Systems, Inc., Oak Ridge Natl. Lab., June 1981.

25. D. L. McElroy et al., Development of Advanced Thermal Insulation for Appliances, ORNL/CON-159, Martin Marietta Energy Systems, Inc., Oak Ridge Natl. Lab., 1984.

26. G. L. Copeland et al., "Insulations With Low Thermal Conduciivity," pp. 367 77 in Thermal Conductivity 17, ed. J. G. Hust, Plenum, New York, 1985. 
27. D. W. Yarbrough et al., High Temp. Sci. 19, 213-23, 1985.

28. D. W. Yarbrough et al., Development of .Advanced Thermal Insulation for Appliances, Progress Report for the Period, Juiy 1984 'tirough June 1985, ORNL/CON-199, Martin Marietta Energy Systems, Inc., Oak Ridge Natl. Lab., 1986.

29. D. W. Yarbrough et al., The Thermal Resistance of Perlite-Based Evacuated Insulations for Refrigerators, ORNL/CON-215, Martin Marietta Energy Systems, Inc., Oak Ridge Natl. Lab., 1986.

30. D. L. McElroy et al., Thermal Resistance of Fine Powders at Atmospheric Pressure and Under Vacuum, ASTM STP 1030, American Society for Testing and Materials, Philadelphia, 1989, pp. 52-65.

31. D. L. McElroy and H. A. Fine, "Powder-Filled Evacuated Panel (PEP) Insulation Technology," ASHRAE (American Society of Heating, Refrigeration, and AirConditioning Engineers, Inc., Atlanta, Ga.) Seminar - Vacuum Alternatives for the Energy-Efficient Insulation of Buildings, Appliances, and Refrigerated Transport, June 25, 1989, Vancouver, B.C., Canada.

32. R. W. Barito et al., Fabrication, Evaluation, and Application of Evacuated Panel Insulation (EPI) to Portable Coolers, ORNL/Sub/88-SD731/1, Martin Marietta Energy Systems, Inc., Oak Ridge Natl. Lab., March 1990.

33. D. L. McElroy et al., A Flat Insulation Tester that uses an Unguarded Nichrome Screen Wire Heater, Guarded Hot Plate and Heat Flow Meter Methodology, ASTM STP 879, American Society for Testing and Materials, Philadelphia, 1985, pp. 121-139.

34. R. S. Graves et al., Apparent Thermal Conductivity Measurements by an Unguarded Technique, pp. 339-56 in Thermal Conductivity 18, Plenum, New York, 1985.

35. "Standard Test Method for Steady-State Thermal Transmission Properties by Means of the Thin-Heater Apparatus," ASTM C 1114-89, pp. 600-606 in 1989 Annual Book of ASTM Standards, Vol. 04.06, American Society for Testing and Materials, Philadelphia, 1989.

36. "Standard Practice for Using the Guarded Hot Plate Apparatus in the OneSided Mode to Measure Steady-State Heat Flux and Thermal Transmission Properties," ASTM C 1044-85, pp. 528-30 in 1989 Annual Book of ASTM Standards, Vol. 04.06, American Society for Testing and Materials, Philadelphia, 1989. 
37. "Standard Test Method for Steady-State Heat Flux Measurements and Thermal Transmission Properties by Means of the Heat Flow Meter Apparatus," ASTM C518-85, pi. 150-62 in 1989 Annual Book of ASTM Standards, Vol. 04.06, American Society for Testing and Materials, Philadelphia, 1989.

38. D. L. McElroy et al., Thermal Resistance of Polyisocyanurate Foam Board Insulation Blown with CFC-11 Substitutes - A Cooperative Industry/Government Project, ORNL/TM-11645, Martin Marietta Energy Systems, Inc., Oak Ridge Natl. Lab., 1991.

39. R. S. Graves et al., Interlaboratory Comparison of Four Heat Flow Meter Apparatuses on Planed Prototypical Polyisocyanurate Boards Foamed with CFC-11, ORNL/TM-11720, Martin Marietta Energy Systems, Inc., Oak Ridge Natl. Lab., 1991.

40. R. S. Graves et al., "Thermal Performance of a Closed-Cell Foamboard Insulation Containing HCFC-22," pp. 35-49 in Proceedings of the Sixth International Insulation Conference, Millbrae, Calif., February 12-14, 1990, Vol. 6, 1990.

41. Private communications.

42. "Standard Method for Determining Gas Permeability Characteristics of Plastic Film and Sheeting, ASTM D 1434-82, pp. 255-66 in 1989 Annual Book of ASTM Standards, Vol. 08.01, American Society for Testing and Naterials, Philadelphia, 1989.

43. Packaging Encyclopedia \& Technical Directory, Cahners Pub. Co., Denver, 1989.

44. Gas Barrier Properties of EVAL Resins, Technical Bulletin No. 110, Eval Company of America, Lisle, Ill.

45. DIN 53380, Testing of Plastic Films: Determination of the Gas Transmission Rate, UDC [678.51.8] - 416: 620.193.29.

46. "Standard Test Method for Oxygen Transmission Rate Through Plastic Film and Sheeting Using a Coulometric Sensor, ASTM D-3985, pp. 387-94 in 1989 Annual Book of ASTM Standards, Vol. 08.03, American Society for Testing and Materials, Philadelphia, 1989.

47. M. Jakob, p. 5 in Heat Transfer, Vol. II, Wiley, New York, 1957.

48. C. R. Roger et al., J. Opt. Soc. Am. 69(10), 1384-90 (1979).

49. C. Davisson and J. R. Weeks, J. Opt. Soc. Am. 8, 581-605 (1924).

50. R. S. Graves et al., Int. J. of Thermophys. 12(2), 409-15 (1991). 


\section{ACKNOWLEDGMENTS}

The authors are grateful for the sponsorship of this work by the Office of Buildings Energy Research, Building Systems and Materials Division, U.S. Department of Energy, under contract DE-AC05-84OR21400 with Martin Marietta Energy Systems, Inc. We also thank Drs. R. K. Williams and D. W. Yarbrough for their very careful review of this manuscript. Finally, we acknowledge Ms. Gabrielle Burn for the preparation and numerous revisions of the manuscript. 
ORNL/TM-11703

\section{INTERNAL DISTRIBUTION}

1-2. Central Research Library

3. Document Reference Section

4-5. Laboratory Records Department

6. Laboratory Records, ORNL RC

7. ORNL Patent Section

8-10. M\&C Records Office

11-20. C. L. Brown

21-30. G. L. Burn

31. R. S. Carlsmith

32. K. W. Childs

33. J. E. Christian

34. G. E. Courville

35. D. F. Craig
36-40. R. S. Graves

41-45. T. G. Kollie

46. M. A. Kuliasha

47-51. D. L. McElroy

52. R. B. Shelton

53. K. E. Wilkes

54. A. D. Brailsford (Consultant)

55. Y. A. Chang (Consultant)

56. H. W. Foglesong (Consultant)

57. J. J. Hren (Consultant)

58. M. L. Savitz (Consultant)

59. J. B. Wachtman, Jr. (Consultant)

\section{EXTERNAL DISTRIBUTION}

60. Aguilar, J., Arthur D. Little, Cambridge, MA

61. Alumbaugh, R. L., Naval Civil Engineering Lab, Port Hueneme, CA

62. Anderson, J., Foam Enterprises, Minneapolis, $M N$

63. Bankvall, C., Swedish National Testing Institute, Boras, Sweden

64. Beck, J. V., Michigan State University, East Lansing, MI

65. Bomberg, M., National Research Council of Canada, Ontario, Canada

66. Boulin, J. J., DOE, Washington, DC

67. Braun, S., MIMA, Alexandria, VA

68. Brod, B., Barrier Systems, Canastota, NY

69. Brown, G. Z., University of Oregon, Eugene, OR

70. Budge, R. A., White Consolidated Industries, Inc., Ontario, Canada

71. Clinton, J. L., NRG Barriers, Inc., Saco, ME

72. Cusick, E. Rockwool Manufacturing Co., Leeds, AL

73. Desjarlais, A. O., Holometrix, Inc., Cambridge, MA

74. Edmunds, W. M., Granville, OH

75. Ellis, W. P., Harleysville, PA

76. Fairey, P., Florida Solar Energy Center, Cape Canaveral, FL

77. Fine, H. A., EPA, Washington, DC

78. Flynn, D. R., NIST, Gaithersburg, MD 20899

79. Gallagher, K. J., CertainTeed, Blue Bell, PA

80. Glicksman, L. R., MIT, Cambridge, MA

81. Goldsmith, J. C., DOE, Washington, DC 
82. Goss, W. P., Amherst, MA

83. Griffin, S. R., W. C. Wood Company, Ltd., Ontario, Canada

84. Hagan, J. R., Jim Walter Research Corp., St. Petersburg, FL

85. Harris, J., Northwest Power Planning Council, Portland, OR

86. Harris, T., BASF Canada, Inc., Ontario, Canada

87. Harshaw, B. D., Central Fiber Corp., Wellsville, KS

88. Haworth, G. J., Admiral Company, Galesburg, IL

89. Hendricks, R. V., EPA, Research Triangle Park, NC

90. Howard, B. D., The Alliance to Save Energy, Washington, DC

91. Hyma, B., Energy Saver Imports, Inc., Broomfield, CO

92. Johnson, L., Chevron, USA, Pascagoula, MS

93. Johnson, R. J., Whirlpool Corp., Evansville, IN

94. Jones, R. E., DOE, Washington, DC

95. Junsson, B., Swedish National Testing Institute, Boras, Sweden

96. Joyner, P., EPRI, Palo Alto, CA

97. Klemens, P. G., University of Connecticut, Storrs, CT

98. Kochhar, G. S., UWI, Trinidad, West 1. idies

99. Laumann, D. J., Sub-Zero Freezer Company, Inc., Madison, WI

100. Leger, G., Leger Designs, New Boston, NH

101. Lichtenberg, F. W., The Society of the Plastics Industry, New York, NY

102. Martin, M., Thermalux, Richmond, CA

103. Martin, R. F., Roof Maintenance Systems, Farmingdale, NJ

104. Martynowicz, L., Huntsman Chemical Corp., Chesapeake, VA

105. McBride, M., Owens-Corning Fiberglas, Granville, $\mathrm{OH}$

106. McGillvary, D., Firestone Building Products Co., Carmel, CA

107. McGuire, D., Regal Industries, Crothersville, IN

108. Miller, R. G., Jim Walter Research Corp., St. Petersburg, FL

109. Millspaugh, L., Reflectix, Inc., Markleville, IN

110. Mulroy, P., Black Gold, Inc., Topeka, KS

111. Mumaw, J. R., Owens-Corning Fiberglas, Granville, $\mathrm{OH}$

112. Nelson, R. E., Amana Refrigeration, Inc., Amana, IA

113. Nisson, N., Energy Design Associates, New York, NY

114. Ober, D. G., Manville Sales Corp., Denver, CO

115. Poppendiek, H. F., Geoscience, Ltd., Solana Beach, CA

116. Portfolio, D. C., Tremco, Inc., Cleveland, $\mathrm{OH}$

117. Roofing Services, Inc., Springfield, VA

118. Seaton, W., ASHRAE, Inc., Atlanta, GA

119. Selkowitz, S., Lawrence Berkeley Laboratory, Berkeley, CA

120. Sherman, M., St. Petersburg, FL

121. Shirtliffe, C. J., NRC, Ottawa, Canada

122. Skinner, A., Roofing Service Associates, Inc., Knoxville, TN

123. Smith, D. R., NIST, Boulder, CO

124. Smith, J. A., National Association of Home Builders, Washington, DC

125. Smith, S. E., Yankee Scientific, Ashland, MA

126. Snell, S., ACEC Research Foundation, Washington, DC

127. Sterling, R. L., Underground Space Center, Minneapolis, MN

128. Stern, E., Quebec, Canada

129. Stumpf, P., Major Industries, Morristown, NJ 
130. Sullivan, R., National Center for Appropriate Technology, Butte, MT

131. Tewes, S., Small Homes Council, Champaign, IL

132. Tong, T. W., Arizona State University, Tempe, AZ

133. Tracy, J., NATAS, Butte, MT

134. Tsongas, G., Portland State University, Portland, OR

135. Tuluca, A., Steven Winter Associates, Inc., Norwalk, CT

136. Tye, R. P., Cohasset, MA

137. Vander Linden, C. R., Vander Linden and Associates, Littleton, CO

138. Van Geem, M. G., CTL, Skokie, IL

139. Wells, J. R., Owens-Corning Fiberglas, Granville, $\mathrm{OH}$

140. Wysocki, D. C., Mobay Corp., Pittsburgh, PA

141. Zarr, R. R., NIST, Gaithersburg, MD

142. Zenor, G. N., Northampton, MA

143. DOE Field Office, P.O. Box 2008, Oak Ridge, TN 37831-8600

144-153. Department of Energy, Office of Scientific and Technical Information, P.O. Box 62, Oak Ridge, TN 37831 

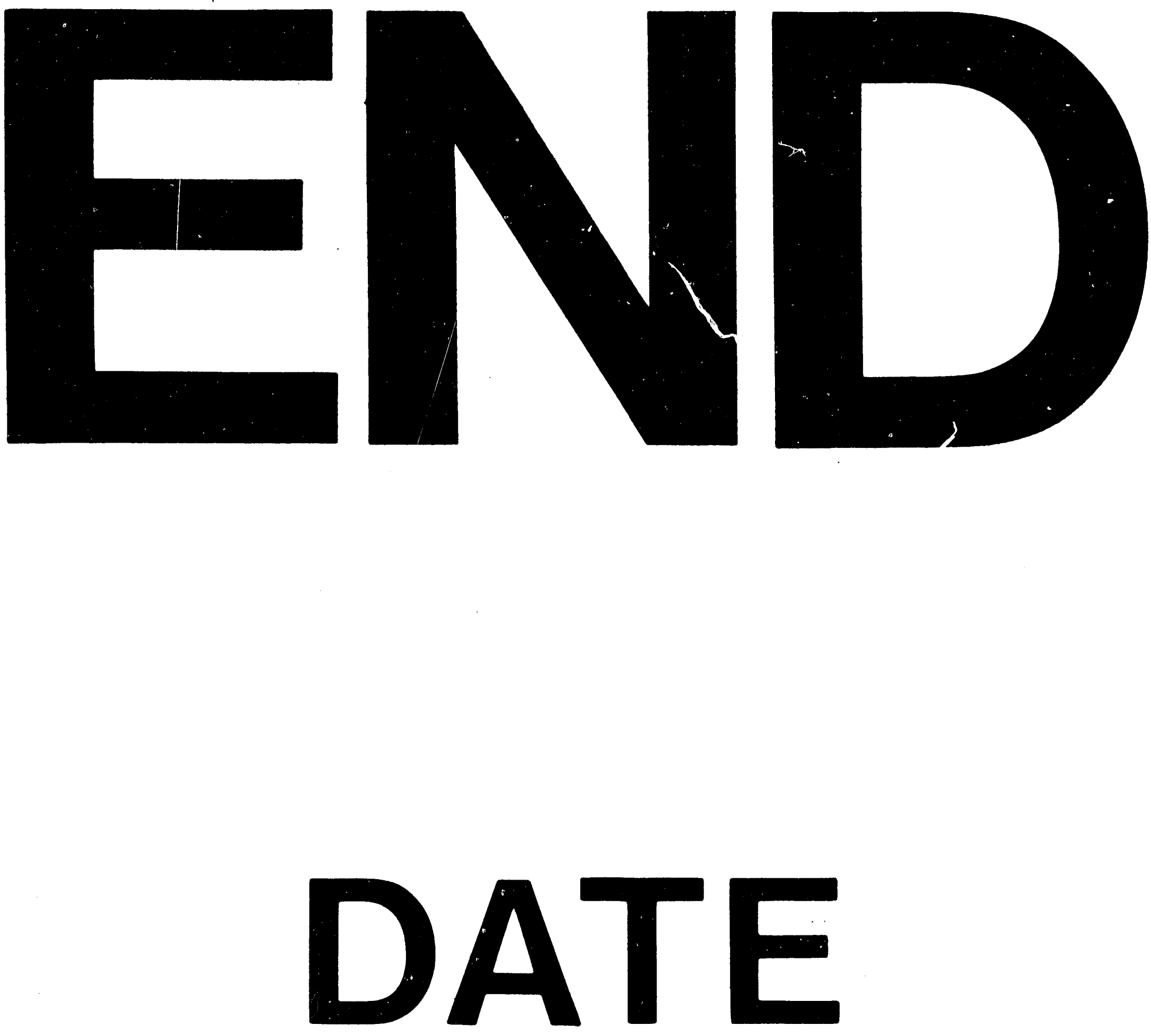

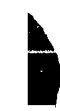
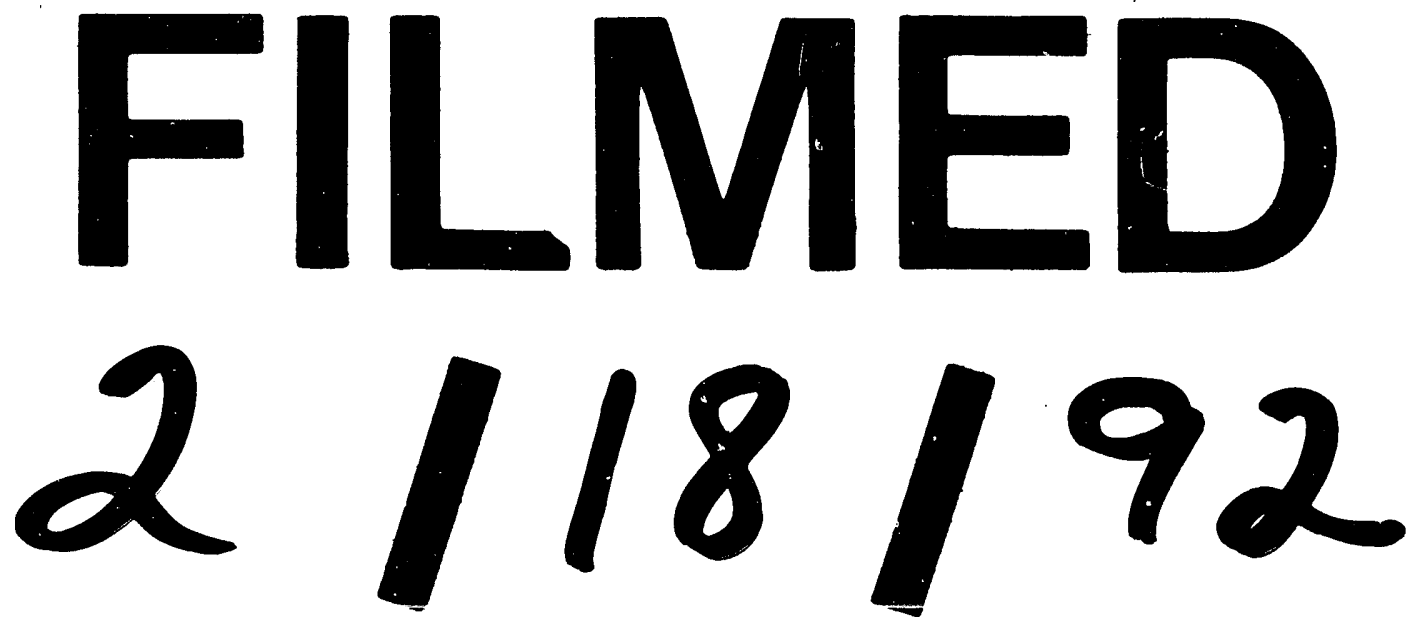
